\title{
SEEKING FOR STRATEGIES TO SUPPORT THE BLOOD-BRAIN BARRIER IN THE PROTECTION AGAINST INVADING CELLS
}

\author{
Ph.D. Thesis
}

János Haskó

Supervisor: István Krizbai M.D., Ph.D., D.Sc.

Universitiy of Szeged, Faculty of Medicine

Doctoral School of Theoretical Medicine

Institute of Biophysics, Biological Research Centre

Hungarian Academy of Sciences

Szeged

2018 


\section{List of publications}

Full papers directly related to the subject of the thesis

I. Wilhelm I, Fazakas C, Molnár K, Végh AG, Haskó J, Krizbai IA. Foe or friend? Janusfaces of the neurovascular unit in the formation of brain metastases. J Cereb Blood Flow Metab. 2017 Jan 1;271678X17732025 (IF2016: 5,081)

II. Hajdu Z*, Haskó J*, Krizbai IA, Wilhelm I, Jedlinszki N, Fazakas C, Molnár J, Forgo P, Hohmann J, Csupor D. Evaluation of lignans from Heliopsis helianthoides var. scabra for their potential antimetastatic effects in the brain. J Nat Prod. 2014 Dec 26;77(12):2641-50 (* = co-first authors) (IF2014: 3,798)

III. Haskó J, Fazakas C, Molnár J, Nyúl-Tóth Á, Herman H, Hermenean A, Wilhelm I, Persidsky Y, Krizbai IA. CB2 receptor activation inhibits melanoma cell transmigration through the blood-brain barrier. Int J Mol Sci. 2014 May 8;15(5):8063-74 (IF2014: 2,862)

IV. Ramirez SH, Haskó J, Skuba A, Fan S, Dykstra H, McCormick R, Reichenbach N, Krizbai I, Mahadevan A, Zhang M, Tuma R, Son YJ, Persidsky Y. Activation of cannabinoid receptor 2 attenuates leukocyte-endothelial cell interactions and blood-brain barrier dysfunction under inflammatory conditions. J Neurosci. 2012 Mar 21;32(12):4004-16 (IF2012: 6,908)

Full papers not included in the thesis

1. Nyúl-Tóth Á, Kozma M, Nagyőszi P, Nagy K, Fazakas C, Haskó J, Molnár K, Farkas AE, Végh AG, Váró G, Galajda P, Wilhelm I, Krizbai IA. Expression of pattern recognition receptors and activation of the non-canonical inflammasome pathway in brain pericytes. Brain Behav Immun. 2017 Aug;64:220-231 (IF2016: 5,964)

2. Krizbai IA, Nyúl-Tóth Á, Bauer HC, Farkas AE, Traweger A, Haskó J, Bauer H, Wilhelm I. Pharmaceutical Targeting of the Brain. Curr Pharm Des. 2016;22(35):5442-5462 (IF2016: 2,611) 
3. Nyúl-Tóth Á, Suciu M, Molnár J, Fazakas C, Haskó J, Herman H, Farkas AE, Kaszaki J, Hermenean A, Wilhelm I, Krizbai IA. Differences in the molecular structure of the blood-brain barrier in the cerebral cortex and white matter: an in silico, in vitro, and ex vivo study. Am $\mathbf{J}$ Physiol Heart Circ Physiol. 2016 Jun 1;310(11):H1702-14 (IF2016: 3,324)

4. Molnár J, Fazakas C, Haskó J, Sipos O, Nagy K, Nyúl-Tóth Á, Farkas AE, Végh AG, Váró G, Galajda P, Krizbai IA, Wilhelm I. Transmigration characteristics of breast cancer and melanoma cells through the brain endothelium: Role of Rac and PI3K. Cell Adh Migr. 2016 May 3;10(3):269-81 (IF2016: 3,872)

5. Nagyőszi P, Nyúl-Tóth Á, Fazakas C, Wilhelm I, Kozma M, Molnár J, Haskó J, Krizbai IA. Regulation of NOD-like receptors and inflammasome activation in Cerebral endothelial cells. J Neurochem. 2015 Nov;135(3):551-64 (IF2015: 3,842)

6. Wilhelm I, Fazakas C, Molnár J, Haskó J, Végh AG, Cervenak L, Nagyőszi P, Nyúl-Tóth A, Farkas AE, Bauer H, Guillemin GJ, Bauer HC, Váró G, Krizbai IA. Role of Rho/ROCK signaling in the interaction of melanoma cells with the blood-brain barrier. Pigment Cell Melanoma Res. 2014 Jan;27(1):113-23 (IF2014: 4,619)

7. Wilhelm I, Molnár J, Fazakas C, Haskó J, Krizbai IA. Role of the blood-brain barrier in the formation of brain metastases. Int J Mol Sci. 2013 Jan 11;14(1):1383-411 (IF2013: 2,339)

8. Fazakas C, Wilhelm I, Nagyoszi P, Farkas AE, Haskó J, Molnár J, Bauer H, Bauer HC, Ayaydin F, Dung NT, Siklós L, Krizbai IA. Transmigration of melanoma cells through the blood-brain barrier: role of endothelial tight junctions and melanoma-released serine proteases. PLoS One. 2011;6(6):e20758 (IF2011: 4,092)

9. Nagyoszi P, Wilhelm I, Farkas AE, Fazakas C, Dung NT, Haskó J, Krizbai IA. Expression and regulation of toll-like receptors in Cerebral endothelial cells. Neurochem Int. 2010 Nov;57(5):556-64 (IF2010: 3,601) 
Table of Contents

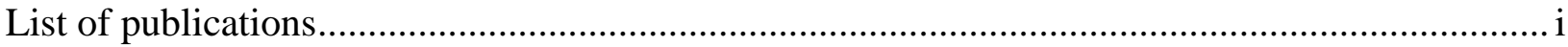

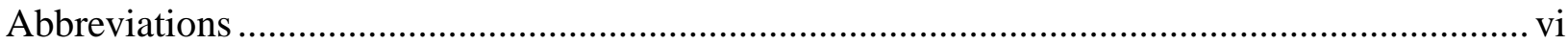

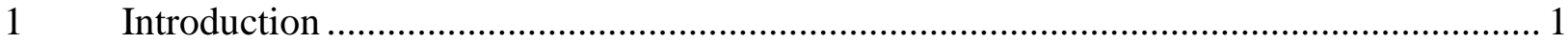

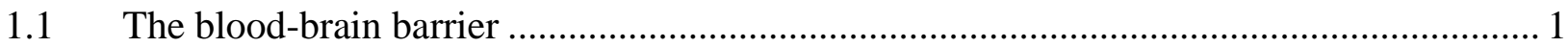

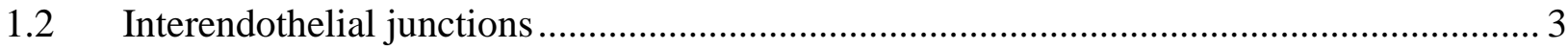

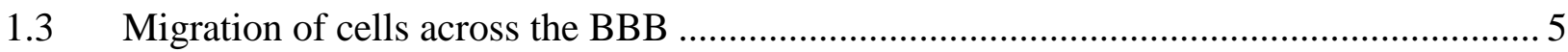

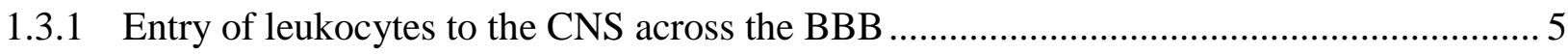

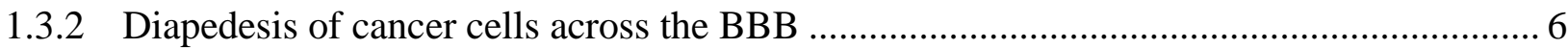

1.4 Targeting neuroinflammation and metastasis formation: CB2 and lignans .................... 9

1.4.1 Effect of CB2 activation on inflammation and metastasis formation ........................... 9

1.4.2 Effect of lignans on inflammation and metastasis formation................................... 11

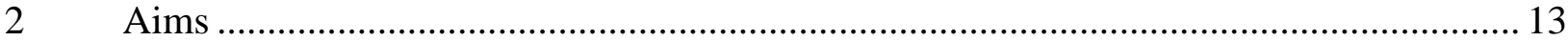

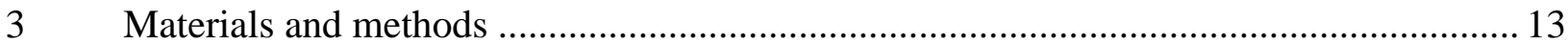

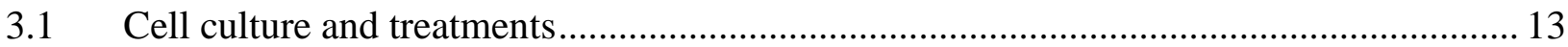

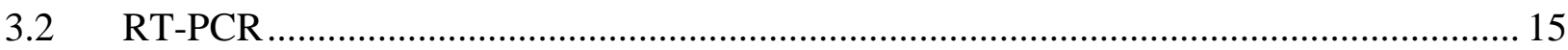

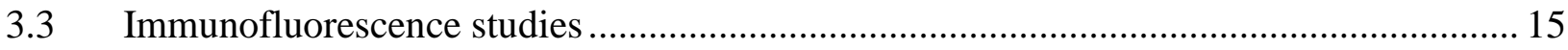

3.4 Phalloidin staining of the actin-cytoskeleton ..................................................... 16

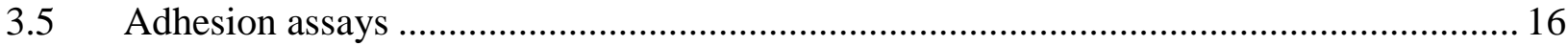

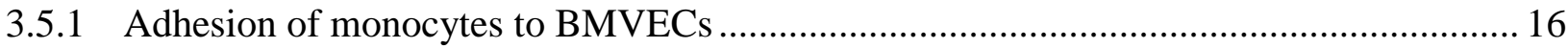

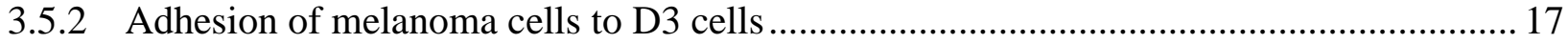

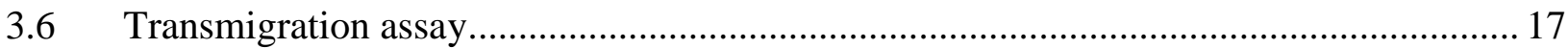

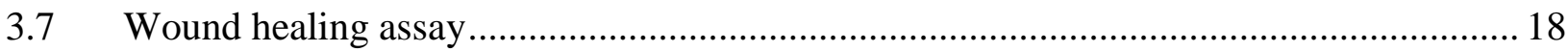

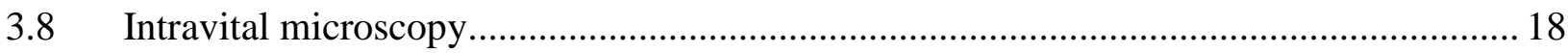

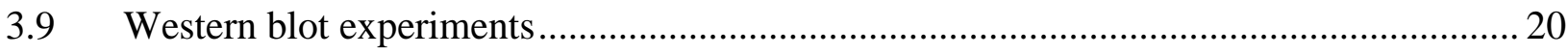


3.10 Measurement of transendothelial electrical resistance ................................................ 20

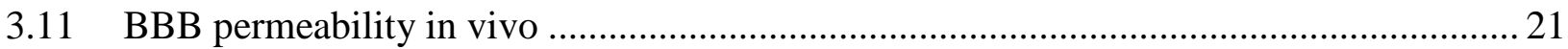

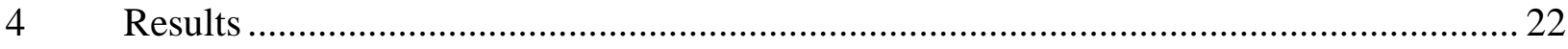

4.1 Expression of cannabinoid receptors and cannabinoid-like receptors in brain endothelial

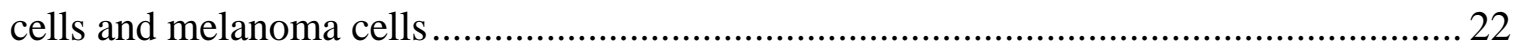

4.1.1 CB2 expression on brain endothelium ............................................................. 22

4.1.2 mRNA expression of cannabinoid receptors and cannabinoid-like receptors in brain

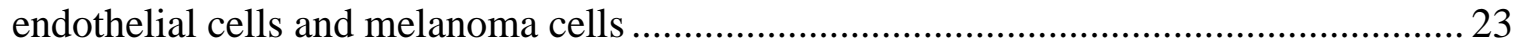

4.2 Effect of CB2 activation on leukocyte-brain endothelial cell interactions and BBB disfunction under inflammatory conditions ................................................................ 24

4.2.1 CB2 activation decreases leukocyte adhesion in pial vessels ..................................... 24

4.2.2 CB2 activation decreases leukocyte adhesion on deep cortical ascending postcapillary venules

4.2.3 Endothelial CB2 activation decreases the number of monocytes adhering to the brain endothelium 28

4.2.4 CB2 agonists prevent BBB dysfunction in vivo and in vitro 29

4.3 Effect of CB2 activation on melanoma-brain endothelial cell interactions .................... 32

4.3.1 CB2 activation decreases the number of melanoma cells adhering to the brain endothelium 32

4.3.2 CB2 agonist attenuates transmigration of melanoma cells through brain endothelial cell layers

4.4 Potential antimetastatic effect of lignans from Heliopsis helianthoides var. scabra in the brain

4.4.1 Compound structure elucidation of lignans from Heliopsis helianthoides var. scabra .... 34

4.4.2 Morphological changes and inhibition of migration of melanoma cells induced by Hel-6 and Hel-11

4.4.3 Hel-6 reduces the adhesion of melanoma cells to brain endothelial cells 
4.4.4 Hel-6 and Hel-11 improve the barrier function of CECs ......................................... 37

4.4.5 Hel-6 and Hel-11 mitigate migration of endothelial cells ............................................ 39

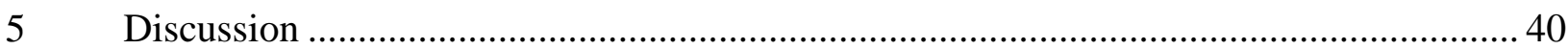

5.1 Expression of cannabinoid receptors in the brain endothelium and in melanoma cells.... 40

5.2 Effect of CB2 activation on endothelial cell-immune cell interactions and on the integrity

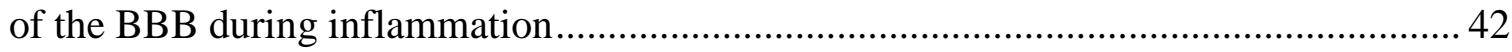

5.3 Inhibition of melanoma cell adhesion and transmigration through the brain endothelium

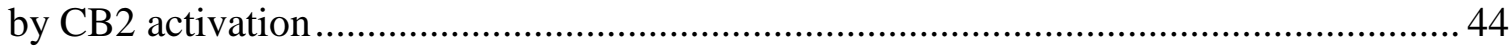

5.4 The possible antimetastatic effect of lignans from Heliopsis helianthoides var. scabra in

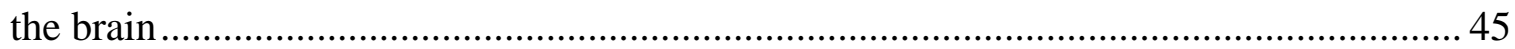

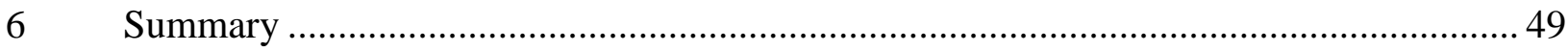

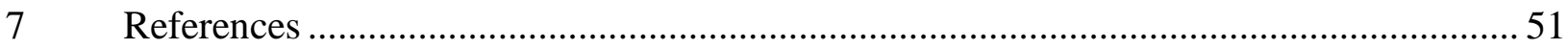

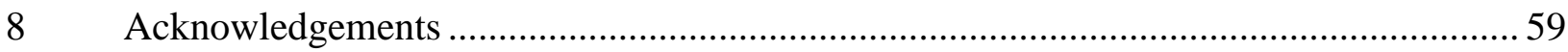

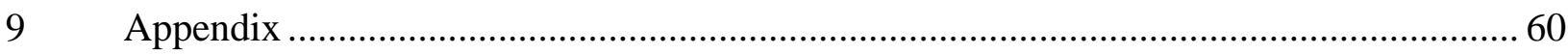




\section{Abbreviations}

\begin{tabular}{|c|c|}
\hline $\mathrm{ABC}$ & -ATP-binding cassette transporters \\
\hline AJ & -Adherens Junction \\
\hline BBB & -Blood-Brain Barrier \\
\hline BMVEC & -human primary Brain Microvascular Endothelial Cell \\
\hline CAM & -Cell Adhesion Molecule \\
\hline CB1 & -Cannabinoid Receptor 1 \\
\hline $\mathrm{CB} 2$ & -Cannabinoid Receptor 2 \\
\hline CEC & -Cerebral Endothelial Cell \\
\hline CNS & -Central Nervous System \\
\hline D3 & -human Microvascular Cerebral Endothelial Cell line (hCMEC/D3) \\
\hline EAE & -Experimental Autoimmune Encephalomyelitis \\
\hline FBS & -Fetal Bovine Serum \\
\hline GPR & -G Protein-coupled Receptors \\
\hline Hel-6 & -Helioxanthin \\
\hline Hel-11 & -(7E)-7,8-dehydroheliobuphthalmin \\
\hline HUVEC & -Human Umbilical Vein Endothelial Cells \\
\hline IL1 $\beta$ & -Interleukin-1 Beta \\
\hline ICAM & -Intercellular Adhesion Molecule \\
\hline JAM & -Junctional Adhesion Molecules \\
\hline LPS & -Lipopolysaccharide \\
\hline MAPK-ERK & -Mitogen-activated Protein Kinases - Extracellular Signal-regulated Kinase \\
\hline OG & -Oregon Green ${ }^{\circledR} 488$ carboxylic acid diacetate succinimidyl ester \\
\hline PECAM & -Platelet Endothelial Cell Adhesion Molecule \\
\hline PTX & -Pertussis Toxin \\
\hline RBEC & -Rat Brain Endothelial Cell \\
\hline SF & -Sodium Fluorescein \\
\hline TEER & -Transendothelial Electrical Resistance \\
\hline TGF- $\beta$ & -Tumor Growth Factor Beta \\
\hline THC & $-\Delta^{9}$-Tetrahydrocannabinol \\
\hline $\mathrm{TJ}$ & -Tight Junction \\
\hline $\mathrm{TNF} \alpha$ & -Tumor Necrosis Factor alpha \\
\hline VCAM & -Vascular Cell Adhesion Molecule \\
\hline VEGF & -Vascular Endothelial Growth Factor \\
\hline $\mathrm{ZO}$ & -Zonula Occludens \\
\hline
\end{tabular}




\section{Introduction}

To protect the central nervous system (CNS), the blood-brain barrier (BBB) shields the brain from blood-borne cells and toxins. During several inflammatory brain diseases, such as multiple sclerosis (Minagar and Alexander 2003) or Alzheimer's disease (Erickson and Banks 2013), this protecting shield becomes impaired and immune cell trafficking is firmly increased. BBB breakdown and leukocyte infiltration are a serious danger to the functioning brain. Besides leukocytes implicated in neuroinflammation, cancer cells can also migrate across the BBB to form brain metastases (Barnholtz-Sloan et al. 2004, Douglas and Margolin 2002, Wilhelm et al. 2017, Wilhelm et al. 2013). The incidence of brain metastases is $9 \%-17 \%$ of cancer cases in the United States based on various studies (Nayak, Lee and Wen 2012). The most frequent origins of brain metastases are primary tumors of lung, breast and skin (melanoma). Of all primary tumors melanoma shows the highest predilection to spread to the brain. Brain metastases of melanoma carry a poor prognosis with a median survival of approximately four months (Davies et al. 2011). Hence, there is an urgent need to find therapeutic targets and effective drugs to prevent or cure brain metastases of melanoma and other types of cancer.

\subsection{The blood-brain barrier}

The BBB controls the movement of substances between the blood stream and the brain parenchyma, so it has a crucial role in maintaining the homeostasis of the CNS. As a barrier, it prevents the entry of cells, potentially harmful molecules or ions which interfere with neuronal communications. On the other hand, the brain vasculature forming the BBB allows the passage of nutrients and metabolites required by the CNS with passive diffusion or active transport.

Endothelial cells lining the cerebral microvasculature, form the anatomic basis of the BBB. Special characteristics of these cells establish the barrier function of the cerebral vasculature. Tight junctions (TJs) between endothelial cells form a physical barrier restricting the paracellular movement of solutes. Low level of endocytosis and transcytosis (transcellular barrier) inhibit transport of substances through the cytoplasm. Beyond this, ABC efflux transporters (ATPbinding cassette transporters) actively pump endogenous metabolites and xenobiotics out of endothelial cells and neuronal tissue. These proteins, acting as vascular gatekeepers, form the transport barrier. Besides, biologically active compounds are metabolized by extracellular and 
intracellular enzymes including acetylcholinesterase, alkaline phosphatase, $\gamma$-glutamyl transpeptidase and monoamine oxidases forming the enzymatic barrier (Abbott 2013).

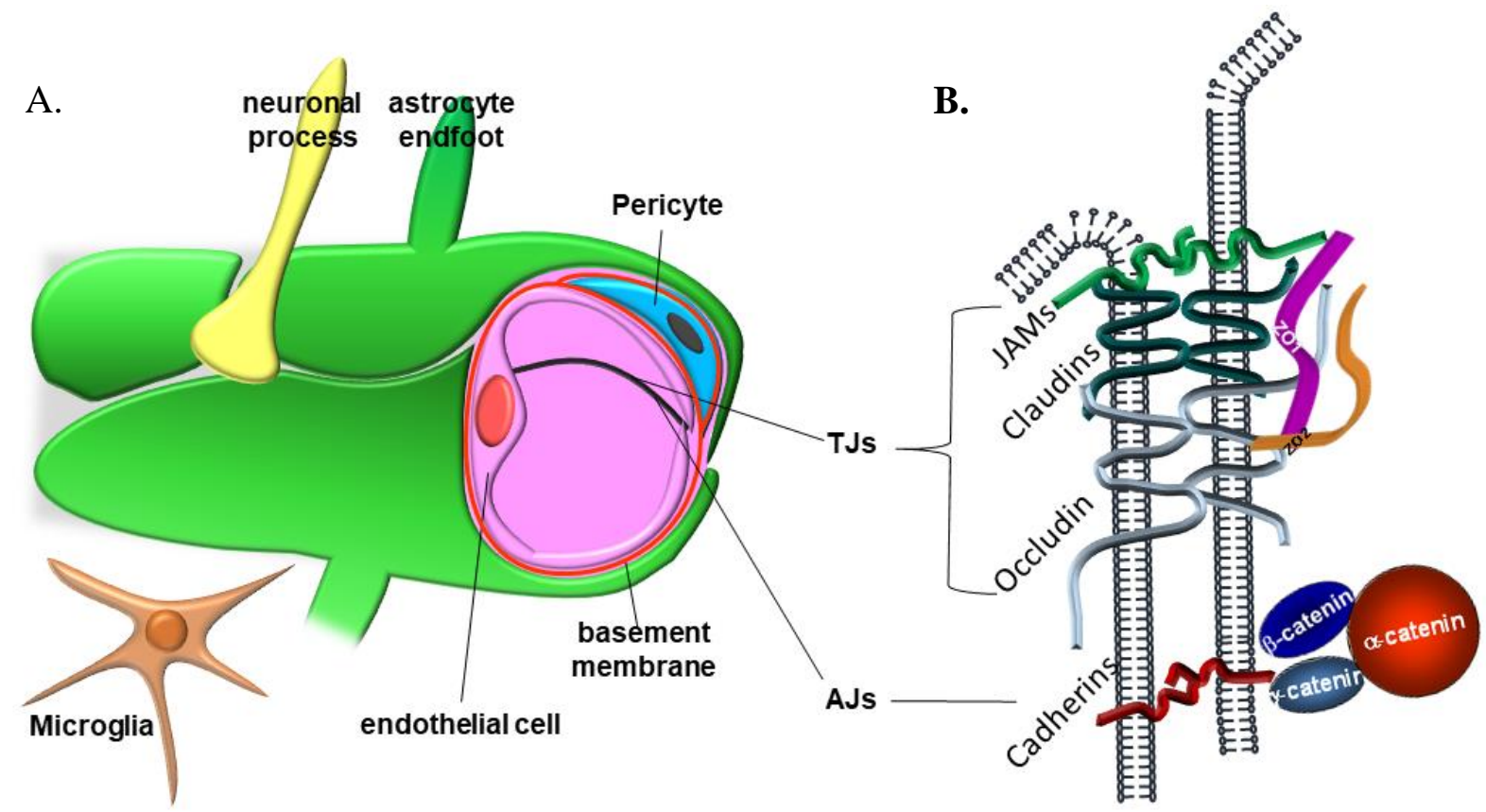

Figure 1: Schematic diagram of the blood-brain barrier. A: Cellular elements of the BBB. B: Intercellular junctions between brain endothelial cells: Tight junctions (TJs) and Adherent junctions (AJs).

Another major function of the brain endothelium and the BBB is the transport of nutrients supplying the brain tissue. Major routes of nutrient delivery are: lipid-mediated diffusion (small lipid soluble molecules), paracellular diffusion (limited by tight junctions), carrier-mediated transport (sugars and amino acids), receptor-mediated transcytosis (peptides and proteins), absorptive-mediated transcytosis (e.g. positively charged molecules) (Campos-Bedolla et al. 2014).

Beyond endothelial cells, the BBB consists of astrocyte end-feet, pericytes and the basal lamina and has an intimate relationship with neurons and microglia (Fig. 1A.). These perivascular cells and structures contribute to the maintenance and modulation of the barrier characteristics.

Endothelial cells, astrocyte end-feet and pericytes are covered by and contribute to the formation of the basement membrane, which provides a structural support for the enclosed cells by anchoring them in place (Engelhardt, Patkar and Ogunshola 2014). 
Astrocytes supply neurons with nutrients and substrates for neurotransmission, contribute to

the clearance and recycling of neurotransmitters and the induction and regulation of the $\mathrm{BBB}$ (Obermeier, Daneman and Ransohoff 2013). Several studies applying in vitro models using astrocyte-endothelial co-cultures and astrocyte-conditioned media demonstrated that astrocytes induce the barrier characteristic of the brain endothelium (Wilhelm and Krizbai 2014).

Pericytes are contractile cells located in the duplication of the basal membrane. Pericytes also play a crucial role in the regulation of the endothelium including angiogenesis, blood flow, immune and phagocytic activity (Sá-Pereira, Brites and Brito 2012). Accumulating data of several in vitro and in vivo experiments indicate that pericytes are also involved in induction and maintenance of barrier properties (Armulik et al. 2010).

\subsection{Interendothelial junctions}

The intercellular space between endothelial cells is sealed by tight junctions (TJs) and adherens junctions (AJs) reducing the permeation of polar solutes and large molecules through the paracellular way (Fig. 1B.). TJs are located in the apical section of the plasma membrane of adjacent cells forming belt-like structures. Beyond the barrier function of the TJs, restricting the paracellular movement of solutes, they segregate proteins and lipid rafts of the luminal and abluminal side of the plasma membrane, thus contribute to the polarity of the endothelial cells (fence function). AJs are located below the TJs, holding the cells together, giving the cellular structural support maintaining blood vessel integrity. They are necessary for the formation of the TJs and these two structures have common structural elements, such as ZO-1 and ZO-2 (zonula occludens-1 and -2) (Itoh, Morita and Tsukita 1999).

TJs are formed by transmembrane proteins and cytoplasmic plaque proteins. Major transmembrane protein components in the endothelial TJs belong to tight junction-associated marvel porteins, claudins and junctional adhesion molecules (JAMs). From them, claudins and marvel proteins are tetraspan proteins characterized by four transmembrane domains. Claudin-5 is the most abundant claudin isoform in the brain endothelium. In addition, claudin-1, -3 and -12 are expressed in brain capillaries, but the level of their mRNA is 600-700 times lower compared to claudin-5 (Ohtsuki et al. 2008). The BBB permeability to small molecules (<800 Da), but not to larger, is increased selectively in claudin-5 defficient mice, showing the importance of this molecule (Nitta et al. 2003). From the marvel family proteins (occludin, tricellulin, marveld3 
(Raleigh et al. 2010)) of the TJs, occludin is mostly located in bicellular contacts and tricellulin is mostly located in tricellular contacts of brain endothelial cells (Iwamoto, Higashi and Furuse 2014). Furthermore, the presence and the influence of marveld 3 on the BBB is unknown. Altough, occludin is expressed in all TJs, studies demonstrated that TJs of occludin knock-out mice are not affected morphologically (Haseloff et al. 2005, Saitou et al. 2000). On the other hand, other studies suggest that occludin has an important role in the regulation and maintenance of the endothelial barriers. The third important transmembrane proteins of the endothelial junctions are the JAMs. They are single span proteins belonging to the immunoglobulin superfamily. JAM-A, JAM-B and JAM-C are expressed in endothelial cells and beyond their role in the formation of TJs, they also play role in leukocyte diapedesis (Engelhardt and Ransohoff 2012).

With their intracellular loops, these transmembrane proteins (except claudin-12) bind to PDZ domains of cytoplasmic scaffold proteins (Tietz and Engelhardt 2015), which mediate the link between the transmembrane proteins and the actin cytoskeleton. Among these PDZ domain containing molecules zonula occludens (ZO) proteins have been largely documented in TJs. From them, ZO-1 (Hirase et al. 1997) and ZO-2 (Jesaitis and Goodenough 1994) are expressed in the brain endothelium. Other, non-PDZ, accessory proteins of the TJs are cingulin (Citi et al. 1989) and junctional-associated coiled-coil protein (JACOP)/paracingulin (Ohnishi et al. 2004). Beyond the molecular scaffold, some of the molecules of the TJ plaque proteins have signaling function.

AJs are also formed by transmembrane proteins and cytoplasmic proteins providing scaffold for transmembrane proteins. Vascular endothelial (VE-) cadherin is the main transmembrane protein of the endothelial AJs necessary for endothelial survival and blood vessel stabilization (Carmeliet et al. 1999, Crosby et al. 2005). Furthermore, N-cadherin may play role during brain angiogenesis (Gerhardt, Wolburg and Redies 2000). Mainly catenins anchor cadherins to the cytoskeleton. $\beta$ - and $\gamma$-catenin (or plakoglobin) directly link to cadherins and to $\alpha$-catenin, which links them to the actin microfilament network (Nieset et al. 1997). In addition, catenins also play role in signaling pathways, such as Wnt- $\beta$-catenin pathway. Other transmembrane proteins of the AJs are nectins belonging to the immunoglobulin superfamily. Nectins are connected to the cytoskeleton by afadin/AF6 (Tietz and Engelhardt 2015). Some of the proteins of AJs may be involved in the adhesion and transmigration of leukocytes. 


\subsection{Migration of cells across the BBB}

Since the CNS lacks a classical lymphatic system, leukocytes and metastatic tumor cells have to pass the blood vessels to reach the brain parenchyma. Cancer cell migration across the brain endothelium is a less studied process than leukocyte diapedesis. Presumably these two processes share cellular and molecular mechanisms, but there are significant differences as well (Strell and Entschladen 2008). Two cell migration pathways across the endothelium have been described: the paracellular route (between endothelial cells) and the transcellular diapedesis. Immune cells can use both pathways during diapedesis across the BBB (Reijerkerk et al. 2006, Dejana 2006); however, pathways of cancer cells across the BBB are less known.

\subsubsection{Entry of leukocytes to the CNS across the BBB}

Immune cell trafficking to the CNS is a multistep process including several interactions of the leukocytes with the brain endothelium (Fig. 2.). These steps are capture of the circulating leukocytes and their rolling along the vessel wall followed by arrest and adhesion to the endothelium and transmigration across the blood vessels. High number of leukocytes cross the BBB during neuroinflammatory diseases, such as Alzheimer's disease, multiple sclerosis, traumatic brain injury (TBI), stroke or HIV-1 encephalitis (Weiss et al. 2009). The massive cellular infiltration is closely associated with dysfunction of the BBB characterized by disruption of TJs and increased permeability (Zlokovic 2008). During these diseases mostly lymphocytes, macrophages and neutrophil granulocytes transmigrate (Chodobski, Zink and SzmydyngerChodobska 2011, Bolton, Anthony and Perry 1998, Fiala et al. 2002, Williams et al. 2012).

Cell adhesion molecules (CAMs) of endothelial cells interact with cognate ligands on immune cells during each step. First, circulating leukocytes transiently make contact with the endothelium and roll along the vessel wall with reduced velocity. This initial step is mediated by endothelial E- and P-selectin and their glycosylated leukocyte ligand, including P-selectin glycoprotein 1 (PSGL1) or $\alpha$-integrins (Kerfoot and Kubes 2002). Rolling leukocytes meet factors of endothelial cells, such as chemokines (e.g. CXCL12), which bind to G-protein coupled receptors on immune cells. This receptor activation increases the affinity of integrins on leukocytes (VLA-4 $\left(\alpha_{4} \beta 1\right)$, LFA-1 $\left(\beta_{2} \alpha_{\mathrm{L}}\right)$ and MAC-1 $\left.\left(\alpha_{\mathrm{M}} \beta_{2}\right)\right)$, mediating the arrest of immune cells to the endothelium connecting to their receptors (ICAM-1 and VCAM-1) on endothelial cells (McCandless et al. 2008, Takeshita and Ransohoff 2012). Arrest of leukocytes is followed 
by cell adhesion strengthening and crawling of immune cells on the endothelium. Crawling cells search for suitable sites on the endothelium with their protrusions to migrate across the vessel wall. VCAM-1, ICAM-1 and LFA-1 are also involved in the crawling process (Steiner et al. 2010). In contrast to diapedesis, rolling and adhesion are reversible steps, so not all leukocytes rolling and attaching to the endothelium will migrate across it.

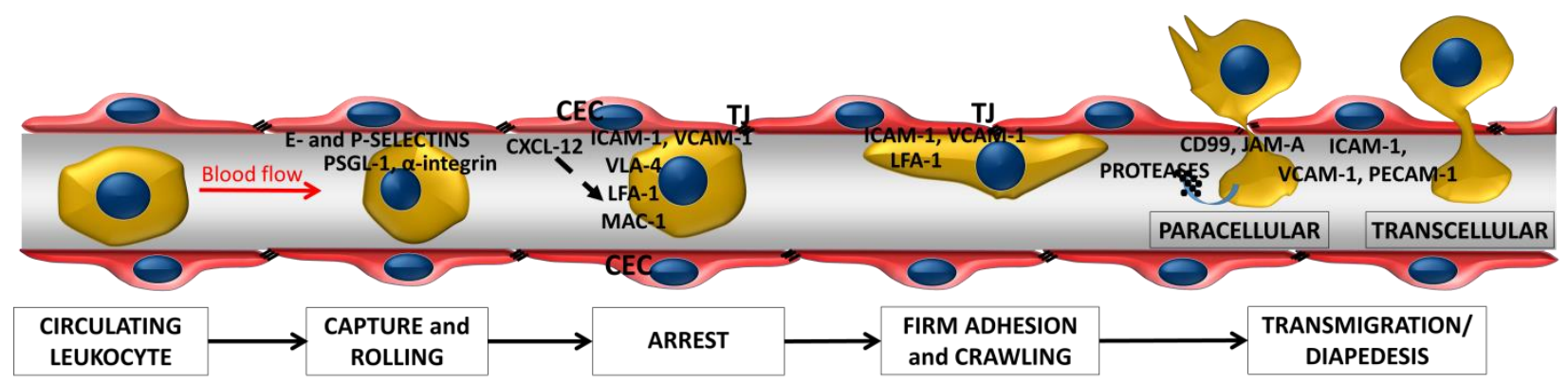

Figure 2: The multistep process of leukocyte extravasation across the BBB. The canonically defined steps and molecules involved in this process: capture and roll (E and P-selections, PSGL-1, $\alpha$-integrin), arrest (CXCL-12, ICAM-1, VCAM-1, VLA-4, LFA-1, MAC-1), adhesion (ICAM-1, VCAM-1, LFA-1), transmigration (several proteases, ICAM-1, VCAM-1, PECAM-1, CD99, JAM-A).

Transmigration, the final stage of this multistep process is also regulated by ICAM-1, VCAM-1 and chemokine signals (Takeshita and Ransohoff 2012). PECAM-1 (platelet endothelial cell adhesion molecule), CD99, JAM-A and presumably other molecules are recruited to sites of diapedesis and form the lateral border recycling compartment, which surrounds the leukocyte in a kinesin-mediated, microtubule-dependent manner and leads to the paracellular diapedesis. During transcellular diapedesis, leukocytes cross the endothelium across pore like structures formed in the endothelial cells (Engelhardt and Ransohoff 2012). Compared to the paracellular diapedesis, the transcellular is less well defined. The process of leukocyte extravasation is intensively studied and its main steps are well characterized, but the organ specific differences, such as BBB specific aspects, are still not fully understood.

\subsubsection{Diapedesis of cancer cells across the BBB}

Lung cancer, breast cancer and melanoma are the most frequent origins of brain metastasis followed by colorectal and renal cancers and lymphoma. Cancer cells originating from breast or colon often form single metastasis; while, lung cancer and melanoma cells tend to produce multiple metastases (Norden, Wen and Kesari 2005). Under physiological conditions, the BBB is an obstacle for the cell trafficking, but some types of cancer cells, especially those listed above, 
prefer to metastasize into the brain. Besides being an obstacle, brain endothelial cells can facilitate the transmigration of cancer cells, then protect them from the immune cells and provide an ideal environment for their survival and growth (Wilhelm et al. 2013, Wilhelm et al. 2017).

Cancer cells may extravasate from capillaries or postcapillary venules to the brain (Lorger and Felding-Habermann 2010, Kienast et al. 2010). A few studies indicate that metastatic cells also roll on the vessel wall; however, further investigations are needed to confirm the existence of this step in vivo, especially in the brain vasculature. Presumably, metastatic tumor cells adhere to and transmigrate across the BBB (Fig. 3.). Besides some similarities several molecular and mechanical characteristics of these processes seem to be different from leukocyte diapedesis, although, cancer cell transmigration is a less known process (Strell and Entschladen 2008). One of the main differences is, that cancer cells (lung, breast cancer cells and melanoma) spend several days in the lumen of the blood vessels of the CNS during extravasation, in contrast to leukocytes transmigrating into the brain or cancer cells metastasizing into other organs (Lorger and Felding-Habermann 2010, Paku et al. 2000, Kienast et al. 2010).

Selectins, the indispensable molecules of leukocyte tethering and rolling, are presumably involved in the endothelial cell-cancer cell interactions; however, their function in this process is less understood. Different studies indicate that the blockage of selectins by antibodies or heparin may inhibit brain metastasis formation (Brayton et al. 1998, Maraveyas et al. 2010). Integrins may play an important role in brain metastasis formation. Antibodies against different integrins have been shown to be able to block or reduce the number of cells metastasizing to the brain. In case of breast cancer cells, integrin $\beta_{4}$ and VLA-4 $\left(\alpha_{4} \beta_{1}\right)$ seem to contribute to the seeding of tumor cells into the brain (Soto et al. 2014, Fan et al. 2011). Furthermore, $\alpha_{3} \beta_{1}$ was suggested to play an important role in the brain metastasis formation of non-small cell lung cancer (Yoshimasu et al. 2004). Brain endothelial expression of two other CAMs, the ICAM-1 and the VCAM-1 was shown to be increased around breast cancer cells (Soto et al. 2014). Other studies suggested that VCAM-1 and ICAM-1 play an important role in brain metastasis formation of lung cancer cells (Langley et al. 2001). 


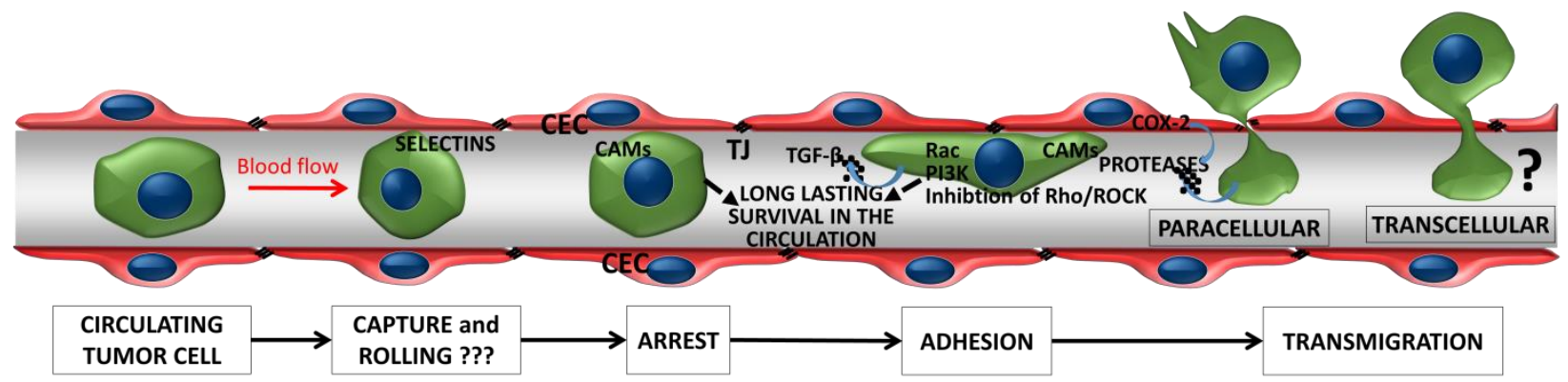

Figure 3: The multistep process of tumor cell extravasation across the BBB. An illustration of the consecutive steps and molecules presumably involved in transendothelial migration of tumor cells: capture and rolling (selectins), arrest (CAMs), adhesion (TGF- $\beta$, Rac, PI3K, Rho/ROCK, CAMs), transmigration (COX-2, different protesases).

In our transmigration in vitro experimental setup we have observed that melanoma cells disrupted the continuous contact between endothelial cells and decreased the transendothelial electrical resistance (TEER) of the brain endothelial monolayer (Fazakas et al. 2011). Our data suggest that melanoma cells use the paracellular way to get across the blood vessels; however, it is possible that they can use the transcellular way as well. Several proteolytic enzymes, including matrix metalloproteinases (Mendes, Kim and Stoica 2005, Xie et al. 2006) or gelatinolytic serine proteases (Fazakas et al. 2011), contribute to disruption of endothelial TJs and transmigration of cancer cells and also the angiogenesis of the metastatic tumors. Several signaling molecules of endothelial cells and cancer cells play important role in the interaction of these cells. Accumulating data suggest that Rho/ROCK signaling-dependent switch between two types of cancer cell movement, the amoeboid and the mesenchymal, is involved in different steps of metastasis. The effect of ROCK activation or inhibition on tumor cell invasion is contradictory and seems to be dependent on the type of cancer cells (Yang et al. 2012, Itoh et al. 1999, Yui et al. 2010, Vishnubhotla et al. 2012). In case of melanoma cells, our experiments revealed that ROCK inhibition increases the number of melanoma cells attached to the brain endothelium, raises the number of melanoma cells migrating through the brain endothelial monolayer and promotes the formation of parenchymal brain metastases in vivo (Wilhelm et al. 2014). MAPKERK and PI3K-AKT are other pathways playing important role in the metastasis formation. Activation of p38 MAPK and ERK1/2 has been shown to promote melanoma cell invasion (Colone et al. 2008). Inhibition of PI3K-AKT pathway have been shown to interfere with invasiveness of melanoma and their transendothelial migration (Peng et al. 2005). In our studies, inhibition of Rac and PI3K hindered the adhesion of breast cancer cells and melanoma cells to 
the brain endothelium. Furthermore, inhibition of Rac and PI3K impeded the late phase of transmigration of breast cancer cells and the early phase of transmigration of melanoma cells which indicates tumor and cell specificity (Molnár et al. 2016). Still, it is important to emphasize that the role of different signaling pathways in brain metastasis formation is mostly unknown and need to be characterized.

\subsection{Targeting neuroinflammation and metastasis formation: CB2 and lignans}

The pathology of neuroinflammatory diseases and brain metastases involves complex cellular and molecular mechanisms. For effective therapies, several steps of these multifactorial diseases should be targeted, such as the diapedesis of leukocytes or cancers cells. New molecular biological findings and chemical compounds discovered during the last few decades might provide new perspectives for interfering with these steps. Among these, cannabinoid receptor 2 (CB2) agonists and lignans might be promising compounds to target immune and metastatic cell transmigration into the brain.

\subsubsection{Effect of CB2 activation on inflammation and metastasis formation}

The cannabinoid system is known mainly for its psychoactive effects; however, it has been previously shown that its activation may induce anti-inflammatory and neuroprotective processes as well. Cannabinoids exert their effects mainly through two receptor types: cannabinoid receptor 1 (CB1) and $\mathrm{CB} 2$ which mediate distinct effects. The psychoactive effect is triggered by CB1, whereas the anti-inflammatory effects are mainly induced by the activation of CB2 (Miller and Stella 2008). CB1 is expressed pre-synaptically mainly in the CNS, whereas CB2 is expressed predominantly in cells of the immune system and hematopoietic cells. In the brain, CB2s have been found primarily on microglia (Cabral et al. 2008). Induction of cannabinoid-like effects by substances which do not activate $\mathrm{CB} 1$ or $\mathrm{CB} 2$ suggested the existence of other cannabinoid receptors as well. Several G protein-coupled receptors (GPRs) considered to be orphan receptors have been shown to be activated by cannabinoids including endocannabinoids. Such GPRs are GPR18, GPR55 and GPR119 (McHugh et al. 2010, Ryberg et al. 2007). All these cannabinoid and cannabinoid-like receptors belong to the superfamily of 7 -transmembrane receptors. These receptors and their endogen natural ligands produced by the body called

endocannabinoids comprise the endocannabinoid system. $\Delta^{9}$-tetrahydrocannabinol (THC), the major psychoactive component of marijuana has been known to bind to both $\mathrm{CB} 2$ and $\mathrm{CB} 1$ with 
high affinity. Furthermore, several synthetic cannabinoids have been discovered and developed during the last two decades.

Some of the synthetic compounds are full agonists, binding to both cannabinoid receptors with high affinity, others are able to bind selectively to CB1 or CB2 with high affinity. Selective CB2 agonists, such as JWH133 and O1966, provide new perspectives to study the role of specific activation of CB2 in several physiological and pathological processes, without activating the CB1 that may induce psychoactive side-effects. These selective agonists are also clinical candidates for the treatment of several diseases associated with inflammation. In the brain, the anti-inflammatory effects of cannabinoids have been demonstrated using different animal models. These effects have been observed with synthetic cannabinoids (using mostly WIN 55212-2) that act on both CB1 and CB2. To elicit their CB1 or CB2 specific effect, animals were co-treated with CB1 or CB2 specific antagonists. WIN 55212-2 has been shown to reduce the number of leukocytes rolling on and adhering to the pial vessels of the brain in an experimental autoimmune encephalomyelitis (EAE) model (acute model of multiple sclerosis) (Ni et al. 2004). The neuroprotective effect of cannabinoids in diseases associated with neuroinflammation has also been confirmed in animal models of Alzheimer's disease, stroke and amyotrophic lateral sclerosis (Cabral and Griffin-Thomas 2009). The improved pathological outcomes observed in vivo with cannabinoids may be a sum effect of the attenuation exerted on leukocyte and endothelial cell activation. Although the modulatory effects of CB2 activation on immune cells have been studied, not much is known about its effects on brain endothelial cells. CB2 has been found to be expressed in brain endothelium (Golech et al. 2004, Lu et al. 2008) and endothelial cells from other organs (Rajesh et al. 2007). Attenuation of endothelial activation by CB2 has been observed in nonbrain endothelial cells; as such, synthetic CB2 agonists were shown to prevent $\mathrm{TNF} \alpha$-induced activation of human coronary artery endothelial cells in vitro (Rajesh et al. 2007).

The antiproliferative, anti-tumoral and anti-metastatic properties of cannabinoids, including natural and synthetic cannabinoids, have been tested in several studies. Either full cannabinoid receptor agonists (e.g.: THC, WIN 52212-2) or CB2 agonists (including JWH133) have been shown to reduce proliferation of lung, breast, prostate cancer and melanoma cells using in vitro and in vivo models (Qamri et al. 2009, Sarfaraz et al. 2005, Vidinský et al. 2012, Blázquez et al. 2006). WIN 52212-2 and JWH133 have been shown to exert anti-migratory action on breast 
cancer cell lines in vitro and to reduce the size of lung cancer metastases (Qamri et al. 2009). The effect of cannabinoids and CB2 activation on tumorigenesis and metastasis formation have been intensively studied recently, however these effects and their molecular and cellular characteristics are not fully described and understood. Presumably, the effectiveness of cannabinoids depends on the expression level of their receptors. Most of the published studies describing the effect of cannabinoids and CB2 activation on metastasis formation have investigated lung metastases. Hence, their effect on metastasis formation in other organs remained unclear, including brain metastasis formation.

\subsubsection{Effect of lignans on inflammation and metastasis formation}

Lignans are polyphenolic substances constituting one of the major classes of phytoestrogens. Other two major groups of phytoestrogens are isoflavones and coumestans. All these chemical compounds are widely distributed throughout the plant kingdom and have structural similarity to the endogenous hormone $17 \beta$-estradiol. The dietary sources of lignans are flaxseed, seaweed, whole grains, legumes, oil seeds, fruits and vegetables. Two best known and most intensively studied lignans in food include secoisolariciresinol-diglucoside and matairesinol which are the precusors of lignans enterodiol and enterolactone found in mammals (Virk-Baker, Nagy and Barnes 2010).

Several lignans have been shown to possess anti-inflammatory effects including neuroinflammatory diseases. Two lignans, magnolol and honokiol have been shown to reduce oxidative and inflammatory responses in neurons and microglial cells (Chuang et al. 2013). Another lignan, arctigenin could reduce cerebral infarction, attenuate microglia activation and decrease expression of IL1 $\beta$ and TNF $\alpha$ (Fan et al. 2012).

There is an evergrowing interest in cancer treatment with natural compounds, such as phytoestrogens including lignans. Inhibitory effects of some lignans such as flax seed lignans (Chen, Stavro and Thompson 2002), honokiol (Bai et al. 2003, Battle, Arbiser and Frank 2005, Chen et al. 2004) and pycropodophyllin (Girnita et al. 2004) on cancer growth have been demonstrated using animal models. From these compounds, honokiol has been shown to exert anti-proliferative effect on and induce apoptosis of leukemia cells, colon cancer cells and breast cancer cells (Chen et al. 2004, Park et al. 2009, Battle et al. 2005). Other lignans have been shown to display anti-metastatic effect in animal models of breast cancer (Bergman Jungeström, 
Thompson and Dabrosin 2007, Liu et al. 2012), melanoma (Kaushik et al. 2012, Girnita et al. 2006) or non-small cell lung cancer (Singh and Katiyar 2013).

Various lignans have been demonstrated to downregulate different matrix metalloproteinases (Singh and Katiyar 2013, Mali et al. 2012, Girnita et al. 2006) and CAMs (Spilioti et al. 2014, Li et al. 2014, Jeong et al. 2012, Wu et al. 2009), such as VCAM-1 and ICAM-1, which are considered to be important in the extravasation of tumor cells. Moreover, different lignans may reduce the migratory potential of highly metastatic tumor cells (Mali et al. 2012).

Besides the above mentioned studies, the effect of lignans on the different steps of metastasis formation, including brain metastases, remained unclear. Considering the possibility of finding lignans with antimetastatic properties, it is really important to examine if some of them can interfere with one or more aspects of metastasis formation. 


\section{Aims}

The entry of leukocytes or cancer cells across the brain endothelium into the CNS is a key event during neuroinflammation or formation of brain metastases. In our studies we addressed the effect of CB2 agonists and the lignans from Heliopsis helianthoides var. scabra on BBB function and cell migration across the brain endothelium. Our investigations had the following specific aims:

To investigate $\mathrm{CB}$ and $\mathrm{CB}-$ like receptor expression in the brain endothelium and melanoma cells.

To examine the effect of CB2 agonists on leukocyte-endothelial cell adhesion using in vivo and in vitro models.

To observe the effect of CB2 agonists on the barrier properties of the brain endothelium in vivo and in vitro.

To determine the role of CB2 activation in the adhesion of melanoma cells to the cerebral endothelium and transmigration of these cells through the BBB.

To evaluate the effect of lignans from Heliopsis helianthoides var. scabra on melanoma brain metastasis formation and on the barrier function of the brain endothelial cells via in vitro models.

\section{Materials and Methods}

\subsection{Cell culture and treatments}

The human microvascular cerebral endothelial cell line (hCMEC/D3; abbreviated as D3) was maintained in EBM-2 medium (Lonza) supplemented with EGM-2 growth factors (Lonza) and 5\% fetal bovine serum (FBS, Sigma-Aldrich). The A2058 human melanoma cell line (obtained from the European Collection of Cell Cultures) was cultured in MEM (Sigma-Aldrich) and $5 \%$ FBS.

Human primary brain microvascular endothelial cells (BMVECs) were supplied by Michael Bernas and Dr. Marlys Witte (University of Arizona, Tucson, AZ). Isolation and the BMVEC culture procedure have been detailed previously (Bernas et al. 2010). Briefly, BMVECs were isolated from vessels of normal tissue derived from brain resections performed for the treatment of intractable epilepsy. The BMVEC cultures were used until passage 5 and were expanded in 
DMEM/F-12 media supplemented with 10\% heat-inactivated FBS, endothelial cell growth supplement (ECGS; BD Biosciences), heparin (1 mg/ml; Sigma-Aldrich), amphotericin B (2.5 $\mu \mathrm{g} / \mathrm{ml}$; Invitrogen), penicillin (100 U/ml; Invitrogen), and streptomycin (100 $\mu \mathrm{g} / \mathrm{ml}$; Invitrogen). Before experimentation, BMVEC monolayers were placed in medium containing the above supplements but lacking ECGS and heparin. Under these conditions, the BMVEC cultures were routinely evaluated for the presence of endothelial markers and barrier formation (Bernas et al. 2010).

Primary human monocytes were supplied by the Human Immunology Core at the University of Pennsylvania (Philadelphia, PA). The cells were isolated by countercurrent centrifugal elutriation and maintained in DMEM containing heat-inactivated 10\% FBS, penicillin (100 $\mathrm{U} / \mathrm{ml})$, streptomycin $(100 \mu \mathrm{g} / \mathrm{ml})$, and L-glutamine $(2 \mathrm{mM})$ and were used within $24 \mathrm{~h}$ of isolation.

Primary rat brain endothelial cells (RBECs) were isolated from 2-week-old rats, as described previously (Wilhelm et al. 2007, Hutamekalin et al. 2008). Briefly, after removal of the meninges, the cerebral cortices were cut into small pieces and digested in two steps with collagenase and collagenase/dispase, followed by centrifugation on a Percoll gradient. Isolated microvessels were plated on fibronectin/collagen-coated dishes. Endothelial cells growing out of the microvessels were cultured in DMEM/F12 (Life Technologies), 10\% plasma-derived serum (PDS, FirstLink Technology, Denver, CO, USA) and growth factors. In the first two days, 4 $\mu \mathrm{g} / \mathrm{ml}$ puromycin was added to remove contaminating cells.

The selective CB2 agonist JWH133 solution (diluted in Tocrisolve, an aqueous soluble emulsion composed of a 1:4 ratio of soya oil to water that is emulsified with the block copolymer Pluronic F68) was purchased from Tocris. The selective CB2 agonist, O1966 (1-[4-(1,1dimethyl-heptyl)-2,6-dimethoxy-phenyl]-3-methyl-cyclohexanol), was acquired from Organix. Crystalline O1966 was dissolved in a pure ethanol/emulphor/saline mixed solution at 1:1:18. The selective CB2 inverse agonist SR144528 (dissolved in ethanol) was from Santa Cruz, the MEK1/2 inhibitor U0126 (dissolved in DMSO) was from Cell Signaling and the Gi/Go inhibitor $_{\alpha}$ pertussis toxin (PTX, dissolved in PBS) was from Sigma-Aldrich.

Lignans from $H$. helianthoides var. scabra were acquired from our collaborators, Zsanett Hajdú et al. (Department of Pharmacognosy, University of Szeged, Szeged, Hungary). Six pure lignans were isolated by chromatographic separation, such as vacuum-liquid chromatography, 
medium-pressure liquid chromatography, preparative thin-layer chromatography, centrifugal planar chromatography. Before the measurements, the purity of the isolated lignans were measured by thin layer chromatography (TLC) and high performance liquid chromatography (HPLC). Isolation and assesmentt of purity were performed by Zsanett Hajdú et al. The compounds were dissolved in DMSO as $10 \mathrm{mM}$ stock solutions. Control cells received an equivalent concentration of DMSO as vehicle.

\subsection{RT-PCR}

Total RNA was isolated using TRIzol reagent (Life Technologies) following the manufacturer's recommendations. RNA was transcribed into cDNA using the SuperScript III reverse transcription kit (Life Technologies). The amplification was performed on a BioRad iQ5 instrument using Maxima SYBR Green Mix (Fermentas) under the following conditions: 40 cycles of $95^{\circ} \mathrm{C}$ for $15 \mathrm{~s}, 56^{\circ} \mathrm{C}$ for $30 \mathrm{~s}, 72^{\circ} \mathrm{C}$ for $30 \mathrm{~s}$. Primer pairs used for amplification are summarized in Table 1. PCR products were electrophoresed on 1.5\% agarose gels stained with ethidium bromide.

Table 1: Primers used for RT-PCR.

\begin{tabular}{|l|l|l|c|}
\hline Name & Forward primer & Reverse primer & Product size \\
\hline hCB2A & TCGCGCGTTGTAAGTGCACAG & TCGGCTGGAGCTCGGTGAGT & 197 \\
\hline hCB2B & TGCCCAGCCACCCACAACACA & TATGAGGGCTTCCGGCGGAGT & 278 \\
\hline rCB2 var. 1. & AGGCCAGACCTCCTCTCACCC & CCCGCCATGGACAGACAGGC & 234 \\
\hline rCB2 var. 2. & CGAGGCCACCCAGCAAACAT & GGGTTGAACTCCAAGCCGCCA & 152 \\
\hline hCB1 & GTTCCTCACAGCCATCGACA & AGAAGCAGTACGCTGGTGAC & 243 \\
\hline hGPR18 var. 1. & AAAGTCAGCCCAGCACCAACTCC & CAGCTGCTCTACTTCAGTGGTTCAC & 250 \\
\hline hGPR18 var. 2. & TCCGACGCCAAGCGTTACACTG & TACCGTGGTTCTCTTCTTGGTGGT & 398 \\
\hline hGPR55 & CTGCAGGACACCACGATCTC & GATCCCTGAACACTGGGTGG & 243 \\
\hline hGPR119 & CGCAGCTGCCTCTGTCCTCA & ACGCAGGAGAGGGTCAGCAC & 252 \\
\hline
\end{tabular}

\subsection{Immunofluorescence studies}

CB2 and ZO-1 protein expression was evaluated by immunofluorescence on monolayers of BMVECs plated on type I collagen-coated coverslips (BD Biosciences). The cells were fixed with 3\% (v/v) formaldehyde (Polysciences) and permeabilized with $0.1 \%$ Triton X-100 in PBS. Primary antibodies and dilutions used included polyclonal antibodies to ZO-1 (1:25; Invitrogen) 
and CB2 (1:100; Thermo Scientific). The cells and primary antibodies were incubated overnight at $4{ }^{\circ} \mathrm{C}$. Alexa-488 conjugated goat anti-rabbit and Alexa-594 conjugated goat anti-mouse (Invitrogen) secondary antibodies were used at 1:400 for $1 \mathrm{~h}$. Cells were then washed and mounted onto slides with Prolong antifade containing DAPI (Invitrogen). Images were recorded with a Nikon Eclipse 80i wide-field fluorescence microscope fitted with a color DS-Fi1 camera for imaging of chromagen stained slides and a Coolsnap EZ CCD camera (Photometrics) for fluorescence imaging. Imaging software NIS Elements BR (Nikon Instruments) was used for image acquisition and processing.

D3 cells and RBECs were cultured until confluency in 96-well plates. The cells were treated for $2 \mathrm{~h}$ and then fixed with ethanol:acetic-acid $(95: 5)$ at $-20{ }^{\circ} \mathrm{C}$ for $5 \mathrm{~min}$. After blocking with $3 \%$ BSA in PBS for $30 \mathrm{~min}$, samples were incubated with primary rabbit antibody against ZO-1 (Invitrogen, Carlsbad, CA, USA) overnight. The stainings were visualized with Cy3 conjugated goat anti-rabbit antibody (Jackson ImmunoResearch Laboratories). After immunostaining, nuclear staining of the cells was carried out with Hoechst 33342 (Sigma-Aldrich). Images were recorded by a Nikon Eclipse TE2000U photomicroscope with epifluorescent capabilities connected to a digital camera (Spot RT KE).

\subsection{Phalloidin staining of the actin-cytoskeleton}

Following treatment for $2 \mathrm{~h}$ with Hel-6 or Hel-11 $(5 \mu \mathrm{M})$, A2058 melanoma cells were fixed with $4 \%$ formaldehyde and permeabilized with acetone at $-20{ }^{\circ} \mathrm{C}$ for $10 \mathrm{~min}$. After blocking, cells were stained with Alexa488-phalloidin (Life Technologies). Mounting was performed in anti-fading embedding medium (Biomeda) and the distribution of the signal was studied with a Nikon Eclipse TE2000U photomicroscope (Nikon Instruments) with epifluorescent capabilities connected to a digital camera (Spot RT KE).

\subsection{Adhesion assays}

\subsubsection{Adhesion of monocytes to BMVECs}

Quantitative adhesion assays were performed as described previously (Ramirez et al. 2008). BMVECs were seeded on collagen type I-coated 96-well black-wall, clear-bottom plates (Corning Costar) at a density of $2.5 \times 10^{4}$ cells per well. Confluent monolayers. were then exposed to the indicated experimental treatments. Freshly isolated human monocytes at $5 \times 10^{6}$ 
cells $/ \mathrm{ml}$ were labeled with $5 \mu \mathrm{M}$ of the fluorescent tracer calcein AM (Invitrogen). All treatments were removed from the endothelial cells before adding monocytes at $2.5 \times 10^{5}$ cells per well. The monocytes and endothelial cells were incubated together for $15 \mathrm{~min}$ and then rinsed three times with PBS to eliminate nonadherent monocytes. The fluorescence of adherent monocytes was measured using a Spectramax M5 fluorescence plate reader (Molecular Devices). The number of adherent monocytes was determined from external standards of known numbers of labeled monocytes.

\subsubsection{Adhesion of melanoma cells to D3 cells}

D3 human brain endothelial cells were grown until confluency in 12-well plates. Both endothelial cells and melanoma cells were pretreated with the tested drugs for $4 \mathrm{~h}$. After pretreatment, A2058 melanoma cells were fluorescently labeled using Oregon Green® 488 carboxylic acid diacetate succinimidyl ester (OG, Life Technologies) using the protocol supplied by the manufacturer. $10^{5}$ melanoma cells/well were loaded onto the endothelial monolayer in serum-free medium and left for $90 \mathrm{~min}$. After washing, cells were fixed using ethanol/acetic acid $(95 / 5)$ at $-20{ }^{\circ} \mathrm{C}$ for $5 \mathrm{~min}$. Melanoma cells attached to endothelial cells were photographed and counted using the Image-Pro Plus software (Media Cybernetics).

\subsection{Transmigration assay}

For transmigration experiments primary brain endothelial cells were used because of their superior barrier characteristics. RBECs were passed onto fibronectin/collagen-coated $8 \mu \mathrm{m}$ pore size filter inserts (Millipore). After reaching confluence, endothelial cells were supplemented with $550 \mathrm{nM}$ hydrocortisone, $250 \mu \mathrm{M}$ CPT-cAMP (Sigma-Aldrich) and $17.5 \mu \mathrm{M}$ RO-201724 (Sigma-Aldrich) from the apical side and astrocyte-conditioned medium from the basolateral side for $24 \mathrm{~h}$. $10^{5}$ OG-labeled melanoma cells were plated into the upper chamber, onto the endothelial monolayer in serum-free medium and left for $5 \mathrm{~h}$. The lower compartment was loaded with serum-free medium containing $100 \mu \mathrm{g} / \mathrm{ml}$ type I collagen. Cells were fixed with ethanol/acetic acid. Cells from the upper compartment were wiped off with a cotton swab. Transmigrated melanoma cells were counted using the Image-Pro Plus software. 


\subsection{Wound healing assay}

A2058 melanoma cells or D3 endothelial cells were seeded into 12-well tissue culture plates coated with rat tail collagen. The cells were grown to $100 \%$ confluency and the monolayer was then wounded by scratching with a pipette tip, washed with PBS and exposed to treatment in Leibovitz's medium supplemented with 5\% FBS. Cells were monitored over $24 \mathrm{~h}$ and phase contrast images were taken with an Andor NEO sCMOS camera (Andor Technology) connected to the Nikon Eclipse Ti-E inverted microscope (Nikon Instruments) equipped with a home built incubator set to $37^{\circ} \mathrm{C}$ and a 10x Nikon Plan Fluor objective, all placed onto a Prior Proscan II motorized stage (Prior Scientific Instruments). The wound healing effect was quantified by averaging the number of migrating cells counted in 5 wounded areas.

\subsection{Intravital microscopy}

All in vivo experiments were performed on 8-10-week-old C57BL/6 wild-type mice or CB2 receptor knock-out mice (strain B6.129P2-Cnr2tm1Dgen/J) purchased from the Jackson Laboratory. Intravital microscopy for in vivo leukocyte adhesion and vascular permeability was performed on adult male mice weighing between 20 and $25 \mathrm{~g}$. Following institutional regulations and guidelines for mouse survival surgery, intravital microscopy was performed on animals that underwent craniotomy and cranial window implantation. At the start of the procedure, the animals were placed under anesthesia [mixture of ketamine $(100 \mathrm{mg} / \mathrm{ml}$, i.p.) and xylazine (20 $\mathrm{mg} / \mathrm{ml}$, i.p.) at a dose of $1 \mathrm{ml} / \mathrm{kg}$ ] and depth of anesthesia was monitored by both toe and pinna pinch tests. Maintenance of normal body temperature was ensured with the use of a rodent thermal blanket. Once fully anesthetized, the head was positioned in a stereotaxic frame (Stoelting) with the nose bar set at zero. The craniotomy was performed lateral to the sagittal suture, and centered between lambda and bregma. A $1 \mathrm{~cm}^{2}$ area of skin on the dorsal surface of the skull over the right cortical hemisphere was excised and the periosteum exposed. The craniotomy was performed by generating a $4 \mathrm{~mm}$ diameter circular osteotomy with a rechargeable cordless micro drill (Stoelting) over the right parietal cortex extending from attachment of the temporal muscle to the midpoint of the sagittal suture in the coronal direction and aligned to the middle of the sagittal suture. A $5 \mathrm{~mm}$ coverslip was then introduced over the exposed brain, and an airtight seal was generated using Nexaband Quick Gel (which shows no histotoxicity). The tissue adhesive quickly created a waterproof seal between the edge of the skin 
and the glass coverslip. A recovery period of at least 7 days was allowed between implantation of the cranial window and intravital microscope observation (Fig. 4.). On the day of microscopy observation, animals were anesthetized and immobilized as described above. Observation of surface cerebral vessels through the cranial window was performed with a Stereo Discovery V20 epifluorescence microscope (Carl Zeiss Microimaging) equipped with a AxioCam MR digital camera (Carl Zeiss Microimaging) that was connected to a PC for image acquisition and analysis using Axiovision imaging software (Carl Zeiss Microimaging). For deep-tissue imaging, we used a Leica TCS SP5 II MP multiphoton microscope configured with a tunable femtosecond pulsed Mai Tai Ti:Sapphire laser (Spectra Physics), a resonant scanner (allowing acquisition of 29 frames per second), and NDD detectors. Dental cement was used around the cranial window to create a well in which distilled water was placed to permit the use of the $20 \mathrm{x}$ dipping objective (NA, 0.95).

For evaluation of adhesion, leukocytes were stained in vivo with an intravenous bolus injection of $50 \mu \mathrm{l}$ of a $0.01 \%$ solution of rhodamine $6 \mathrm{G}$ (Sigma-Aldrich). Identification of the brain vasculature and evaluation of vessel permeability was performed using intravenously injected $40 \mathrm{kDa}$ fluorescein-conjugated dextrans (at $10 \mathrm{mg} / \mathrm{ml}$ in a $100 \mu \mathrm{l}$ saline solution). For wide-field epifluorescence, leukocytes were visualized by fluorescent light (601 nm excitation). Selective filtering allowed visualization of the fluorescent cells on a dark background. A $30 \mathrm{~s}$ video (timeseries image set between 16 and 20 frames/s) was captured using the digital highspeed recorder Axiovision module (Carl Zeiss Microimaging). Adherent leukocytes were defined as the total number of the leukocytes firmly attached to the endothelium that did not change their location during the entire $30 \mathrm{~s}$ observation period. Adherent leukocytes were scored as the number of cells per square millimeter of the vascular surface area, calculated from the diameter and standardized length $(100 \mu \mathrm{m})$ of the vessel segment under observation. For multiphoton imaging, randomly selected cortical postcapillary venules $(20-30 \mu \mathrm{m}$ in diameter and down to $600 \mu \mathrm{m}$ below the cortical surface) were selected for imaging. $Z$ stacks of $400 \mu \mathrm{m}$ thickness at 1 $\mu \mathrm{m}$ steps were collected. Rendered three-dimensional constructs using the Imaris imaging software (Bitplane) were analyzed to obtain the number of adherent leukocytes per $100 \mu \mathrm{m}$ of vessel segment. 


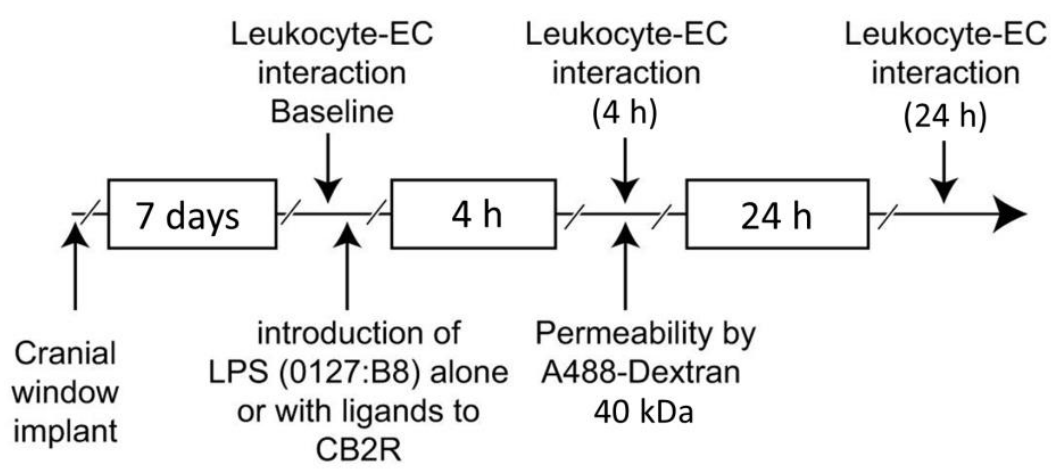

Figure 4: Experimental flow schematic of treatments and intravital microscopy endpoints.

\subsection{Western blot experiments}

Low-passage BMVECs or isolated brain microvessels were used for the Western blots. BMVEC cellular fractions were collected using the ProteoExtract kit (EMD Chemicals) as outlined by the manufacturer's protocol. Brain microvessels were isolated as described previously (Dogrukol-Ak et al., 2009), and lysates were prepared using the CelLytic-M reagent (Sigma-Aldrich). The protein concentrations in fractions were estimated using the BCA method (Thermo Scientific). Cellular fractions were loaded at $50 \mu \mathrm{g}$ per lane and resolved by SDSPAGE on 4-20\% precast gradient gels (Thermo Scientific). Proteins were transferred to nitrocellulose membranes and incubated overnight with polyclonal antibodies against CB2 (1:1000; Cayman Chemicals), occludin (1:500; Invitrogen), claudin-5 (1:300; Invitrogen), and sodium potassium ATPase (1:1000; Abcam). Secondary antibodies conjugated to HRP (Thermo Scientific) were then added for $1 \mathrm{~h}$ and detected using Supersignal West Pico chemiluminescence substrate (Thermo Scientific). Chemiluminescence signal detection was performed with the gel documentation system G:Box Chemi HR16 (Syngene). Densitometry analysis was performed with the GeneTools software package (Syngene).

\subsection{Measurement of transendothelial electrical resistance}

To determine the integrity of BMVEC monolayers, transendothelial electrical resistance (TEER) measurements were performed using the 1600R electric cell-substrate impedance sensing (ECIS) system (Applied Biophysics) as described previously (Ramirez et al., 2009). The ECIS system provides real-time monitoring of changes in TEER. In brief, BMVECs at a density of $1 \times 10^{5}$ per well were plated on collagen type I-coated $8 \mathrm{~W} 10 \mathrm{E}+$ electrode arrays (Applied Biophysics). The cells were then allowed to form monolayers reaching stable TEER values. 
After 7 days (with medium change every 3 days), the monolayers were exposed to the specific treatment. The readings were acquired continuously at $4 \mathrm{kHz}$ at $30 \mathrm{~min}$ intervals. Confluent BMVEC monolayers demonstrated baseline TEER readings between 1500 and $2400 \Omega$.

To measure the TEER of RBEC monolayer CellZscope instrument (nanoAnalytics) was used. RBECs were grown on collagen/fibronectin-coated semipermeable filters $(0.4 \mathrm{~mm}$ pore size, $1.12 \mathrm{~cm}^{2}$, Costar Corning Transwell, Tewksbury, MA, USA). After reaching confluency, the endothelial monolayer was supplied with $550 \mathrm{nM}$ hydrocortisone, $250 \mu \mathrm{M}$ CPT-cAMP (Sigma-Aldrich) and 17.5 $\mu \mathrm{M}$ RO-201724 (Sigma-Aldrich) and placed into the wells of the CellZscope instrument containing astrocyte conditioned medium. After TEER had reached its plateau, the endothelial cells were treated with Hel-6 $(5 \mu \mathrm{M})$ or Hel-11 $(5 \mu \mathrm{M})$ and TEER was followed for $2 \mathrm{~h}$.

\subsection{BBB permeability ex vivo}

Changes in BBB permeability were assessed using the fluorescent tracer sodium fluorescein (SF); the procedure performed was a modification of methods described previously (Hawkins and Egleton 2006). Briefly, animals were injected intravenously with $50 \mu$ of $2 \%$ SF in PBS. The tracer was allowed to circulate for $30 \mathrm{~min}$. The mice were anesthetized and then transcardially perfused with PBS until colorless perfusion was visualized. The animals were then decapitated and the brains quickly isolated. After removal of the meninges, cerebellum, and brain stem, the tissue was weighed and homogenized in a $10 \mathrm{x}$ volume of $50 \%$ trichloroacetic acid. The homogenate was centrifuged for $10 \mathrm{~min}$ at $13000 \mathrm{x} \mathrm{g}$, and the supernatant was neutralized with $5 \mathrm{M} \mathrm{NaOH}$. Measurement of SF fluorescence was determined at excitation/emission wavelengths of 440/525 nm using a SpectraMax M5 microplate reader (Molecular Devices). Fluorescent dye content was calculated using external standards with a range of 10-200 ng/ml. The data are expressed as the fold (compared to control) amount of tracer found per mg of tissue. 


\section{Results}

\subsection{Expression of cannabinoid receptors and cannabinoid-like receptors in brain endothelial cells and melanoma cells}

\subsubsection{CB2 expression on brain endothelium}

As the first step, the expression of $\mathrm{CB} 2$ of brain endothelial cell was evaluated by immunofluorescence using confluent cultures of BMVECs. We performed double immunostaining for CB2 and ZO-1, a highly expressed TJ protein in barrier-forming BMVECs. Moderate immunostaining for the $\mathrm{CB} 2$ was observed with strong intercellular expression of ZO1 (Fig. 5A.).

Given the important role the BBB plays during inflammation, we sought to characterize whether the expression level of CB2 changes in brain endothelium under inflammatory insult. CB2 protein in membrane fractions was evaluated by Western blot from BMVECs exposed to various proinflammatory stimuli. BMVECs express CB2 under untreated culture conditions (Fig. 5B,C.). CB2 expression on BMVECs was induced by proinflammatory cytokines (IL1 $\beta, 50$ $\mathrm{ng} / \mathrm{ml}$; TNF $\alpha, 25 \mathrm{ng} / \mathrm{ml}$ for $24 \mathrm{~h}$ ) or LPS (50 $\mathrm{ng} / \mathrm{ml}$ for $24 \mathrm{~h}$ ). Although all proinflammatory stimuli tested raised the expression of CB2, ranging between 1.71- and 3.36-fold over untreated BMVECs, TNF $\alpha$ and LPS consistently produced the highest induction of CB2. These data suggest that CB2 is expressed in brain endothelium and is upregulated by inflammatory insults.

In addition, we observed increased expression of CB2 in endothelium of human brain samples from patients with neuroinflammation, namely, HIV-1 CNS infection compared to seronegative controls. These results are reported and discussed in Ramirez et al. 2012. 
A.
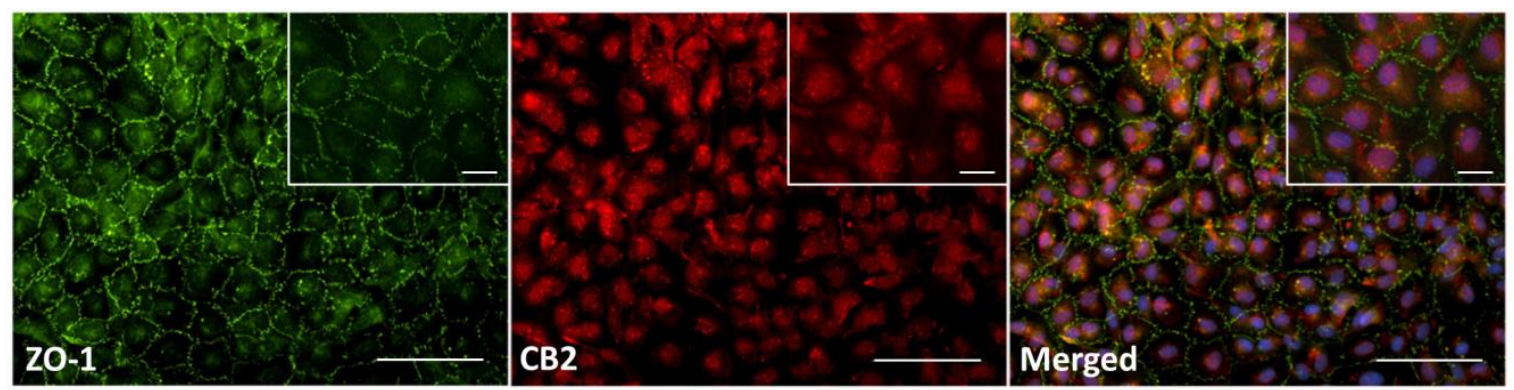

B.

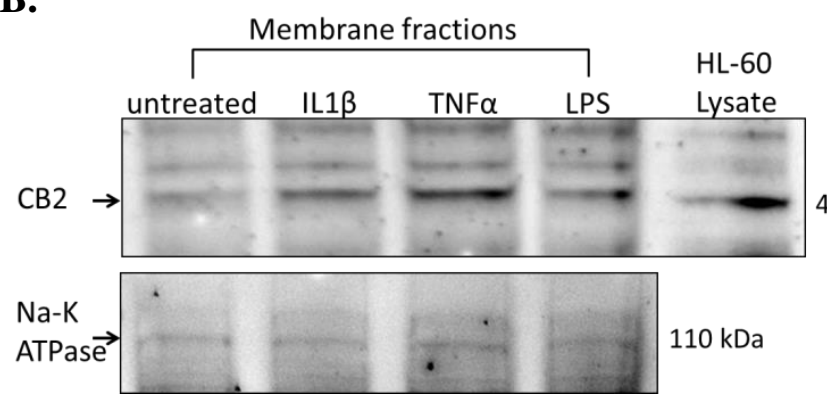

C.
$45 \mathrm{kDa}$

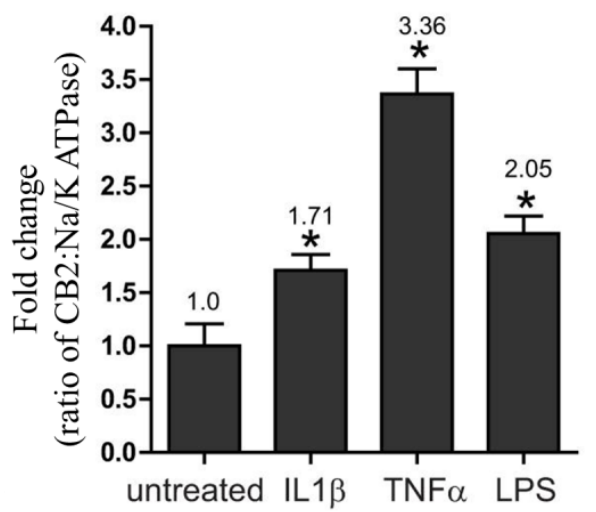

Figure 5: Expression and inflammatory mediator-induced upregulation of CB2 expression in the brain endothelium. A: Representative images showing immunofluorescence labeling of TJ protein ZO-1 and CB2 on cultured primary human BMVECs. Note the continuous pattern of ZO-1 immunostaining depicting the location of endothelial TJs. The images shown were taken under 20x and 60x (insert) objective power; the scale bars are at $100 \mu \mathrm{m}$ and the insets are at $25 \mu \mathrm{m}$. B: Analysis of CB2 expression in membrane fractions from BMVEC exposed to pro-inflammatory stimuli. BMVEC were exposed to the following inflammatory mediators for $24 \mathrm{~h}$ : IL1ß at $50 \mathrm{ng} / \mathrm{ml}$, TNF $\alpha$ at $25 \mathrm{ng} / \mathrm{ml}$ or LPS at $50 \mathrm{ng} / \mathrm{ml}$. C: Densitometry values for CB2 expression were calculated from the ratio of CB2 expression to that of $\mathrm{Na} / \mathrm{K}$ ATPase (loading control). The HL-60 lysate is shown as a reference (positive control) to indicate the presence of CB2. The values are represented as fold change relative to the untreated control.

4.1.2 mRNA expression of cannabinoid receptors and cannabinoid-like receptors in brain endothelial cells and melanoma cells

As a next step we determined the expression pattern of cannabinoid and cannabinoid-like receptors in CECs and melanoma cell lines, applied for our following experiments, by using RTPCR. Our results demonstrate that D3 human brain endothelial cells and A2058 human melanoma cells express the $\mathrm{CB} 2 \mathrm{~A}$ transcriptional variant of the $\mathrm{CB} 2$ but not the CB2B (Fig. 6A,B.). RBECs were found to express variants 1 and 2 of CB2 (Fig. 6C,D.). In addition D3 cells express CB1, GPR18 (transcriptional variant 1, but not transcriptional variant 2) and GPR55, whereas the presence of GPR119 was not detectable in this cell line (Fig. 6E-I.). Furthermore, 
we detected the presence of CB1, GPR18 transcriptional variants 1 and 2, GPR55 and GPR119 in A2058 melanoma cells (Fig. 6E-I.).

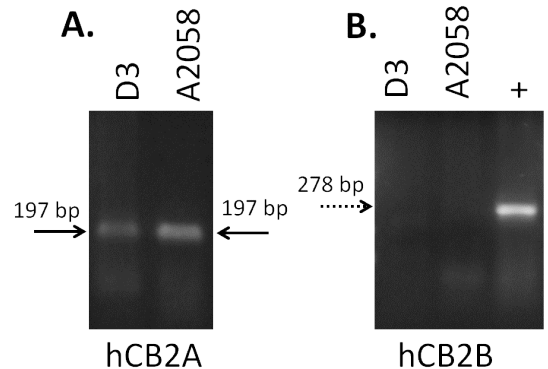
hCB2B

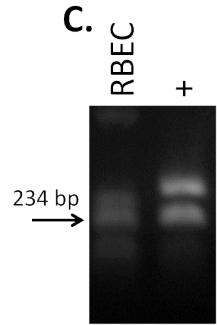

rCB2 var. 1.

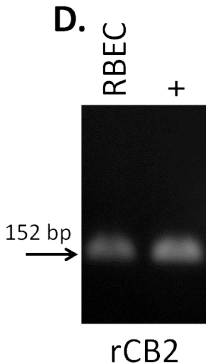

var. 2.

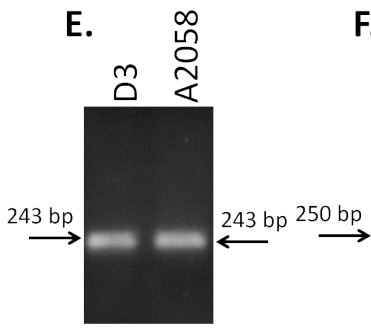

hCB1
F.

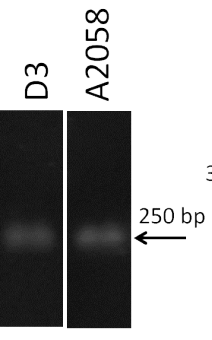

hGPR18

var. 1.

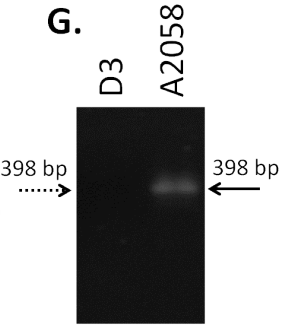

hGPR18

var. 2.

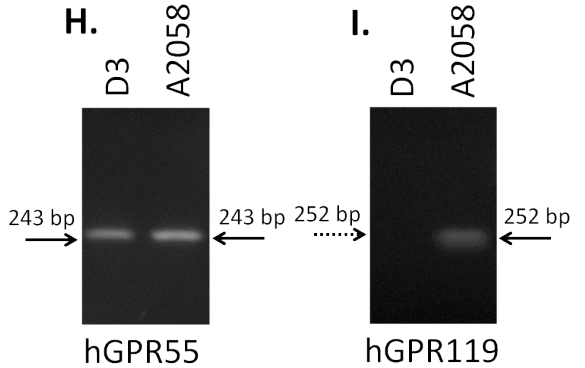

hGPR55

Figure 6: Expression of cannabinoid and cannabinoid-like receptors in brain endothelial and melanoma cells. RT-PCR was performed to determine the expression of CB2A and CB2B (positive control: HL-60) transcriptional variants of human CB2 in D3 brain endothelial and A2058 melanoma cells (A, B), the expression of transcriptional variant 1 and 2 of rat CB2 (C, D) in RBECs (positive control: rat spleen), the expression of CB1 (E), transcriptional variant 1 and 2 of GPR18 (F, G), GPR119 (H) and GPR55 (I) in D3 human brain endothelial cells and A2058 melanoma cells.

\subsection{Effect of CB2 activation on leukocyte-brain endothelial cell interactions and BBB disfunction under inflammatory conditions}

\subsubsection{CB2 activation decreases leukocyte adhesion in pial vessels}

Elevated expression of $\mathrm{CB} 2$ on brain endothelium could serve as a target for antiinflammatory effects of CB2 agonists via diminishing endothelial cell engagement by leukocytes, leading to their migration and associated tissue injury. To explore this idea, we investigated whether CB2 stimulation would diminish leukocyte adhesion in vivo, using an animal model of systemic inflammatory responses. We used intravital microscopy via cranial window to allow the direct observation of cerebral vascular changes and leukocyte-endothelial cell interactions in real time. A week after cranial window implantation, LPS (from E. coli 0127:B8) was injected to induce systemic inflammation and cytokine production. Selective CB2 
agonist (JWH133) was injected simultaneously with LPS $(6 \mathrm{mg} / \mathrm{kg})$. The first row in Fig. 7A. shows the baseline leukocyte adhesion before LPS insult, which was minimal. At $4 \mathrm{~h}$ after LPS injection, leukocyte adhesion was markedly increased (Fig. 7A., middle, first column), showing a 30 -fold induction in adhesion over baseline. At $24 \mathrm{~h}$, adhesion still remained increased by $\sim 18$ fold compared to baseline. Of note, leukocyte marginalization occurred only in the veins and not in arterial vessels, which have a more straight and consistent vessel caliber than veins.

Administration of JWH133 in combination with LPS attenuated leukocyte adhesion by $56 \%$ (P <0.001; Fig. 7B.) $4 \mathrm{~h}$ after and by 65\% (P <0.001; Fig. 7B.) $24 \mathrm{~h}$ after injection. JWH133. The effects of the JWH133 agonist on reducing leukocyte adhesion appeared to be specific to CB2, since nearly complete reversal was observed when the potent CB2 antagonist SR144528 was also present (Fig. 7A. and 7B.). Of note, whether at 4 or $24 \mathrm{~h}$, systemic inflammatory response produced no observable diapedesis of immune cells into the brain parenchyma by these methods.

Given the response observed with the commercially available CB2 agonist JWH133, we sought to test the same in vivo parameters with a novel resorcinol derivative CB2 agonist (O1966) in a similar fashion (Wiley et al. 2002). Fig. 7C. shows that this highly selective CB2 agonist also markedly reduced adhesion of leukocytes to cerebral vessels at 4 and $24 \mathrm{~h}$ (by 50 and $60 \%$, respectively; $\mathrm{P}<0.001)$. 
A.
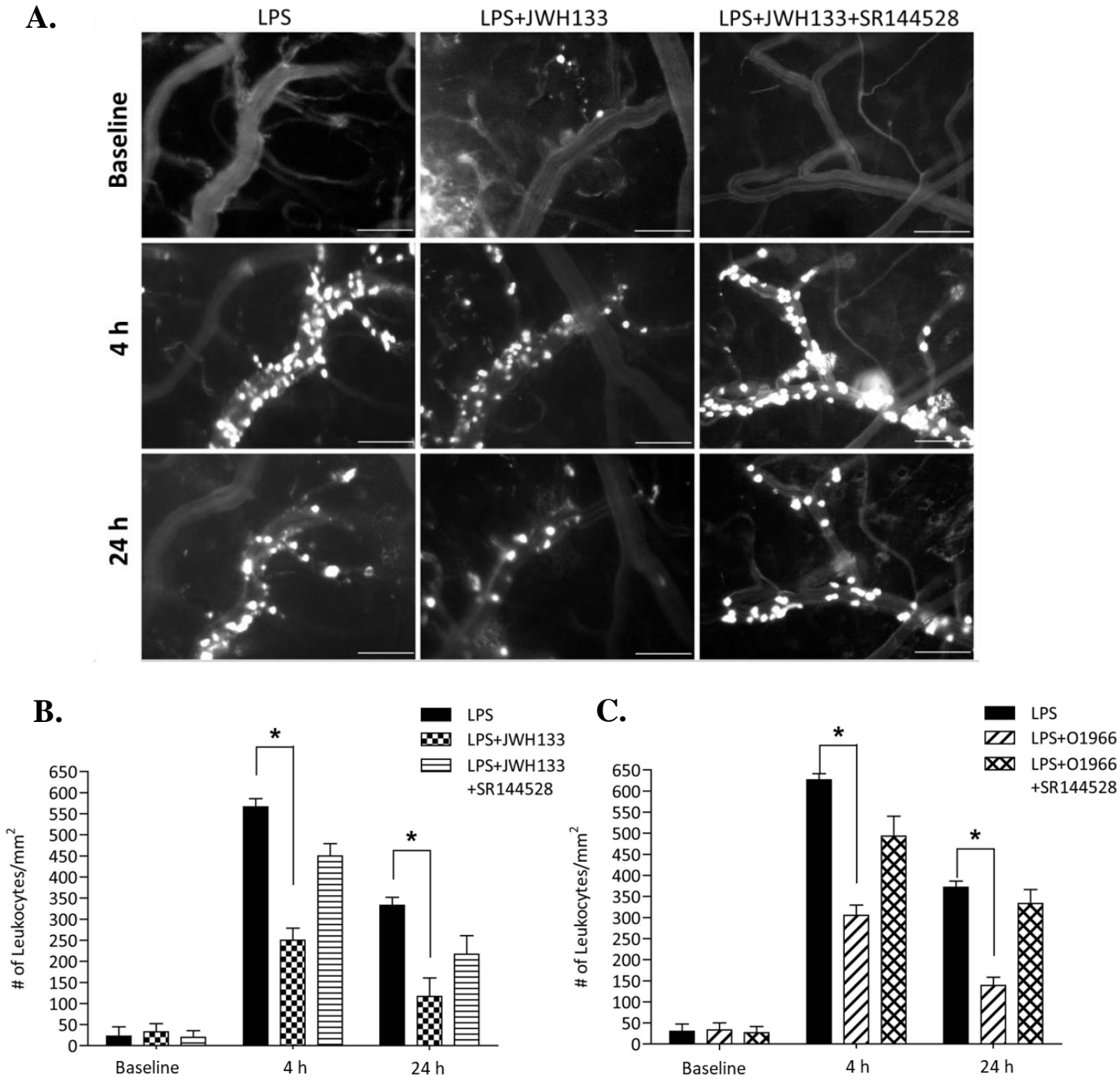

Figure 7: Effect of CB2 agonists on leukocyte adhesion in pial vessels. Animals were administered LPS (i.p, 6 mg/kg) alone, LPS with JWH133, LPS with JWH133 and SR144528, LPS with 01966 or LPS with O1966 and SR144528. A: Representative images from video of leukocytes labeled with the fluorescent compound, rhodamine 6G, visualized for adhesion in pial venules at 0,4 and $24 \mathrm{~h}$ by intravital microscopy. The scale bars are $100 \mu \mathrm{m}$. B, C: Quantitative measurements of leukocytes under firm adhesion (not rolling) during an observation period of $30 \mathrm{~s}$. The results are shown as the means adhesion + SEM ( $n=3)$. (*) denotes a difference of $P<0.001$ between the groups compared (bracket).

To further assure that the effects of the CB2 agonist are indeed mediated by the CB2, we used CB2 -/- animals. JWH133 CB2 knock-out animals treated with LPS only had a similar level of leukocyte adhesion as wild-type animals, resulting in $\sim 30$-fold increase by $4 \mathrm{~h}$ and $\sim 18$-fold by $24 \mathrm{~h}$ (Fig. 8.) compared to baseline. As expected, the CB2 agonists had no effect on minimizing leukocyte-endothelial cell interaction in the CB2 knockout animals (Fig. 8.). Therefore, the effects of either JWH133 or O1966 appear to be entirely dependent on the presence of the $\mathrm{CB} 2$. 


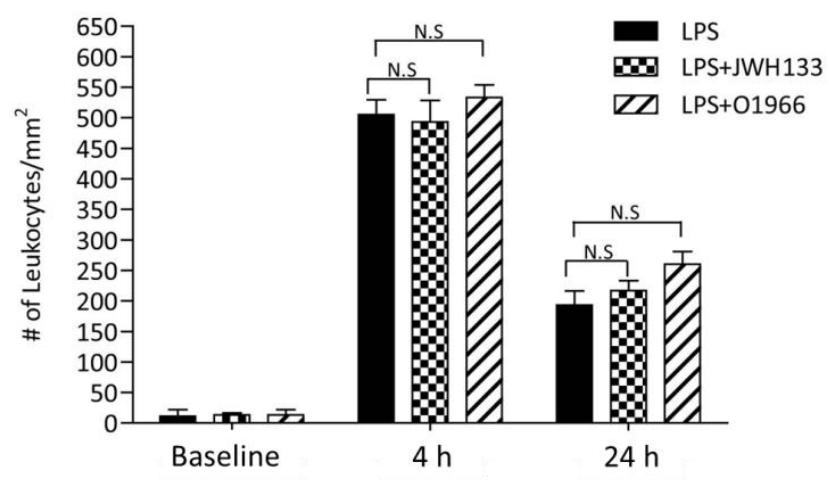

Figure 8: Analysis of adherent leukocytes in CB2 knockout animals treated with LPS alone, LPS with JWH133 or LPS with 01966 . Measurements calculated from image and video analysis of immune cells attached to the brain endothelium during the indicated time points. The results are shown as the means adhesion + SEM (n=3). N.S., not significant.

4.2.2 CB2 activation decreases leukocyte adhesion on deep cortical ascending postcapillary venules

Because conventional wide-field fluorescence microscopy is limited with respect to the depth to which an object can be imaged, analysis of leukocyte adhesion in brain parenchymal vessels was visualized with multiphoton microscopy. Leukocytes and the vasculature were concomitantly imaged with rhodamine 6G and high-molecular-weight FITC-dextrans. Fig. 9A. (top) shows the lack of adhesion in untreated animals, with streaking and rolling leukocytes. As expected, the LPS insult revealed significant immune-endothelial interaction (Fig. 9A., middle), with red-stained leukocytes attached to the endothelium. Introduction of O1966 with LPS reduced the number of adherent cells, thus confirming the previous results in surface vessels (Fig. 9A., bottom). Of note, similar results were achieved with JWH133 (data not shown). Fig. 9B. provides a quantitative assessment of the findings from multiphoton microscopy. 
A.
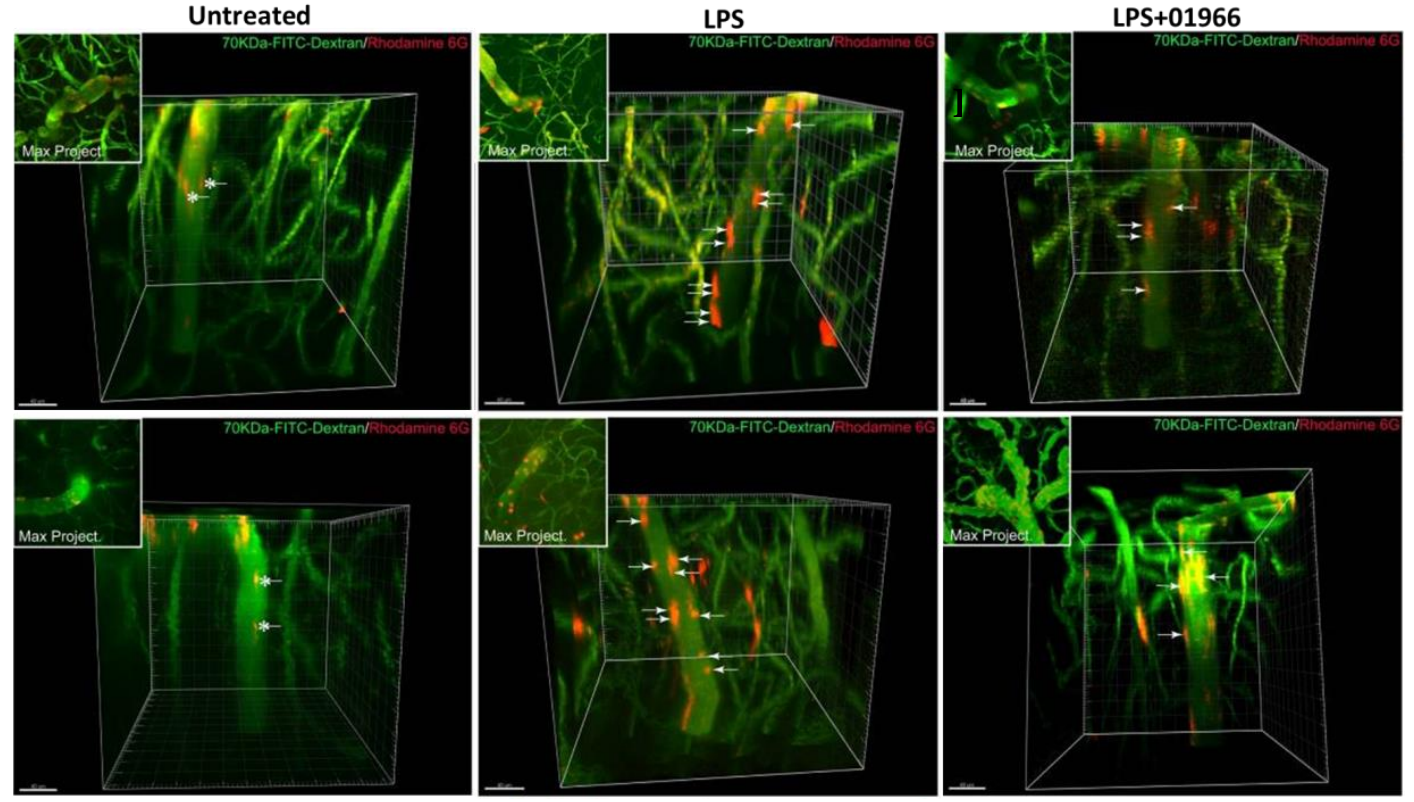

B.

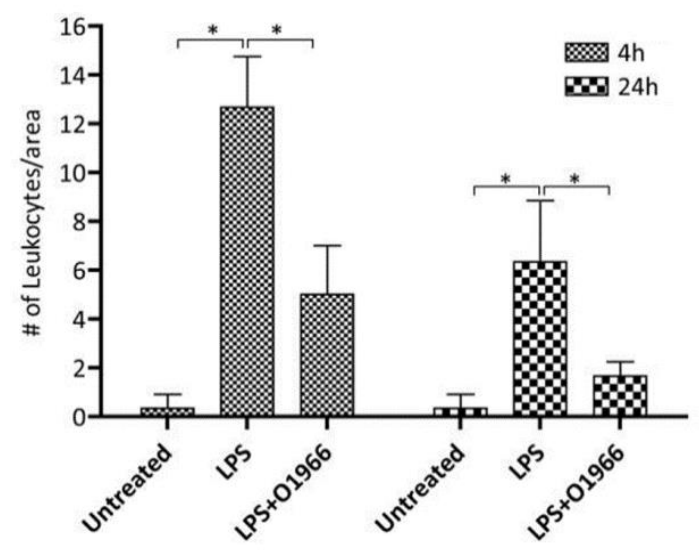

Figure 9: Effect of CB2 activation on leukocyte adhesion on deep cortical ascending postcapillary venules. A: Representative images of 3-D reconstructions of z-stacks taken by multicolor two-photon intravital microscopy using animals with the indicted experimental conditions. The intraparenchymal microvasculature of the brain cortex (down to $800 \mu \mathrm{m}$ below the cortex surface) was outlined by i.v injection of $40 \mathrm{kDa}$ FITC-conjugated dextrans (green). Leukocytes were fluorescently labeled by i.v. injection of rhodamine 6G (red). Leukocyte adhesion events were identified in ascending postcapillary venules ranging from 20-30 $\mu \mathrm{m}$ in diameter. In untreated control animals only moving leukocytes were apparent (streaking and rolling cells; asterisks). Animals where LPS $(6 \mathrm{mg} / \mathrm{kg})$ was administered showed significant leukocyte adhesion (arrows). Corner insert shows max projection composites providing a top view of the z-stack. The scale bars $=40 \mu \mathrm{m}$. B: The results of particle counting, providing a measure of the number of attached leukocytes per vessel surface area (assuming cylindrical dimensions and using $100 \mu \mathrm{m}$ of vessel length). The results are shown as the means adhesion + SEM $(n=3)$. (*) denotes a difference of $P<0.001$ between the groups compared (bracket).

4.2.3 Endothelial CB2 activation decreases the number of monocytes adhering to the brain endothelium

We performed experiments in primary human BMVECs to determine whether the observations in vivo could be confirmed in human brain endothelial cells and distinguish the 
effects of the CB2 agonist on endothelial cells from leukocytes. BMVEC monolayers were stimulated with TNF $\alpha(20 \mathrm{ng} / \mathrm{ml})$ for $4 \mathrm{~h}$ with increasing concentrations of JWH133 or O1966. Purified primary human monocytes were placed on the BMVECs to initiate adhesion only after all treatments were removed and the medium was changed. Unlike the in vivo experiments, the change in medium before the monocyte introduction allows for the evaluation of the effects of the CB2 agonist on BMVECs only. As shown in Fig. 10. the results from the adhesion assays indicate that human brain endothelial cells respond similarly to CB2 agonists in preventing immune cell adhesion. In addition, the effects with either CB2 agonist are dose dependent for the reduction in adhesion. Exposure to TNFa induced an average fourfold increase in the number of monocytes attaching to the BMVEC monolayers. O1966 diminished monocyte adhesion from 2.8- to 1.5-fold, whereas JWH133 was ineffective at the lowest concentration, attenuating adhesion from 2.8- to 2.1-fold at the higher doses.

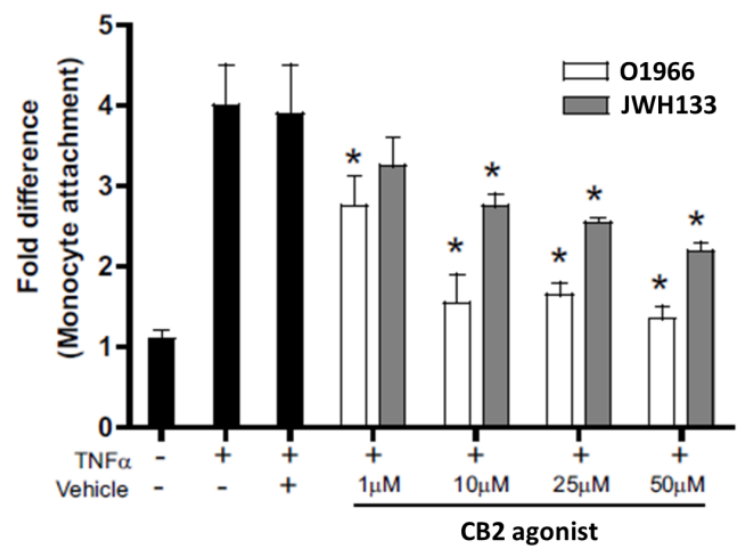

Figure 10: Adhesion assays performed with primary human BMVECs and primary human monocytes. BMVECs were exposed to TNFa $(20 \mathrm{ng} / \mathrm{ml})$ alone or with increasing concentrations of 1-50 $\mu$ M of either CB2 agonist, JWH133 or 01966. BMVECs were treated for $4 \mathrm{~h}$, and the treatments were removed before the addition of monocytes. The data are represented as the fold difference (means \pm SEM) of adhesion, which is the number of adherent cells from the treated condition divided by the basal adhesion in untreated cells. All data collected were from at least three different BMVEC donors and performed in triplicate.

\subsection{4 $\mathrm{CB} 2$ agonists prevent $\mathrm{BBB}$ dysfunction in vivo and in vitro}

LPS exposure induces an acute opening of the BBB, which is also potentiated by the presence of inflammatory mediators and activated immune cells. Animals were treated with LPS and some of them were co-treated with O1966. The leakage of fluorescein labeled dextran was visualized by intravital microscopy. Fig. 11A. shows that there was no leakage of FITC-dextran from the cerebral vessels at baseline. In contrast, $4 \mathrm{~h}$ after LPS injection, animals had considerable, vascular permeability. However, in the presence of O1966 the vessel staining was 
more clear indicating that CB2 activation attenuated the enhanced permeability of the brain vessels (Fig. 11A.). As a more precise quantitative comparison of permeability, animals were injected with the small molecular tracer $\mathrm{Na}-\mathrm{F}\left(\mathrm{M}_{\mathrm{r}}=376 \mathrm{Da}\right)$, and the brain tissue content of Na-F was measured (Fig. 11B.). Tracer content in the whole brain was elevated by threefold in the LPS condition compared to naive animals. Animals administered with either O-1966 or JWH133 showed reduced LPS enhanced permeability by $50 \%$ when compared to the LPS animals. Taken together, the results indicate that $\mathrm{CB} 2 \mathrm{R}$ agonist provides a barrier protective effect.
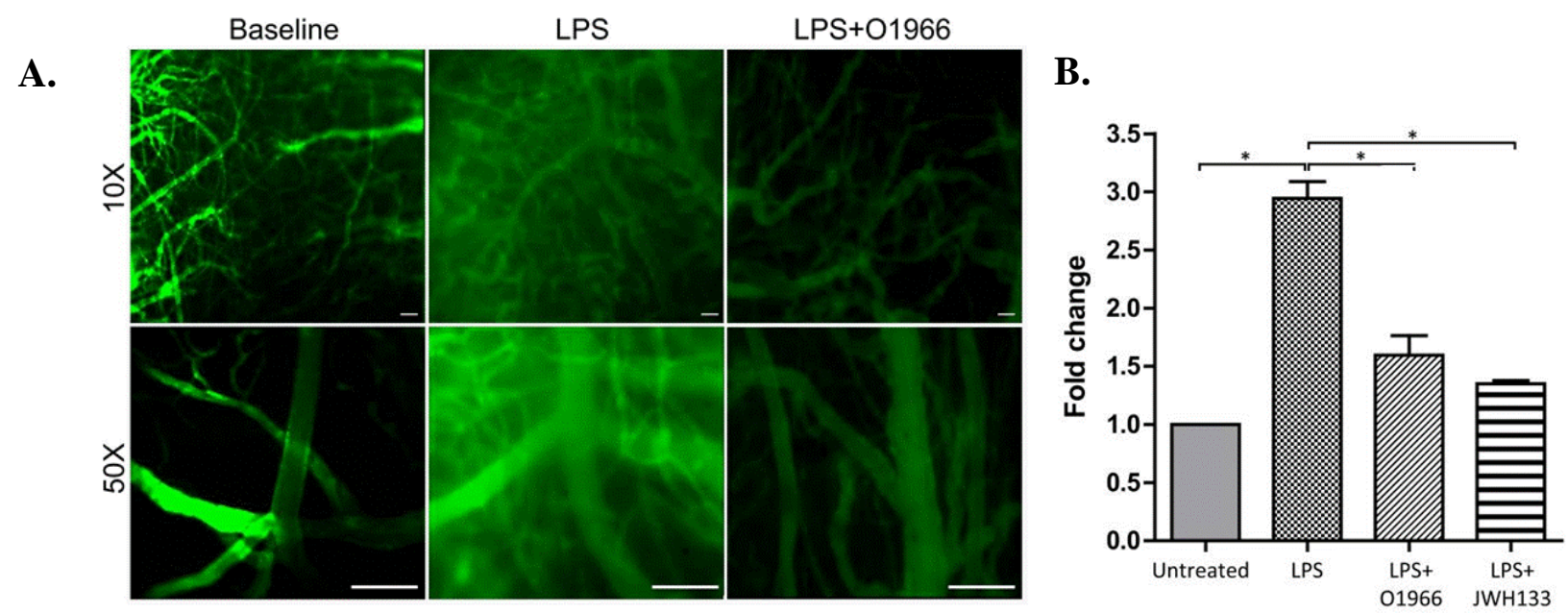

Figure 11: Restoration of the BBB integrity under inflammatory conditions by CB2 activation. A: LPS induction of BBB leakiness in vivo was visualized by FITC-dextran (40 kDa) extravasation. Images were taken at low magnification (10x) and high magnification (50x); scale bars $=100 \mu \mathrm{m}$. B: BBB permeability was evaluated by administration of the tracer, SF in saline via i.v. route as described in the Methods. Following perfusion, the content of SF in homogenized brain tissue was measured. The results are expressed in fold change from calculating the relative fluorescence (RFU) in mg of brain tissue, and dividing the treated by untreated. The graph shows the results as the average + SEM, $(*) \mathbf{P}<0.001$. SF $(376-$ Da) as a tracer substrate was used for quantitative comparison of permeability. Tracer content in the whole brain was elevated by threefold in the LPS condition compared to naive animals. Animals administered with either 01966 or JWH133 showed reduced LPS enhanced permeability by $50 \%$ when compared to the LPS treated animals.

In vitro, BBB leakiness and integrity was assessed via measurement of TEER. TEER was monitored continuously over the course of 24 and $36 \mathrm{~h}$ (Fig. 12A-C). Treatment of BMVEC monolayers with LPS $(50 \mathrm{ng} / \mathrm{ml})$ induced a rapid drop in resistance (80\% of control) over time, which was significantly attenuated by 01966 (Fig. 12A., P < 0.05). These data indicate that CB2 stimulation can provide BBB protection under inflammatory conditions, supporting our in vivo observations (prevention of BBB disruption after LPS injection in mice).

Our next set of experiments was designed to understand whether CB2 activation could increase barrier structural integrity under physiological conditions. Application of the highly 
selective CB2 agonists (O1966, JWH133) resulted in dose- and time-dependent augmentation of tightness of BMVEC monolayers (11-15\%, P < 0.05; Fig. 12B,C.).

A.

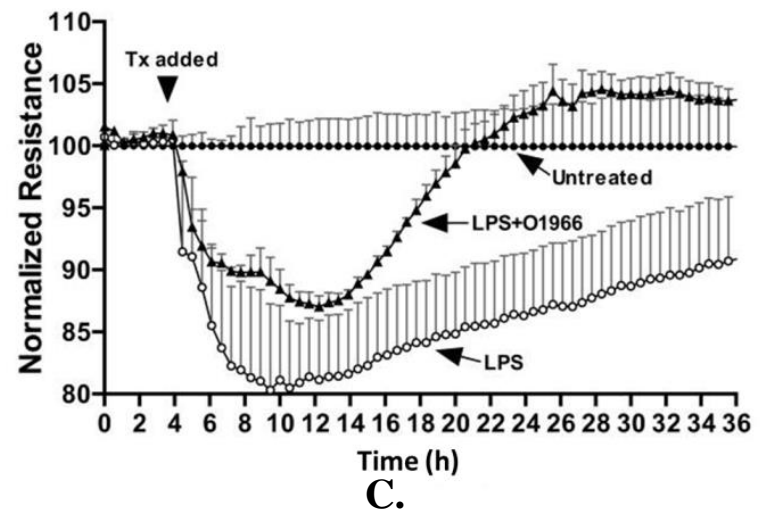

B.

C.
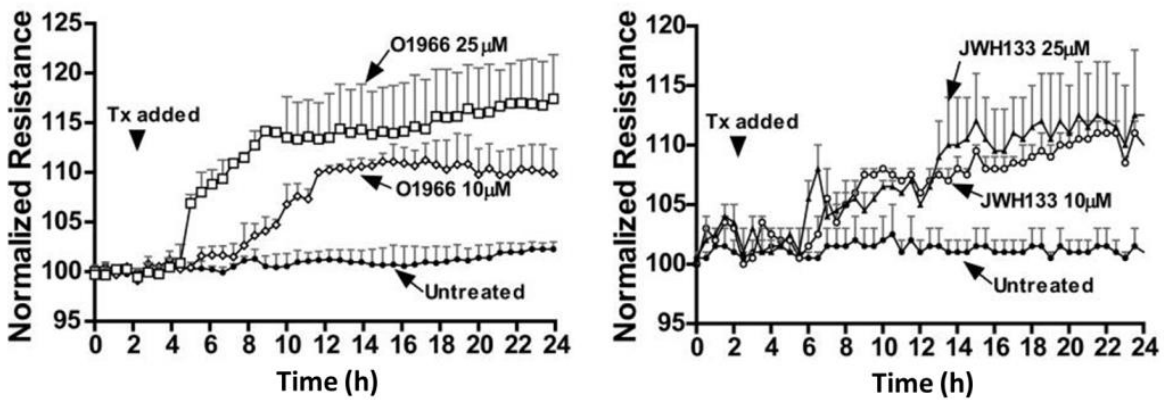

Figure 12: Enhancement of barrier function in human BMVECs by CB2 agonists. A: TEER, an indicator of barrier integrity, was measured (by ECIS) in monolayers untreated or treated with either LPS (50 ng/ml) or LPS with O1966 (10 $\mu M)$. The resistance was measured at $400 \mathrm{~Hz}$ in $30 \mathrm{~min}$ intervals for the duration of the time shown. Treatments were initiated (arrow) after stable resistance was reached. The data are presented as percent change from baseline, which is the resistance measured post-treatment divided by the resistance acquired before treatment introduction $+\mathrm{SEM}(\mathrm{n}=3)$. $\mathrm{B}$ : TEER measurements in BMVEC treated with low $(10 \mu \mathrm{M})$ and high $(25 \mu \mathrm{M})$ concentrations of O1966. C: TEER measurements in BMVEC treated with low $(10 \mu \mathrm{M})$ and high $(25 \mu \mathrm{M})$ concentrations of JWH133. CB2 agonists induced a further tightening of the barrier, evident by a rise in the degree of resistance above the basal level (B and C).

Although various signaling mechanisms can influence BBB tightness, the culminating effect is on TJ proteins located between brain endothelial cells assuring tightness of the BBB. Therefore, TJ protein amount in BMVEC membrane fractions was evaluated after treatment with CB2 agonists. Four hour stimulation of CB2 with O1966 or JWH133 caused a 2.2- to 2.7-fold increase in the amount of occludin and claudin-5 (Fig. 13A,B.) present in the membranous fraction of BMVEC lysates. Longer exposure to JWH133 resulted in further increases in occludin (3.8-fold) and claudin-5 (2.8-fold), while O1966 increased occludin only by 50\% and claudin -5 by $20 \%$ when compared to untreated controls. In summary, these results suggest that 
$\mathrm{CB} 2$ protective effects on $\mathrm{BBB}$ function are mediated in part by the increased presence of TJ proteins in the membrane fraction of brain endothelium.

A.
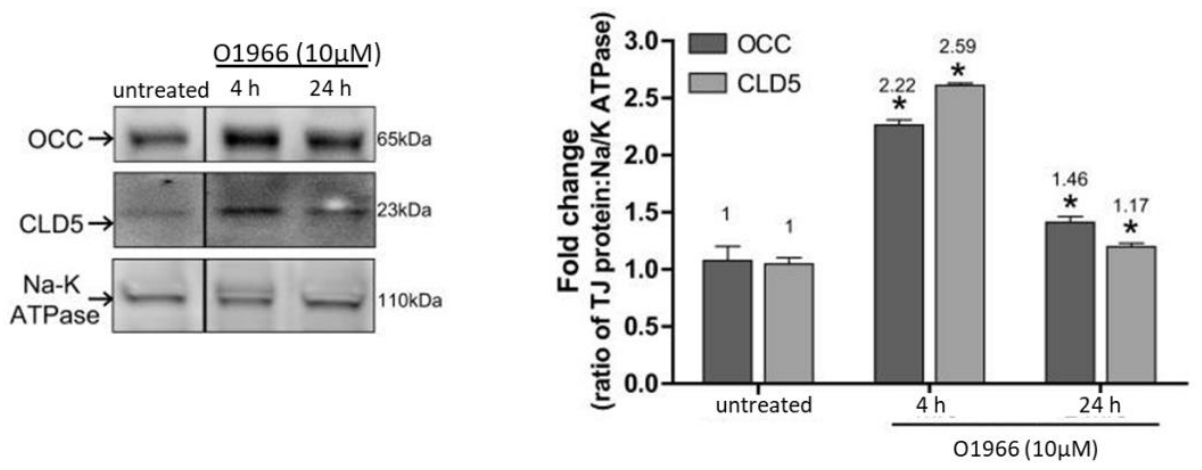

B.
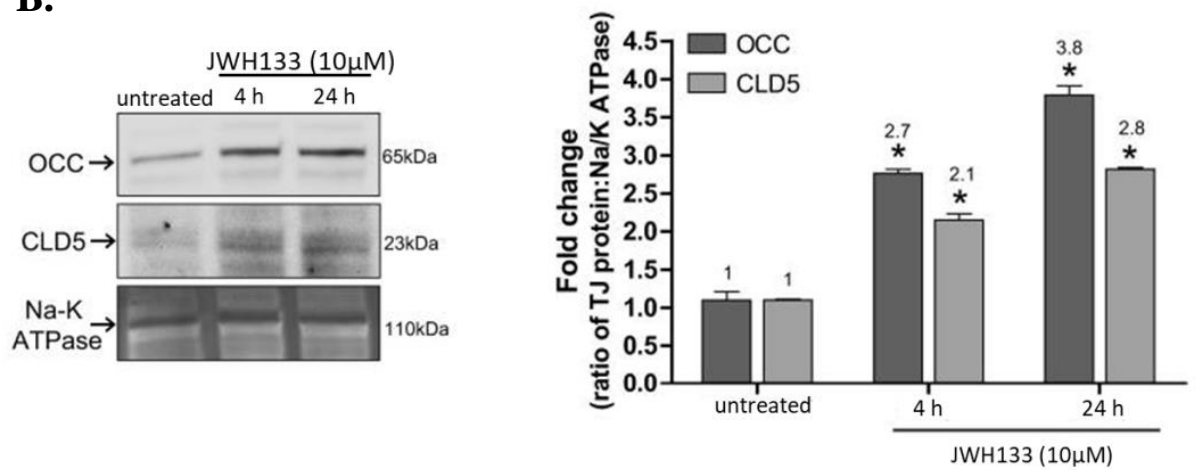

Figure 13: Increase of TJ protein expression in the presence of CB2 agonists. Western blots of BMVEC membrane fractions show the TJ protein levels of occludin (OCC) and claudin-5 (CLD5) in untreated BMVEC and BMVECs treated with 01966 (A) or JWH133 (B) for $4 \mathrm{~h}$. Densitometry values, indicated to the right, were calculated using the $\mathrm{Na} / \mathrm{K}$ ATPase loading control and the data are represented as the fold change from the untreated cells.

\subsection{Effect of CB2 activation on melanoma-brain endothelial cell interactions}

4.3.1 CB2 activation decreases the number of melanoma cells adhering to the brain endothelium

In order to understand the role of $\mathrm{CB} 2$ in tumor metastasis formation, we tested whether activation of the CB2 with its agonist JWH133 can affect the attachment of melanoma cells to brain endothelial cells. Treatment of human brain endothelial cells (D3) or human melanoma cells (A2058) with JWH133 during the adhesion assay did not alter adhesion of melanoma cells to the endothelium (Fig. 14A.). However, a $4 \mathrm{~h}$ long pretreatment of both endothelial cells and 
melanoma cells with JWH133 and treatment with the same compound during the adhesion assay significantly reduced the number of adhered melanoma cells compared to the untreated control (Fig. 14A.). These results suggest that activation of CB2 on both endothelial cells and melanoma cells contribute to the adhesion reducing effect of JWH133 (Fig. 14A.).
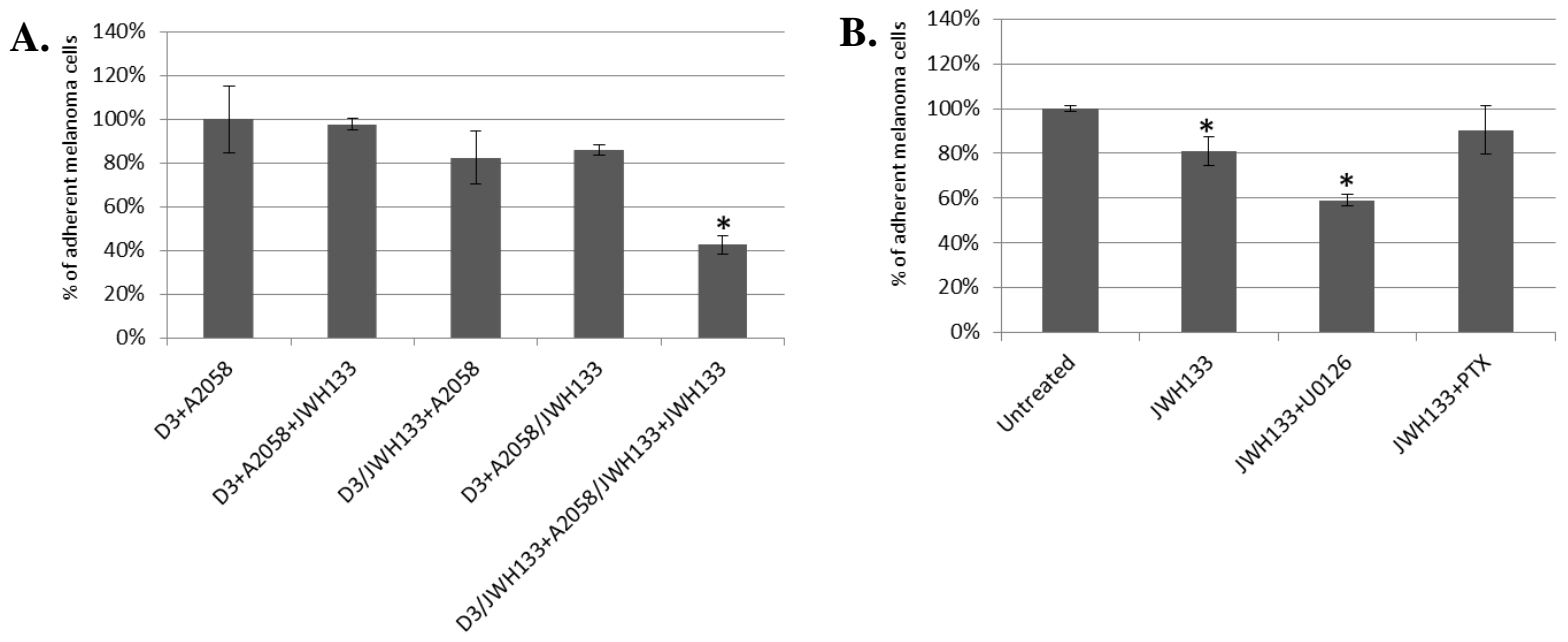

Figure 14: Effect of CB2 activation on the attachment of melanoma cells on the brain endothelium. Results are represented as \% control (i.e., $\mathrm{D3}+\mathbf{A 2 0 5 8}$ ) and given as means $\pm \mathrm{SD}$. $\mathrm{N}=3\left(^{*}\right)=\mathbf{P}<0.05$ as assessed by ANOVA and Bonferroni's post hoc test. A: D3(JWH133) and A2058(JWH133) represent cells pretreated with JWH133 for 4 h. D3+A2058+JWH133 denotes cells treated with JWH133 during the 90 min adhesion assay. B: JWH133, U0126 and PTX were applied in pretreatment of both cell types and treatment during the adhesion assay.

CB2 exert their effect through $\mathrm{Gi} / \mathrm{Go}_{\alpha}$ subunits and are also coupled to the MAPK-ERK pathway (Console-Bram, Marcu and Abood 2012). In order to explore which pathway is responsible for the observed impact of CB2 activation on melanoma cell adhesion, adhesion experiments were performed in the presence of pertussis toxin (PTX) as a $\mathrm{Gi} / \mathrm{Go}_{\alpha}$ inhibitor and U0126 as a MEK inhibitor. PTX blocked the effect of the CB2 agonist whereas U0126 did not reverse the adhesion reducing effect of CB2 activation (Fig. 14B.) This indicates that CB2 exerts its anti-adhesive effect mainly through activation of $\mathrm{Gi} / \mathrm{Go}_{\alpha}$.

4.3.2 CB2 agonist attenuates transmigration of melanoma cells through brain endothelial cell layers

Next experiments were conducted to understand whether CB2 activation can interfere with the transendothelial migration of melanoma cells as well. Transendothelial migration of A2058 cells was tested on primary rat brain endothelial cells (RBECs) cultured on filter inserts with 8 $\mu \mathrm{m}$ pore size to allow migrating cells to reach the bottom of the filter. Pretreatment of brain 
endothelial cells with JWH133 reduced the migration rate of melanoma cells. A more potent reduction in the number of transmigrated melanoma cells was observed when both cell types were pretreated with the CB2 agonist, which was also applied during the transmigration assay (Fig. 15A.). The CB2 reverse agonist SR144528 completely blocked the effect of JWH133 on the transendothelial migration of A2058 melanoma cells, proving the CB2 specific effect of JWH133 (Fig. 15B.). SR144528 alone did not have any effect on transmigration.
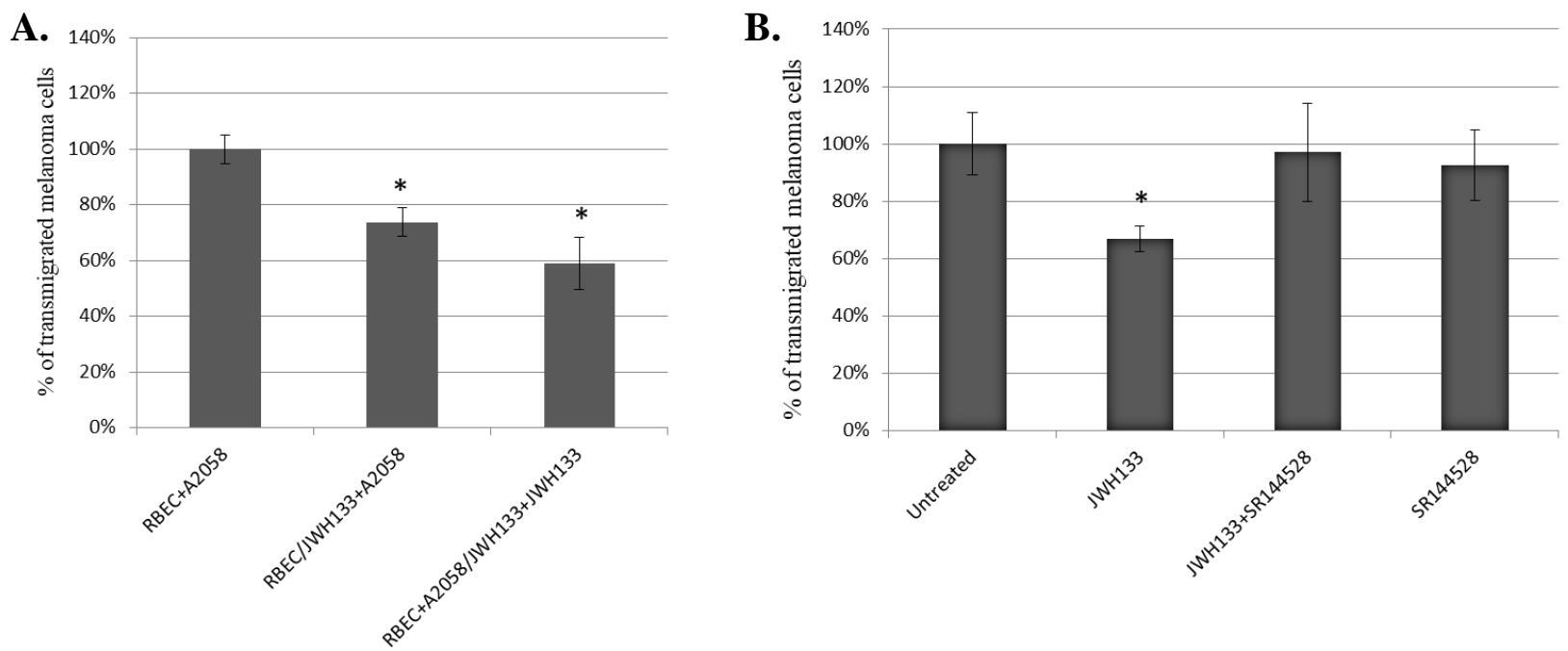

Figure 15: Effect of CB2 activation on the transendothelial migration of melanoma cells. Results are represented as \% control (i.e., RBEC+A2058) and given as means $\pm \mathrm{SD}$. $\mathrm{N}=3(*)=\mathrm{P}<0.01$ (compared to control) as assessed by ANOVA and Bonferroni's post hoc test. A: RBEC/JWH133+A2058 represents endothelial cells pretreated with JWH133 for 4 h. RBEC/JWH133+A2058/JWH133+JWH133 denotes that both endothelial and melanoma cells were pretreated with JWH133 for $4 \mathrm{~h}$ and treated with JWH133 during the $5 \mathrm{~h}$ transmigration assay. B: JWH133 and SR144528 were applied in pretreatment of both cell types and treatment during the transmigration assay.

\subsection{Potential antimetastatic effect of lignans from Heliopsis helianthoides var. scabra in the brain}

\subsubsection{Compound structure elucidation of lignans from Heliopsis helianthoides var. scabra}

All of the lignans were identified from the chloroform-soluble fraction of the methanol extract of the fresh root of Heliopsis helianthoides var. scabra. Mass spectrometry, advanced 2D-NMR methods, including ${ }^{1} \mathrm{H}$ NMR, JMOD, ${ }^{1} \mathrm{H}-{ }^{1} \mathrm{H}-\mathrm{COSY}, \mathrm{HMQC}$ and HMBC experiments, and comparison with literature data were used to structurally elucidate these compounds. Their identification and structural investigation were performed by Zsanett Hajdú et al. (Department of Pharmacognosy, University of Szeged, Szeged, Hungary). The results are discussed in detail in Hajdu et al. 2014 and in the Ph.D. thesis of Zsanett Hajdú: An ethnopharmacological survey conducted in the Bolivian Amazon, and identification of $\mathrm{N}$-alkylamides and lignans from 
Lepidium meyenii and Heliopsis helianthoides var. scabra with effects on the central nervous system, 2014, Szeged). Six lignans from the fresh roots of $H$. helianthoides var. scabra were identified: two new arylbenzofuran-type neolignans, 1"-dehydroegonol 3"-methyl ether (Hel-2) and egonol 3"-methyl ether (Hel-3), and four known lignan derivatives, namely helioxanthin (Hel-6), (7E)-7,8-dehydroheliobuphthalmin (Hel-11), heliobuphthalmin (Hel-12) and 7acetoxyhinokinin (Hel-19).

4.4.2 Morphological changes and inhibition of migration of melanoma cells induced by Hel-6 and Hel-11

Phase contrast microscope images revealed that Hel-6 treatment $(5 \mu \mathrm{M})$ resulted in numerous melanoma cells which had an elongated (spindle-like) shape and longer protrusions, and treatment with Hel-11 also changed the morphology of the melanoma cells (phase contrast images represented in Hajdu et al 2014). To visualize the morphological and cytoskeletal changes, cells treated with Hel-6 or Hel-11 (each $5 \mu \mathrm{M}$ ) were stained with Alexa-488-conjugated phalloidin (Fig. 16A.) Exposure to Hel-6 resulted in many cells with elongated morphology with actin-rich protrusions, filopodia and actin stress fibers. In contrast, the presence of Hel-11 induced melanoma cells with a more expanded shape without large filopodia.

A wound healing assay was used to investigate the effects of Hel-6 and Hel-11 on the directional migration of melanoma cells. Both lignans reduced the rate of migration of A2058 cells (Fig. 16B.). The presence of $10 \mu \mathrm{M}$ Hel-11 reduced most effectively the migration of the melanoma cells 
A.
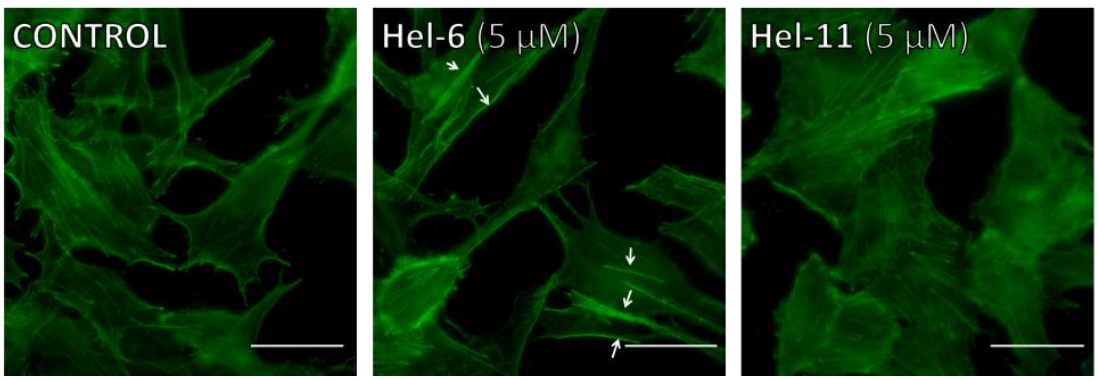

B.

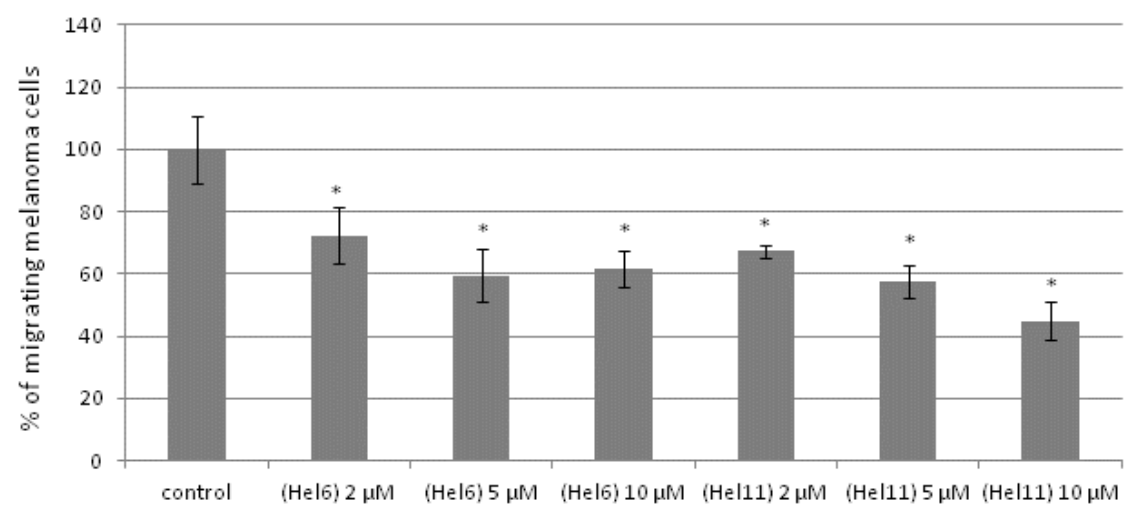

Figure 16: Morphological changes and inhibition of melanoma cell migration induced by Hel-6 and Hel-11. A: A2058 melanoma cells were treated with Hel-6 and Hel-11 $(5 \mu \mathrm{M})$. After $2 \mathrm{~h}$, the cells were fixed and stained with Alexa-488labeled phalloidin to visualize the cytoskeleton of the cells. Arrows indicate actin stress fibers. Scale bars: $25 \mu \mathrm{m}$. B: The migration of A2058 melanoma cells was evaluated with the wound-healing assay in the presence or absence of Hel-6 or Hel-11 $(2 \mu \mathrm{M}, 5 \mu \mathrm{M}$ or $10 \mu \mathrm{M})$. The migration of cells was monitored for $24 \mathrm{~h}$ by using a Nikon Eclipse Ti-E inverted microscope equipped with a 10× Nikon Plan Fluor objective. Results are shown as percentages of the control (cells migrated during the $24 \mathrm{~h}$ experiment) and given as means $\pm \mathrm{SD}(\mathrm{n}=4),\left(\left(^{*}\right)=\mathrm{P}<0.01\right.$, as assessed by ANOVA and Bonferroni's post hoc test).

\subsubsection{Hel-6 reduces the adhesion of melanoma cells to brain endothelial cells}

As the next step, the ability of the isolated compounds to inhibit the attachment of melanoma cells to brain endothelial cells was investigated. For this, D3 human brain endothelial cells and A2058 human melanoma cells were pretreated with the different lignans for $3 \mathrm{~h}$ and then treated with the same lignan during the adhesion assay. Hel-6 $(2 \mu \mathrm{M})$ decreased the number of melanoma cells adhering to the endothelial layer, while the other compounds had no effect (Fig. 17A.). There were no differences observed in the case of treatment with the other lignans even when the cells were treated with a higher concentration of the compounds $(10 \mu \mathrm{M})$, and therefore subsequent experiments were performed with Hel-6 and Hel-11 only. 
A.

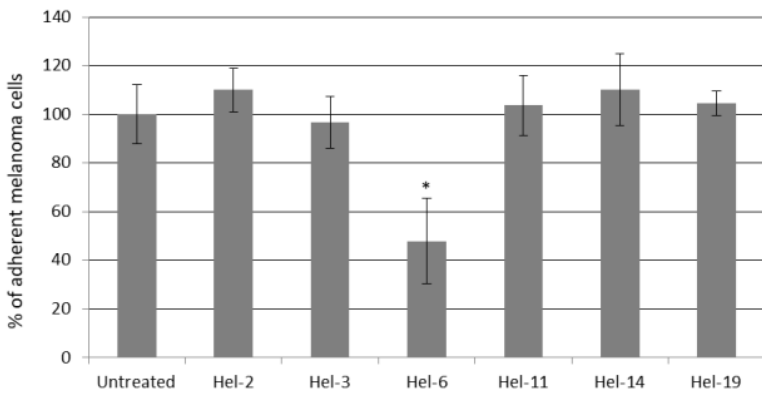

B.

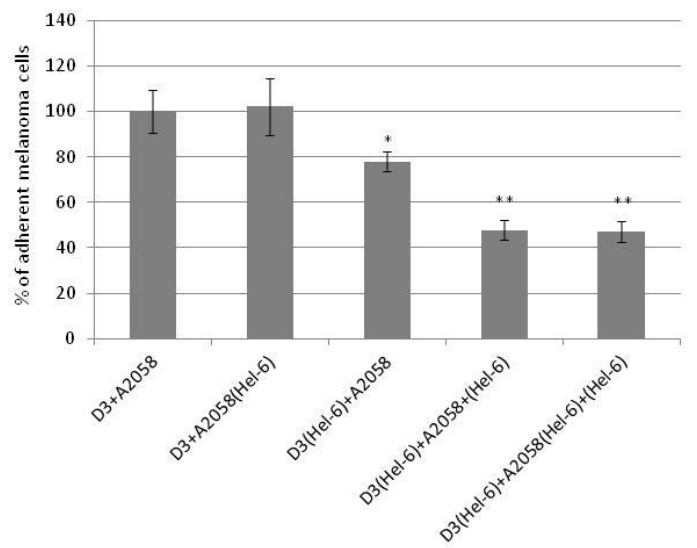

Figure 17: Adhesion of melanoma cells to the brain endothelium in the presence of the isolated lignans. A2058 and D3 cells were pretreated with each of the isolated lignans for $3 \mathrm{~h}$, and melanoma cells were then plated onto a confluent monolayer of the endothelial cells in the presence of the same compound and left for 80 min. A: Each of the isolated compounds were used individually in a concentration of $10 \mu \mathrm{M}$. For evaluation of the effect of Hel-6, melanoma cells were pretreated with $5 \mu \mathrm{M}$, D3 cells were pretreated with $2 \mu \mathrm{M}$, and during the attachment of melanoma cells $2 \mu \mathrm{M}$ Hel-6 was used. B: Five different experimental groups were used: D3+A2058: untreated control; D3(Hel-6)+A2058: adhesion of untreated A2058 cells on Hel-6 (2 $\mu \mathrm{M})$-pretreated D3 cells; D3+A2058(Hel-6): adhesion of Hel-6 (5 $\mu \mathrm{M})$-pretreated A2058 cells; D3(Hel-6)+A2058+Hel-6: adhesion of untreated A2058 cells on Hel-6 $(2 \mu \mathrm{M})$-pretreated D3 cells in the presence of Hel-6 (2 $\mu \mathrm{M})$; D3(Hel-6)+A2058(Hel-6)+Hel-6: adhesion of Hel-6 (5 $\mu \mathrm{M})$-pretreated A2058 cells on pretreated D3 cells (2 $\mu M)$ in the presence of Hel-6 $(2 \mu M)$. Results are presented as percentages of the control and given as means \pm SD $(n=3)$, $\left(\left(^{*}\right)=\mathrm{P}<0.05,\left({ }^{* *}\right)=\mathrm{P}<0.01\right.$ as assessed by ANOVA and Bonferroni's post hoc test $)$.

In order to determine the cell-type-specific impact of Hel-6, either melanoma or endothelial cells were pretreated with the compound and adhesion experiments were performed in the absence of the lignan (Fig. 17B.). Incubation of the melanoma cells with $5 \mu \mathrm{M}$ Hel-6 did not have any effect on the adhesion. However, when the brain endothelial cells were pretreated with $2 \mu \mathrm{M}$ Hel-6, the extent of adhesion of the melanoma cells to the brain endothelium decreased significantly but to a lesser extent than that observed when Hel-6 was present during the adhesion experiment. In the latter case, pretreatment was not able to reduce the adhesion further. These findings indicate a specific role of the endothelial changes induced by Hel-6 in reducing the adhesion, and these changes are reversible.

\subsubsection{Hel-6 and Hel-11 improve the barrier function of CECs}

The BBB integrity was evaluated via measurement of the TEER, which is a widely used marker of the tightness of the paracellular junctions. $2 \mathrm{~h}$ after the treatment of a monolayer of primary RBECs with $5 \mu \mathrm{M}$ Hel-6, the TEER was significantly elevated by about $15-20 \%$ relative to the control. A minor elevation of the TEER was likewise observed in the presence of Hel-11 (5 $\mu \mathrm{M})$ as well (Fig. 18A.). 
A.

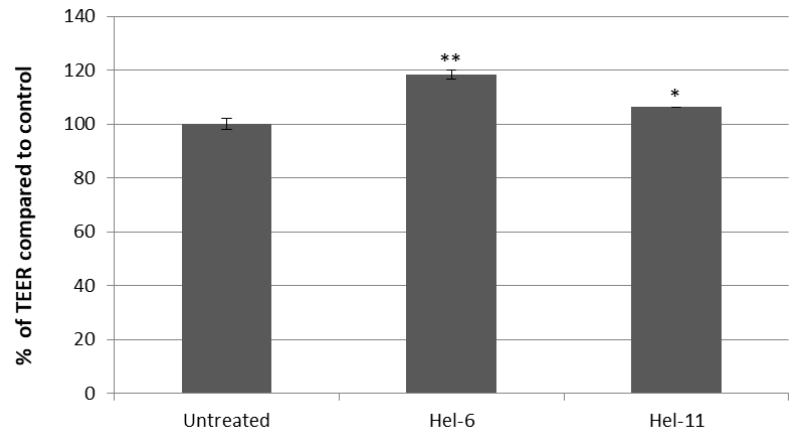

B.

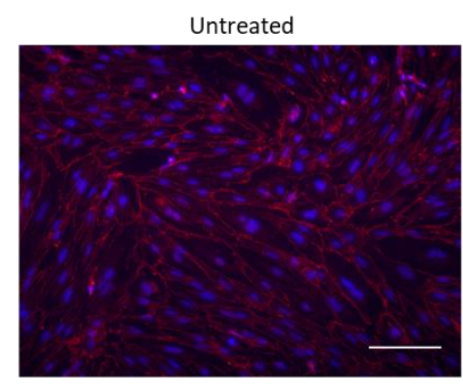

Untreated

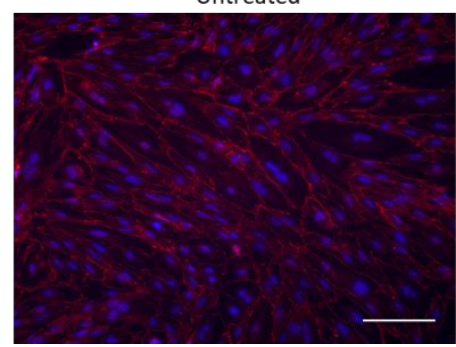

Untreated

C.

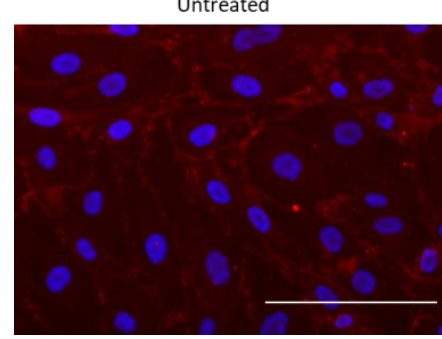

Hel-6 (2 $\mu \mathrm{M})$

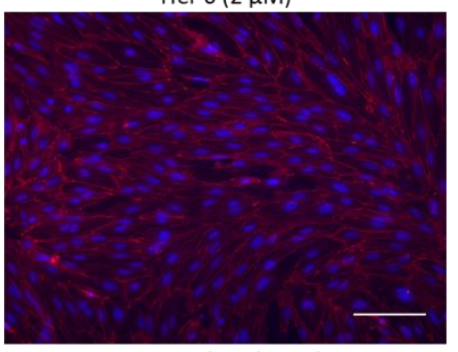

Hel-11 $(2 \mu \mathrm{M})$

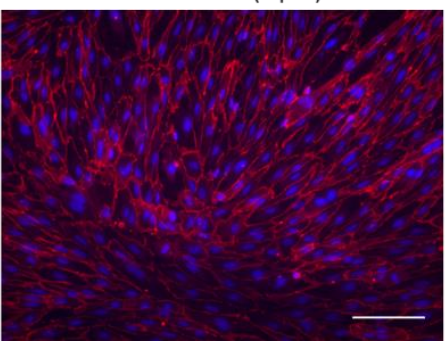

Hel-6 (2 $\mu \mathrm{M})$

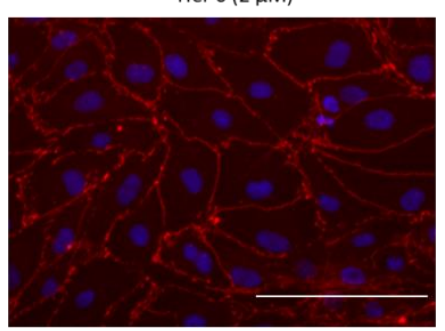

Hel-6 (5 $\mu \mathrm{M})$

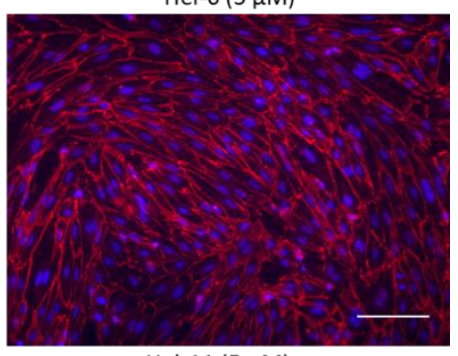

Hel-11 (5 $\mu \mathrm{M})$

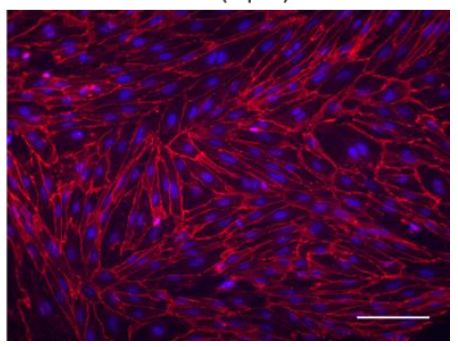

Hel-11 $(5 \mu \mathrm{M})$

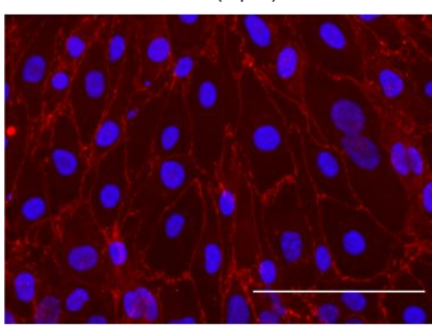

Figure 18: Effects of Hel-6 and Hel-11 on the barrier function of the BBB. A: Measurement of TEER. Data are presented as the percentage resistance of untreated RBECs measured $2 \mathrm{~h}$ after treatment. Results are presented as percentages of the control and given as means $\pm S D(n=3),((*)=P<0.05,(* *)=P<0.01$ as assessed by ANOVA and Bonferroni's post hoc test). ZO-1 immunofluorescence staining of RBECs (B) and D3 cells (C). After the $2 \mathrm{~h}$ induction of the endothelial layer with the compounds, the cells were stained with anti-ZO-1 anti-body (red), a marker of endothelial TJs and with Hoechst 33342 (blue) as nuclear staining. Scale bars: $100 \mu \mathrm{m}$.

Continuous lines of TJs between brain endothelial cells are essential for the integrity of the BBB. Therefore, expression and localization of ZO-1 was investigated, which is an important protein component of TJs (Fig. 18B, C.). Immunofluorescence studies revealed a stronger ZO-1 staining at the cell-cell contacts between adjacent endothelial cells in the presence of $5 \mu \mathrm{M} \mathrm{Hel-}$ 
6 , and a similar effect was seen when the cells were treated with Hel-11. Furthermore, even 2 $\mu \mathrm{M}$ Hel-6 resulted in a more pronounced and continuous staining of $\mathrm{ZO}-1$ on the edge of the human endothelial D3 cells than in the control D3 culture. This suggests that Hel-6 can stimulate human CECs in lower concentrations than RBECs. Primary RBECs are able to preserve better barrier characteristics than are cell lines and besides possible species differences, this might cause slight differences in the observed effects of the lignans on TJs. Moreover, Hel-11, which also increased the TEER, enhanced the presence of ZO-1 in the junctions of the cells at both 2 and $5 \mu \mathrm{M}$. This appears to be the first evidence of the barrier-enhancing effect of a lignan.

\subsubsection{Hel-6 and Hel-11 mitigate migration of endothelial cells}

An important step in the growth of metastases is the vascularization of the tumor. In this angiogenic process, migration of endothelial cells is a key element. As the next step, therefore, effects of Hel-6 and Hel-11 on the migration of brain endothelial cells were assessed by using the wound healing assay. As shown in Fig. 19., each of these compounds led to a significant reduction in endothelial cell migration. This appeared to be a concentration-dependent effect, 10 $\mu \mathrm{M}$ Hel-6 and $10 \mu \mathrm{M}$ Hel-11 displaying a more pronounced influence on the migration than 5 $\mu \mathrm{M}$ and $2 \mu \mathrm{M}$, respectively. This trend is reminiscent of the concentration-dependent mitigation of melanoma cell migration evoked by Hel-6 and Hel-11.

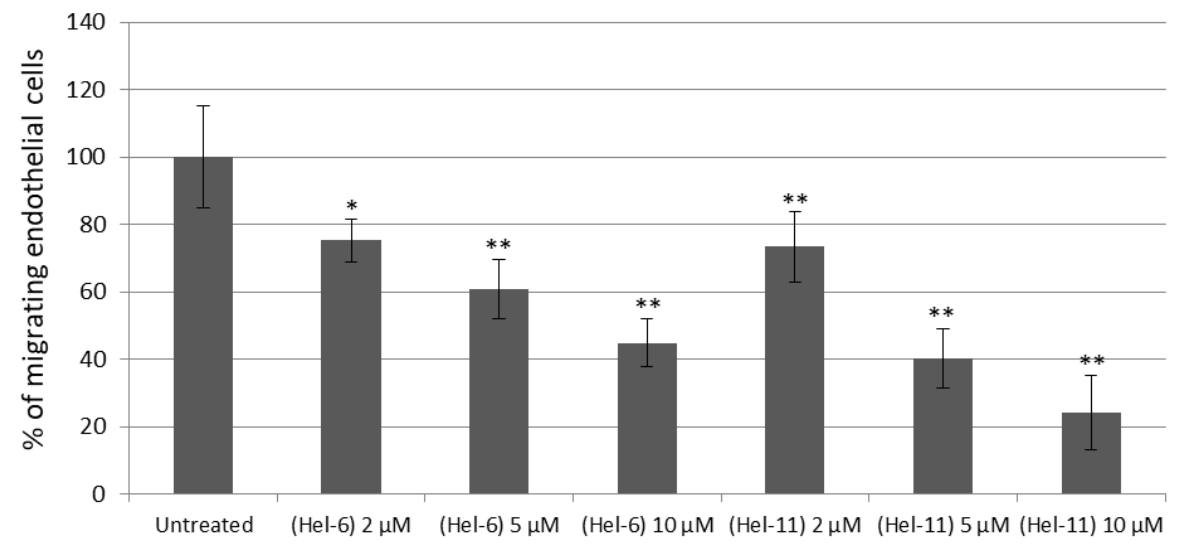

Figure 19: Endothelial cell migration inhibited by Hel-6 and Hel-11. Migration of D3 endothelial cells was evaluated with the wound-healing assay for $24 \mathrm{~h}$. Results are shown as percentages of the control (cells migrated during the $24 \mathrm{~h}$ experiment) and given as means \pm SD $(n=4),(*)=P<0.05,(* *)=P<0.01$ as assessed by ANOVA and Bonferroni's post hoc test. 


\section{Discussion}

\subsection{Expression of cannabinoid receptors in the brain endothelium and in melanoma cells}

Previous studies indicated that CB2 expression was restricted to peripheral tissues, particularly to immune cells (Cabral and Griffin-Thomas 2009). However, it is now known that CB2 can also be found in cells of the CNS, predominantly as a consequence of neuroinflammation (Benito et al. 2005) or other pathological process. In the CNS, expression of CB2 has been detected in microglial and perivascular cells (Benito et al. 2008) in response to neuroinflammatory processes. Brain microvascular endothelial cells have also been described to express CB2 (Mestre et al. 2006). Our observations, regarding BMVECs, RBECs and D3 human brain endothelial cell line confirm previous findings. D3 cells express the CB2A transcriptional variant of the $\mathrm{CB} 2$ but not the $\mathrm{CB} 2 \mathrm{~B}$. $\mathrm{CB} 2 \mathrm{~A}$ and $\mathrm{CB} 2 \mathrm{~B}$ differ in their untranslated 5' region indicating that the two variants may differ in regulatory aspects only. CB2A has higher expression in the testis and the brain, whereas $\mathrm{CB} 2 \mathrm{~B}$ is expressed in higher amounts in peripheral tissues (Liu et al. 2009).

Using Western blot analysis we could detect an upregulated CB2 expression in BMVECs under inflammatory conditions. Analysis of human brain tissue sections from patients having HIV-1 encephalitis, revealed a strong upregulated immunopositive staining for CB2 on the vasculature compared to normal human brain samples (Persidsky et al. 2011). To our best knowledge these are the first demonstrations of increased CB2 level in the brain endothelium under inflammatory conditions. Besides inflammation, tumor cells can also upregulate CB2 expression in the vessels of the brain, as shown in proliferating microvessels of glioblastomas (Schley et al. 2009).

In addition to brain endothelial cells, we detected CB2 expression in melanoma cells as well. Little is known about the presence of CB2 in different cancer cells, presumably it varies among cancer-types. The A2058 human melanoma cells, used for our experiments express the CB2A, but not the $\mathrm{CB} 2 \mathrm{~B}$ transcriptional variant of the $\mathrm{CB} 2$ similar to $\mathrm{D} 3$ cells. Other studies have shown the expression of CB2 in two breast cancer cell-lines: MCF-7 and a highly metastatic MDA-MB-231 clone (Nasser et al. 2011), in 55\% of the 29 investigated human non-small cell lung cancer (NSCLC) samples and in A549 and SW-1573 NSCLC cell lines (Preet et al. 2011). 
Also CB2 expression has been shown in cancer tissue samples from melanoma patients (Zhao et al. 2012).

GPR18, GPR55 and GPR119 and some other GPR "orphan receptors" show little structural similarity to $\mathrm{CB} 1$ and $\mathrm{CB} 2$, but respond to some natural/synthetic cannabinoid receptor ligands (Pertwee et al. 2010). Hence these receptors are considered to be cannabinoid-like receptors. Expression profile of these receptors which could mediate the effect of cannabinoids is less well known. Thus, we determined the expression pattern of these cannabinoid-like receptors in CECs and melanoma cells by using RT-PCR. Our results complement previous data demonstrating the expression of CB1 and CB2 in melanoma cells and brain endothelial cells (Blázquez et al. 2006, Zhang et al. 2011).

Initially GPR18 has been detected in testis and spleen (Gantz et al. 1997), but it is expressed in the thymus, peripheral white blood cells and small intestine as well. No expression has been detected so far in the brain (Alexander 2012). Under culture conditions it is expressed in metastatic melanoma (Qin et al. 2011), BV2 murine microglial cells (McHugh et al. 2010) and HEC-1B human endometrial cells (McHugh et al. 2012) as well. To our knowledge this is the first report of its expression in CECs. However, further experiments are needed to understand the role of GPR18 splice variants.

GPR55 is another cannabinoid-like receptor which can be activated by $\mathrm{N}$-arachidonoylserine, an endocannabinoid-like lipid with structural similarities to the endocannabinoid Narachidonoyl ethanolamide (anandamide) (Ho 2010). N-arachidonoyl-serine promotes proliferation, migration and tube formation of primary human dermal microvascular endothelial cells, an effect at least partially mediated by GPR55 (Zhang et al. 2010). In the brain this receptor regulates microglia migration (Walter et al. 2003) and can be involved in microgliamediated neuroprotection (Kreutz et al. 2009). The role of GPR55 in CECs is still unknown. In addition, GPR55 is expressed in malignant tumors as well including cholangiocarcinoma cells, melanoma cells and human squamous cell carcinomas. The role of GPR55 activation seems to be cell type specific: while in cholangiocarcinoma cells and melanoma cell activation of GPR55 has anti-proliferative or even toxic effects (Adinolfi et al. 2013, Huang et al. 2011), in human squamous cell carcinomas drives carcinogenesis (Pérez-Gómez et al. 2013). We have observed the presence of GPR55 in brain endothelial cells and in A2058 melanoma cells; however, the effect of its activation on cancer cell - endothelial cell interactions is unclear. In the future we 
are planning to investigate it by using cannabidiol, a component of marihuana, found to activate GPR55.

Furthermore, we have detected the expression of GPR119 in A2058 cells, which is in accordance with previous results demonstrating this receptor in melanoma cells (Qin et al. 2011). GPR119 was found in pancreatic and intestinal tissues and in some brain regions (for review see: (Godlewski et al. 2009)), but CECs seem not to express this receptor.

\subsection{Effect of CB2 activation on endothelial cell-immune cell interactions and on the integrity of the BBB during inflammation}

To characterize the effects of $\mathrm{CB} 2$ on immune-endothelial interactions and BBB function, we used the CB2 agonists JWH133 and O1966. Using LPS-induced encephalitis and intravital microscopy, we showed that leukocyte adhesion in cerebral vessels was significantly reduced after JWH133 or O1966 administration. This effect is specific to CB2 since both compounds were ineffective when coadministered in the presence of CB2 antagonist SR144528 or when used in CB2 knock-out mice. Changes in leukocyte adhesion to endothelium with CB2 agonists were noted both in pial vessels and deep cortical ascending post capillary venules, the most frequent site of most leukocyte-endothelial cell interaction during neuroinflammation. Evaluation of CB2 agonists in surface and deep cerebral vessels is important because surface pial vessels do not have an integrated neurovascular unit, and thus anti-inflammatory responses differ between the two sites (Persidsky et al. 2006). Interestingly, cannabidiol was shown to decrease leukocyte adhesion and vasodilatation in LPS-associated encephalitis (Ruiz-Valdepeñas et al. 2011). Cannabidiol is a GPR55 agonist and a weak CB1 and CB2 antagonist. Given that the brain endothelium also expresses the CB2 (Golech et al. 2004) and GPR55 (our described data), it remains unknown which receptor provides the endothelial protective effects of cannabidiol.

Previous studies in ischemia/reperfusion injury and EAE have shown the effectiveness of CB2 agonists to reduce leukocyte adhesion (Zhang et al. 2009, Murikinati et al. 2010). However, these investigations did not address whether the effects of CB2 apply only to the immune cell, the endothelial cell, or both, given that these cell types express CB2. As the continuation of our work, our collaborators have observed that the selective in vivo CB2 activation in leukocytes resulted a significant diminution in leukocyte-endothelial cell engagement in mice (Rom et al. 2013). 
To examine the endothelial specific effect of CB2 agonists on immune cell-endothelial cell interaction, we continued our investigations in vitro with primary human BMVECs. Therefore, BMVECs were activated with cytokines in the presence of CB2 agonist, and then the agonist was removed and adhesion with human monocytes was evaluated. Our experiments revealed a CB2 agonist concentration-dependent decrease in monocyte adhesion to cytokine activated endothelium. Continuing our work Rom et. al. revealed that CB2 activation of monocytes largely attenuated adhesion to and migration across monolayers of primary human brain microvascular endothelial cells (Rom et al. 2013).

Analysis of the effect of CB2 activation on molecules responsible for regulation of brain endothelial cell-immune cell interactions is necessary. We have investigated the effect of CB2 activation on the expression of two important cell adhesion molecules, ICAM-1 and VCAM-1. So far, our histological examination revealed a low basal level in ICAM-1 expression in cortical vessels and an induction in ICAM-1 expression in after LPS treatment. The elevated ICAM-1 expression was prevented by O1966 CB2 agonist treatment (data not shown in the thesis, see in Ramirez et al. 2012). Furthermore, flow cytometry confirmed the CB2 mediated diminution of ICAM-1 and VCAM-1 surface expression on brain endothelium induced by LPS or TNF $\alpha$ (data not shown in the thesis, see in Ramirez et al. 2012). Rom et al. also described that CB2 stimulation in monocytes down-regulated active forms of two integrins playing role in immune cell-endothelial cell interactions, LFA-1 and VLA-4. Their results also suggest the importance of monocyte Rac1 and RhoA supression by CB2 activation in the attenuated adhesion and migration across the brain endothelium (Rom et al. 2013). These studies mentioned above indicate that both brain endothelium and the immune cells also clearly respond to CB2 agonists and prevents the induction of adhesion molecules under inflammatory insult.

During neuroinflammation the permeability of BBB is increased, which can seriously exacerbate neurodegeneration. To study the role of $\mathrm{CB} 2$ in BBB function, we assessed BBB permeability in vivo. We examined whether a breach in the BBB, as a result of LPS-induced encephalitis, could be abrogated. We observed that CB2 agonists did maintain barrier integrity as visualized by the absence of fluorescence-labeled high-molecular-weight dextrans (40 kDa) entering the brain parenchyma. Since BBB permeability evaluations with large molecular tracers may fail to detect permeability to smaller molecules, we also used a low molecular-weight tracer. Although significantly reduced, global assessment of BBB permeability with SF (376 Da) 
showed that permeability still remained at half a fold higher than the basal level. Perhaps this is due to the low number of leukocytes that still remained adherent. Permeability changes were also assessed in vitro using TEER measurement of BMVECs. Our results showed the expected sustained decrease in TEER after LPS treatment. Both O1966 and JWH-133 were able to prevent the full drop in resistance caused by LPS and allowed the barrier to rebound back to normal levels more rapidly. Surprisingly, the protection in barrier integrity was achieved beyond the anti-inflammatory effects of CB2, since the TEER showed a further enhancement of barrier tightness with just the CB2 agonists present. These results are reminiscent of other barrier enhancing agents such as steroids, cAMP or growth factors (Liu et al. 2002, Helms et al. 2010, Kashiwamura et al. 2011). We also found that CB2 agonist treatment increased the expression of two important TJ proteins, occludin and claudin-5 in BMVECs (data not shown in the thesis, see in Ramirez et al. 2012). The barrier-enhancing effects could be explained in part by the augmentation of these TJ proteins. Together, these analyses provide compelling evidence that CB2 agonists, independent of their anti-inflammatory effects, promote and enhance BBB integrity.

\subsection{Inhibition of melanoma cell adhesion and transmigration through the brain endothelium by CB2 activation}

Besides having an important role in inflammation the cannabinoid system is involved in different aspects of cancer formation (Pisanti et al. 2013). However, its role in brain metastasis formation is less well understood. Steps of brain metastasis formation include adhesion of cancer cells to the cerebral endothelium, transmigration through the BBB and proliferation of tumor cells in the brain parenchyma. The first two steps are characterized by complex interactions of endothelial cells with metastatic cells (Fazakas et al. 2011, Végh et al. 2012, Wilhelm et al. 2014).

Similarly to leukocytes, we also found a reduction in the adhesion of A2058 melanoma cells to the cerebral endothelium. However, the reduction could only be observed when both endothelial cells and melanoma cells were pretreated with the CB2 agonist. CB2 signaling is mainly mediated by Gi/God subunits, but the MAPK-ERK pathway can also be activated by CB2. Both signaling pathways are active in CECs (Fábián et al. 1998, Krizbai et al. 2005). The Gi subunit inhibitor PTX completely abolished the effect of CB2 stimulation, whereas inhibition 
of the MAPK-ERK pathway had an additive effect to JWH133 indicating that the adhesion reducing effect of $\mathrm{CB} 2$ activation is rather Gi/Go $\alpha$ subunits than MAPK-ERK signaling dependent.

JWH133 significantly reduced the number of transmigrated melanoma cells, and this reduction could be seen when only endothelial cells were pretreated with CB2 agonist suggesting that changes induced in endothelial cells by CB2 agonists are critical in the mediation of the effect of CB2 agonists. One such change could be the improvement of barrier properties in response to $\mathrm{CB} 2$ activation since $\mathrm{CB} 2$ agonists increase the TEER of brain endothelial cells as we have shown before. Presumably, increased claudin-5 and occludin expression triggered by CB2 agonist contributes to the inhibition of melanoma transmigration by strengthening the TJs obstructing the paracellular way of migration. Indeed, melanoma cells were shown to primarily utilize the paracellular transmigration pathway through the brain endothelium (Molnár et al. 2016). Our experiments and other studies have shown the downregulation of adhesion molecules like ICAM or VCAM and matrix metalloproteinases (Adhikary et al. 2012) by CB2 activation. These molecular changes could also contribute to a reduced transmigration of melanoma cells; however, further investigation is needed to evaluate the molecular details of these processes.

\subsection{The possible antimetastatic effect of lignans from Heliopsis helianthoides var. scabra in the brain}

Beside CB2 agonists, we also characterized the effect of lignans from Heliopsis helianthoides var. scabra on brain endothelial cells, melanoma cells and the interactions of these two cell types. Identification and structural investigation of these compounds were performed by Zsanett Hajdú et al. (Department of Pharmacognosy, University of Szeged, Szeged, Hungary). Before the investigation of the effect of the isolated lignans on the cellular mechanisms, we have tested them on the viability of CECs and melanoma cells. There were no significant changes in the viability of the brain endothelial (D3, RBEC) and melanoma cells (A2058) (Hajdu et al. 2014), indicating that the experimental results were not influenced by possible cytotoxic effects of the tested compounds.

The first changes which we have observed were the elongated morphology of melanoma cells with actin-rich protrusions, filopodia and actin stress fibers in the presence of Hel-6 and a more expanded shape of melanoma cells without larger filopodias induced by Hel-11. 
Furthermore, the same lignans, Hel-6 and Hel-11, reduced the directional migration of melanoma cells. Other lignans have also been shown to inhibit the migratory properties of different cancer cells. Schisandrin B (Girnita et al. 2006) and enterolactone suppressed breast cancer cell migration, honokiol reduced non-small cell lung cancer migration (Singh and Katiyar 2013), and picropodophyllin inhibited the migration of uveal melanoma cells in vitro (Liu et al. 2012). Some of these lignans effectively inhibited the metastasis of cancer cells in mice (Liu et al. 2012, Zhang, Liu and Hu 2013). Although Hel-6 and Hel-11 induced different morphological changes, both compounds inhibited the migration of the melanoma cells. Others have shown that enterolactone treatment resulted in morphological changes with fewer filopodia and inhibited the migration of breast cancer cells (Mali et al. 2012). Furthermore, schisandrin B and honokiol reversed the TGF- $\beta$-induced elongated morphology, eliminated the filopodia, and enhanced the migration of the cancer cells (Girnita et al. 2006, Pan et al. 2013). Taken all around, some of the lignans, inhibiting cellular migration, are also able to induce morphological changes of the cells, but these morphological changes may be different in case of different lignans. Further studies are needed to investigate the relationship between these two effects.

Different lignans have been reported to reduce the expression of cell adhesion molecules (Chen et al. 2002, Li et al. 2014, Jeong et al. 2012, Wu et al. 2010), while their direct effects on cell adhesion (leukocytes or tumor cells) to the endothelium remain largely unexplored. Adhesion to the endothelial cells forming the blood vessels of the brain vasculature is the first crucial step of the extravasation and the formation of brain metastasis of melanoma cells (Day et al. 1999). Therefore, the ability of the isolated compounds to inhibit the attachment of melanoma cells to brain endothelial cells was investigated. From the six tested lignans only Hel-6 reduced significantly the number of adhering melanoma cells to the brain endothelium. These findings indicate a specific role of the endothelial changes induced by Hel-6 in reducing the adhesion and these changes proved to be reversible.

A large number of studies have shown that CAMs and selectins of endothelial cells are among the molecules that may affect tumor adhesiveness to endothelia (Wilhelm et al. 2013). Previous investigations have shown that the expression of ICAM-1, VCAM-1, and E-selectin of human umbilical vein endothelial cells (HUVECs) activated with TNF $\alpha$ or other reagents is downregulated by lignans, including honokiol (Jeong et al. 2012), sauchinone (Li et al. 2014), or sesaminol-6-catechol (Mochizuki et al. 2010). These studies are in line with our observations 
suggesting the key role of endothelial cells in the reduction of melanoma attachment caused by treatment with Hel-6. However, further investigations are needed to identify which adhesion molecules affected by Hel-6 on CECs.

CECs forming the BBB have a crucial role in hindering the entry of solutes and cells into the brain. Hence, further characterization of the effects of the tested lignans on the barrier function of the endothelial layer was undertaken. Both Hel-6 and Hel-11 elevated the TEER of brain endothelial layer indicating the enhanced barrier function. TJ between endothelial cells are crucial for the integrity of the BBB. Therefore, we investigated the presence of ZO-1, an important TJ protein and a good marker of the integrity of TJs. Both lignans which increased the TEER, resulted in a more pronounced ZO-1 staining at the cell border. Our findings appear to be the first evidence of the barrier-enhancing effect of a lignan. Lignans, as one of the major classes of phytoestrogens, are structurally similar to estrogen. Both estrogen and the steroid hormone hydrocortisone enhance the tightness of the BBB by upregulating another TJ protein, claudin-5 (Burek et al. 2010, Kashiwamura et al. 2011).

Previously it was demonstrated that TEER of RBECs decreased in the presence of A2058 and B16/F10 melanoma cells (Fazakas et al. 2011). It is therefore tempting to assume that treatment with Hel-6 or Hel-11 may contribute to a reduction in the rate of transmigration of melanoma cells by strengthening the barrier function of the CECs.

Besides contributing to a lowering of the transmigration rate, the barrier-strengthening effects of Hel-6 and Hel-11 may be of clinical relevance in other pathologies. Several pathological conditions of the CNS are associated with the opening of the $\mathrm{BBB}$, and lignans might prove to be protective against this phenomenon by strengthening the TJs of CECs. However, further investigations are needed to test whether compounds Hel-6 and Hel-11 can protect the TJs in pathological conditions.

Metastatic tumor growth is often associated with the formation of tumor vasculature i.e. tumor angiogenesis (Kienast et al. 2010). One of the possible strategies to prevent tumor angiogenesis is to inhibit endothelial cell migration into the tumor. Similar to melanoma cells, we observed the inhibition of endothelial cell migration in the presence of Hel-6 and Hel-11. Interestingly, secoisolariciresinol diglucoside, a plant lignan isolated from flaxseed, exerts an angiogenic effect mediated with increased levels of vascular endothelial growth factor (VEGF) and angiopoietin-1 protein in human coronary arteriolar endothelial cells (Penumathsa et al. 
2007). Moreover, the same effect of this lignan was demonstrated in vitro in HUVECs without the induction of vascular permeability and the upregulation of ICAM-1 and VCAM-1 expression (Chung et al. 2010). In contrast, another study has indicated the antiangiogenic property of honokiol, with a pronounced downregulation of VEGF and ICAM-1 in H1299 human lung adenocarcinoma cells treated with this lignan (Ahn et al. 2006). Apart from the complexity of the roles of different lignans in angiogenesis, the present in vitro experiments indicate that Hel-6 and Hel-11 may have antiangiogenic properties.

Taken together, we have clarified the expression of classical and potential cannabinoid receptors on cerebral endothelial cells and melanoma cells. Our studies identify CB2 as a potential target in shielding the brain from leukocyte diapedesis preserving the blood-brain barrier in neuroinflammation and in reducing the number of brain metastases originating from melanoma. Our results regarding to lignans indicate that, Hel-6 and Hel-11 might successfully interfere with several steps of metastasis formation of melanoma. Since these two compounds also augment barrier properties of the brain endothelium, they could be involved in therapies protecting brain vasculature. 


\section{Summary}

Trafficking of damage-causing immune cells and metastasis forming cancer cells across the BBB are pivotal steps in the formation of severe and often incurable neuroinflammatory disorders or brain metastases. Therefore, new treatment strategies inhibiting and preventing the entry of these cells into the brain are needed to improve the clinical outcomes, such as cure rate and also the quality of life of the patients suffering from these diseases.

In our studies we addressed the effect of CB2 agonists and lignans from Heliopsis helianthoides var. scabra on BBB integrity and cell movements across the brain endothelium. First, the expression of CB2 was detected in human brain endothelial cells and in melanoma cells. To note, CB2 expression had been show on several types of leukocytes before. We found enhanced CB2 expression in human brain endothelial cells exposed to various proinflammatory stimuli. We also identified the presence of other cannabinoid and cannabinoid-like receptors, such as CB1, GPR18 and GPR55 receptors, but not GPR119 in D3 human brain endothelial cell line, while A2058 melanoma cells expressed CB1, GPR18, GPR55 and GPR119.

To evaluate the effects of CB2 activation on the elevated leukocyte-endothelial cell adhesion, we tested CB2 agonists, in an LPS-induced encephalitis model in both surface and ascending cortical vessels. Administration of $\mathrm{CB} 2$ agonists could significantly reduce the leukocyte adhesion in our model. Inhibitory effect of CB2 activation on leukocyte adhesion to the endothelial layer was also observed in vitro. Furthermore, our results showed a BBB protective effect of $\mathrm{CB} 2$ activation which was due to the upregulated expression of tight junction proteins.

Similar to leukocytes, activation of CB2 reduced the adhesion of melanoma cells to the layer

of brain endothelial cells. CB2 agonism decreased the transendothelial migration rate of melanoma cells as well.

Besides CB2 agonists, two compounds from the six tested lignans helioxanthin (Hel-6) and dibenzylbutane dehydroheliobuphthalmin (Hel-11) enhanced the barrier function and also increased the expression of the TJ protein ZO-1 at the junctions of the brain endothelial cells. These two lignans inhibited the migration of both melanoma and brain endothelial cells, and helioxanthin also reduced the adhesion of melanoma cells to the brain endothelium. 
Our findings suggest that CB2 agonists and the lignans Hel-6 and Hel-11 may have the potential to be involved in therapies for preventing and curing diseases associated with immune cell or cancer call trafficking across the BBB. 


\section{References}

Abbott, N. J. (2013) Blood-brain barrier structure and function and the challenges for CNS drug delivery. J Inherit Metab Dis, 36, 437-49.

Adhikary, S., V. P. Kocieda, J. H. Yen, R. F. Tuma \& D. Ganea (2012) Signaling through cannabinoid receptor 2 suppresses murine dendritic cell migration by inhibiting matrix metalloproteinase 9 expression. Blood, 120, 3741-9.

Adinolfi, B., A. Romanini, A. Vanni, E. Martinotti, A. Chicca, S. Fogli \& P. Nieri (2013) Anticancer activity of anandamide in human cutaneous melanoma cells. Eur J Pharmacol, 718, 154-9.

Ahn, K. S., G. Sethi, S. Shishodia, B. Sung, J. L. Arbiser \& B. B. Aggarwal (2006) Honokiol potentiates apoptosis, suppresses osteoclastogenesis, and inhibits invasion through modulation of nuclear factor-kappaB activation pathway. Mol Cancer Res, 4, 621-33.

Alexander, S. P. (2012) So what do we call GPR18 now? Br J Pharmacol, 165, 2411-3.

Armulik, A., G. Genové, M. Mäe, M. H. Nisancioglu, E. Wallgard, C. Niaudet, L. He, J. Norlin, P. Lindblom, K. Strittmatter, B. R. Johansson \& C. Betsholtz (2010) Pericytes regulate the blood-brain barrier. Nature, 468, 557-61.

Bai, X., F. Cerimele, M. Ushio-Fukai, M. Waqas, P. M. Campbell, B. Govindarajan, C. J. Der, T. Battle, D. A. Frank, K. Ye, E. Murad, W. Dubiel, G. Soff \& J. L. Arbiser (2003) Honokiol, a small molecular weight natural product, inhibits angiogenesis in vitro and tumor growth in vivo. J Biol Chem, 278, 35501-7.

Barnholtz-Sloan, J. S., A. E. Sloan, F. G. Davis, F. D. Vigneau, P. Lai \& R. E. Sawaya (2004) Incidence proportions of brain metastases in patients diagnosed (1973 to 2001) in the Metropolitan Detroit Cancer Surveillance System. J Clin Oncol, 22, 2865-72.

Battle, T. E., J. Arbiser \& D. A. Frank (2005) The natural product honokiol induces caspase-dependent apoptosis in B-cell chronic lymphocytic leukemia (B-CLL) cells. Blood, 106, 690-7.

Benito, C., W. K. Kim, I. Chavarría, C. J. Hillard, K. Mackie, R. M. Tolón, K. Williams \& J. Romero (2005) A glial endogenous cannabinoid system is upregulated in the brains of macaques with simian immunodeficiency virus-induced encephalitis. J Neurosci, 25, 2530-6.

Benito, C., R. M. Tolón, M. R. Pazos, E. Núñez, A. I. Castillo \& J. Romero (2008) Cannabinoid CB2 receptors in human brain inflammation. Br J Pharmacol, 153, 277-85.

Bergman Jungeström, M., L. U. Thompson \& C. Dabrosin (2007) Flaxseed and its lignans inhibit estradiol-induced growth, angiogenesis, and secretion of vascular endothelial growth factor in human breast cancer xenografts in vivo. Clin Cancer Res, 13, 1061-7.

Bernas, M. J., F. L. Cardoso, S. K. Daley, M. E. Weinand, A. R. Campos, A. J. Ferreira, J. B. Hoying, M. H. Witte, D. Brites, Y. Persidsky, S. H. Ramirez \& M. A. Brito (2010) Establishment of primary cultures of human brain microvascular endothelial cells to provide an in vitro cellular model of the blood-brain barrier. Nat Protoc, 5, 1265-72.

Blázquez, C., A. Carracedo, L. Barrado, P. J. Real, J. L. Fernández-Luna, G. Velasco, M. Malumbres \& M. Guzmán (2006) Cannabinoid receptors as novel targets for the treatment of melanoma. FASEB J, 20, 2633-5.

Bolton, S. J., D. C. Anthony \& V. H. Perry (1998) Loss of the tight junction proteins occludin and zonula occludens1 from cerebral vascular endothelium during neutrophil-induced blood-brain barrier breakdown in vivo. Neuroscience, 86, 1245-57.

Brayton, J., Z. Qing, M. N. Hart, J. C. VanGilder \& Z. Fabry (1998) Influence of adhesion molecule expression by human brain microvessel endothelium on cancer cell adhesion. J Neuroimmunol, 89, 104-12.

Burek, M., P. A. Arias-Loza, N. Roewer \& C. Y. Förster (2010) Claudin-5 as a novel estrogen target in vascular endothelium. Arterioscler Thromb Vasc Biol, 30, 298-304.

Cabral, G. A. \& L. Griffin-Thomas (2009) Emerging role of the cannabinoid receptor CB2 in immune regulation: therapeutic prospects for neuroinflammation. Expert Rev Mol Med, 11, e3.

Cabral, G. A., E. S. Raborn, L. Griffin, J. Dennis \& F. Marciano-Cabral (2008) CB2 receptors in the brain: role in central immune function. Br J Pharmacol, 153, 240-51.

Campos-Bedolla, P., F. R. Walter, S. Veszelka \& M. A. Deli (2014) Role of the blood-brain barrier in the nutrition of the central nervous system. Arch Med Res, 45, 610-38. 
Carmeliet, P., M. G. Lampugnani, L. Moons, F. Breviario, V. Compernolle, F. Bono, G. Balconi, R. Spagnuolo, B. Oosthuyse, M. Dewerchin, A. Zanetti, A. Angellilo, V. Mattot, D. Nuyens, E. Lutgens, F. Clotman, M. C. de Ruiter, A. Gittenberger-de Groot, R. Poelmann, F. Lupu, J. M. Herbert, D. Collen \& E. Dejana (1999) Targeted deficiency or cytosolic truncation of the VE-cadherin gene in mice impairs VEGF-mediated endothelial survival and angiogenesis. Cell, 98, 147-57.

Chen, F., T. Wang, Y. F. Wu, Y. Gu, X. L. Xu, S. Zheng \& X. Hu (2004) Honokiol: a potent chemotherapy candidate for human colorectal carcinoma. World J Gastroenterol, 10, 3459-63.

Chen, J., P. M. Stavro \& L. U. Thompson (2002) Dietary flaxseed inhibits human breast cancer growth and metastasis and downregulates expression of insulin-like growth factor and epidermal growth factor receptor. Nutr Cancer, 43, 187-92.

Chodobski, A., B. J. Zink \& J. Szmydynger-Chodobska (2011) Blood-brain barrier pathophysiology in traumatic brain injury. Transl Stroke Res, 2, 492-516.

Chuang, D. Y., M. H. Chan, Y. Zong, W. Sheng, Y. He, J. H. Jiang, A. Simonyi, Z. Gu, K. L. Fritsche, J. Cui, J. C. Lee, W. R. Folk, D. B. Lubahn, A. Y. Sun \& G. Y. Sun (2013) Magnolia polyphenols attenuate oxidative and inflammatory responses in neurons and microglial cells. J Neuroinflammation, 10, 15.

Chung, B. H., J. J. Lee, J. D. Kim, D. Jeoung, H. Lee, J. Choe, K. S. Ha, Y. G. Kwon \& Y. M. Kim (2010) Angiogenic activity of sesamin through the activation of multiple signal pathways. Biochem Biophys Res Commun, 391, 254-60.

Citi, S., H. Sabanay, J. Kendrick-Jones \& B. Geiger (1989) Cingulin: characterization and localization. J Cell Sci, 93 ( Pt 1), 107-22.

Colone, M., A. Calcabrini, L. Toccacieli, G. Bozzuto, A. Stringaro, M. Gentile, M. Cianfriglia, A. Ciervo, M. Caraglia, A. Budillon, G. Meo, G. Arancia \& A. Molinari (2008) The multidrug transporter P-glycoprotein: a mediator of melanoma invasion? J Invest Dermatol, 128, 957-71.

Console-Bram, L., J. Marcu \& M. E. Abood (2012) Cannabinoid receptors: nomenclature and pharmacological principles. Prog Neuropsychopharmacol Biol Psychiatry, 38, 4-15.

Crosby, C. V., P. A. Fleming, W. S. Argraves, M. Corada, L. Zanetta, E. Dejana \& C. J. Drake (2005) VE-cadherin is not required for the formation of nascent blood vessels but acts to prevent their disassembly. Blood, 105, 2771-6.

Davies, M. A., P. Liu, S. McIntyre, K. B. Kim, N. Papadopoulos, W. J. Hwu, P. Hwu \& A. Bedikian (2011) Prognostic factors for survival in melanoma patients with brain metastases. Cancer, 117, 1687-96.

Day, S. H., N. Y. Chiu, S. J. Won \& C. N. Lin (1999) Cytotoxic lignans of Justicia ciliata. J Nat Prod, 62, 1056-8.

Dejana, E. (2006) The transcellular railway: insights into leukocyte diapedesis. Nat Cell Biol, 8, 105-7.

Douglas, J. G. \& K. Margolin (2002) The treatment of brain metastases from malignant melanoma. Semin Oncol, $29,518-24$.

Engelhardt, B. \& R. M. Ransohoff (2012) Capture, crawl, cross: the T cell code to breach the blood-brain barriers. Trends Immunol, 33, 579-89.

Engelhardt, S., S. Patkar \& O. O. Ogunshola (2014) Cell-specific blood-brain barrier regulation in health and disease: a focus on hypoxia. Br J Pharmacol, 171, 1210-30.

Erickson, M. A. \& W. A. Banks (2013) Blood-brain barrier dysfunction as a cause and consequence of Alzheimer's disease. J Cereb Blood Flow Metab, 33, 1500-13.

Fan, J., B. Cai, M. Zeng, Y. Hao, F. G. Giancotti \& B. M. Fu (2011) Integrin $\beta 4$ signaling promotes mammary tumor cell adhesion to brain microvascular endothelium by inducing ErbB2-mediated secretion of VEGF. Ann Biomed Eng, 39, 2223-41.

Fan, T., W. L. Jiang, J. Zhu \& Y. Feng Zhang (2012) Arctigenin protects focal cerebral ischemia-reperfusion rats through inhibiting neuroinflammation. Biol Pharm Bull, 35, 2004-9.

Fazakas, C., I. Wilhelm, P. Nagyoszi, A. E. Farkas, J. Haskó, J. Molnár, H. Bauer, H. C. Bauer, F. Ayaydin, N. T. Dung, L. Siklós \& I. A. Krizbai (2011) Transmigration of melanoma cells through the blood-brain barrier: role of endothelial tight junctions and melanoma-released serine proteases. PLoS One, 6, e20758.

Fiala, M., Q. N. Liu, J. Sayre, V. Pop, V. Brahmandam, M. C. Graves \& H. V. Vinters (2002) Cyclooxygenase-2positive macrophages infiltrate the Alzheimer's disease brain and damage the blood-brain barrier. Eur $J$ Clin Invest, 32, 360-71.

Fábián, G., C. A. Szabó, B. Bozó, J. Greenwood, P. Adamson, M. A. Deli, F. Joó, I. A. Krizbai \& M. Szucs (1998) Expression of G-protein subtypes in cultured cerebral endothelial cells. Neurochem Int, 33, 179-85. 
Gantz, I., A. Muraoka, Y. K. Yang, L. C. Samuelson, E. M. Zimmerman, H. Cook \& T. Yamada (1997) Cloning and chromosomal localization of a gene (GPR18) encoding a novel seven transmembrane receptor highly expressed in spleen and testis. Genomics, 42, 462-6.

Gerhardt, H., H. Wolburg \& C. Redies (2000) N-cadherin mediates pericytic-endothelial interaction during brain angiogenesis in the chicken. Dev Dyn, 218, 472-9.

Girnita, A., C. All-Ericsson, M. A. Economou, K. Aström, M. Axelson, S. Seregard, O. Larsson \& L. Girnita (2006) The insulin-like growth factor-I receptor inhibitor picropodophyllin causes tumor regression and attenuates mechanisms involved in invasion of uveal melanoma cells. Clin Cancer Res, 12, 1383-91.

Girnita, A., L. Girnita, F. del Prete, A. Bartolazzi, O. Larsson \& M. Axelson (2004) Cyclolignans as inhibitors of the insulin-like growth factor-1 receptor and malignant cell growth. Cancer Res, 64, 236-42.

Godlewski, G., L. Offertáler, J. A. Wagner \& G. Kunos (2009) Receptors for acylethanolamides-GPR55 and GPR119. Prostaglandins Other Lipid Mediat, 89, 105-11.

Golech, S. A., R. M. McCarron, Y. Chen, J. Bembry, F. Lenz, R. Mechoulam, E. Shohami \& M. Spatz (2004) Human brain endothelium: coexpression and function of vanilloid and endocannabinoid receptors. Brain Res Mol Brain Res, 132, 87-92.

Haseloff, R. F., I. E. Blasig, H. C. Bauer \& H. Bauer (2005) In search of the astrocytic factor(s) modulating bloodbrain barrier functions in brain capillary endothelial cells in vitro. Cell Mol Neurobiol, 25, 25-39.

Hawkins, B. T. \& R. D. Egleton (2006) Fluorescence imaging of blood-brain barrier disruption. J Neurosci Methods, $151,262-7$.

Helms, H. C., H. S. Waagepetersen, C. U. Nielsen \& B. Brodin (2010) Paracellular tightness and claudin-5 expression is increased in the BCEC/astrocyte blood-brain barrier model by increasing media buffer capacity during growth. AAPS J, 12, 759-70.

Hirase, T., J. M. Staddon, M. Saitou, Y. Ando-Akatsuka, M. Itoh, M. Furuse, K. Fujimoto, S. Tsukita \& L. L. Rubin (1997) Occludin as a possible determinant of tight junction permeability in endothelial cells. J Cell Sci, 110 ( Pt 14), 1603-13.

Ho, W. S. (2010) Angiogenesis: a new physiological role for N-arachidonoyl serine and GPR55? Br J Pharmacol, $160,1580-2$.

Huang, L., J. C. Ramirez, G. A. Frampton, L. E. Golden, M. A. Quinn, H. Y. Pae, D. Horvat, L. J. Liang \& S. DeMorrow (2011) Anandamide exerts its antiproliferative actions on cholangiocarcinoma by activation of the GPR55 receptor. Lab Invest, 91, 1007-17.

Hutamekalin, P., A. E. Farkas, A. Orbók, I. Wilhelm, P. Nagyoszi, S. Veszelka, M. A. Deli, K. Buzás, E. HunyadiGulyás, K. F. Medzihradszky, D. Meksuriyen \& I. A. Krizbai (2008) Effect of nicotine and polyaromtic hydrocarbons on cerebral endothelial cells. Cell Biol Int, 32, 198-209.

Itoh, M., K. Morita \& S. Tsukita (1999) Characterization of ZO-2 as a MAGUK family member associated with tight as well as adherens junctions with a binding affinity to occludin and alpha catenin. J Biol Chem, 274, 5981-6.

Iwamoto, N., T. Higashi \& M. Furuse (2014) Localization of angulin-1/LSR and tricellulin at tricellular contacts of brain and retinal endothelial cells in vivo. Cell Struct Funct, 39, 1-8.

Jeong, J. J., J. H. Lee, K. C. Chang \& H. J. Kim (2012) Honokiol exerts an anticancer effect in T98G human glioblastoma cells through the induction of apoptosis and the regulation of adhesion molecules. Int J Oncol, $41,1358-64$.

Jesaitis, L. A. \& D. A. Goodenough (1994) Molecular characterization and tissue distribution of ZO-2, a tight junction protein homologous to ZO-1 and the Drosophila discs-large tumor suppressor protein. J Cell Biol, 124, 949-61.

Kashiwamura, Y., Y. Sano, M. Abe, F. Shimizu, H. Haruki, T. Maeda, M. Kawai \& T. Kanda (2011) Hydrocortisone enhances the function of the blood-nerve barrier through the up-regulation of claudin-5. Neurochem Res, 36, 849-55.

Kaushik, G., S. Ramalingam, D. Subramaniam, P. Rangarajan, P. Protti, P. Rammamoorthy, S. Anant \& J. M. Mammen (2012) Honokiol induces cytotoxic and cytostatic effects in malignant melanoma cancer cells. Am J Surg, 204, 868-73.

Kerfoot, S. M. \& P. Kubes (2002) Overlapping roles of P-selectin and alpha 4 integrin to recruit leukocytes to the central nervous system in experimental autoimmune encephalomyelitis. J Immunol, 169, 1000-6.

Kienast, Y., L. von Baumgarten, M. Fuhrmann, W. E. Klinkert, R. Goldbrunner, J. Herms \& F. Winkler (2010) Real-time imaging reveals the single steps of brain metastasis formation. Nat Med, 16, 116-22. 
Kreutz, S., M. Koch, C. Böttger, C. Ghadban, H. W. Korf \& F. Dehghani (2009) 2-Arachidonoylglycerol elicits neuroprotective effects on excitotoxically lesioned dentate gyrus granule cells via abnormal-cannabidiolsensitive receptors on microglial cells. Glia, 57, 286-94.

Krizbai, I. A., H. Bauer, N. Bresgen, P. M. Eckl, A. Farkas, E. Szatmári, A. Traweger, K. Wejksza \& H. C. Bauer (2005) Effect of oxidative stress on the junctional proteins of cultured cerebral endothelial cells. Cell Mol Neurobiol, 25, 129-39.

Langley, R. R., R. Carlisle, L. Ma, R. D. Specian, M. E. Gerritsen \& D. N. Granger (2001) Endothelial expression of vascular cell adhesion molecule-1 correlates with metastatic pattern in spontaneous melanoma. Microcirculation, 8, 335-45.

Li, B., Y. J. Lee, Y. C. Kim, J. J. Yoon, S. M. Lee, Y. P. Lee, D. G. Kang \& H. S. Lee (2014) Sauchinone from Saururus chinensis protects vascular inflammation by heme oxygenase-1 induction in human umbilical vein endothelial cells. Phytomedicine, 21, 101-8.

Liu, F., K. L. Schaphorst, A. D. Verin, K. Jacobs, A. Birukova, R. M. Day, N. Bogatcheva, D. P. Bottaro \& J. G. Garcia (2002) Hepatocyte growth factor enhances endothelial cell barrier function and cortical cytoskeletal rearrangement: potential role of glycogen synthase kinase-3beta. FASEB J, 16, 950-62.

Liu, Q. R., C. H. Pan, A. Hishimoto, C. Y. Li, Z. X. Xi, A. Llorente-Berzal, M. P. Viveros, H. Ishiguro, T. Arinami, E. S. Onaivi \& G. R. Uhl (2009) Species differences in cannabinoid receptor 2 (CNR2 gene): identification of novel human and rodent CB2 isoforms, differential tissue expression and regulation by cannabinoid receptor ligands. Genes Brain Behav, 8, 519-30.

Liu, Z., B. Zhang, K. Liu, Z. Ding \& X. Hu (2012) Schisandrin B attenuates cancer invasion and metastasis via inhibiting epithelial-mesenchymal transition. PLoS One, 7, e40480.

Lorger, M. \& B. Felding-Habermann (2010) Capturing changes in the brain microenvironment during initial steps of breast cancer brain metastasis. Am J Pathol, 176, 2958-71.

Lu, T. S., H. K. Avraham, S. Seng, S. D. Tachado, H. Koziel, A. Makriyannis \& S. Avraham (2008) Cannabinoids inhibit HIV-1 Gp120-mediated insults in brain microvascular endothelial cells. J Immunol, 181, 6406-16.

Mali, A. V., U. V. Wagh, M. V. Hegde, S. S. Chandorkar, S. V. Surve \& M. V. Patole (2012) In vitro anti-metastatic activity of enterolactone, a mammalian lignan derived from flax lignan, and down-regulation of matrix metalloproteinases in MCF-7 and MDA MB 231 cell lines. Indian J Cancer, 49, 181-7.

Maraveyas, A., M. J. Johnson, Y. P. Xiao \& S. Noble (2010) Malignant melanoma as a target malignancy for the study of the anti-metastatic properties of the heparins. Cancer Metastasis Rev, 29, 777-84.

McCandless, E. E., L. Piccio, B. M. Woerner, R. E. Schmidt, J. B. Rubin, A. H. Cross \& R. S. Klein (2008) Pathological expression of CXCL12 at the blood-brain barrier correlates with severity of multiple sclerosis. Am J Pathol, 172, 799-808.

McHugh, D., S. S. Hu, N. Rimmerman, A. Juknat, Z. Vogel, J. M. Walker \& H. B. Bradshaw (2010) N-arachidonoyl glycine, an abundant endogenous lipid, potently drives directed cellular migration through GPR18, the putative abnormal cannabidiol receptor. BMC Neurosci, 11, 44.

McHugh, D., J. Page, E. Dunn \& H. B. Bradshaw (2012) $\Delta(9)$-Tetrahydrocannabinol and N-arachidonyl glycine are full agonists at GPR18 receptors and induce migration in human endometrial HEC-1B cells. $\mathrm{Br} \mathrm{J}$ Pharmacol, 165, 2414-24.

Mendes, O., H. T. Kim \& G. Stoica (2005) Expression of MMP2, MMP9 and MMP3 in breast cancer brain metastasis in a rat model. Clin Exp Metastasis, 22, 237-46.

Mestre, L., F. Correa, F. Docagne, D. Clemente \& C. Guaza (2006) The synthetic cannabinoid WIN 55,212-2 increases COX-2 expression and PGE2 release in murine brain-derived endothelial cells following Theiler's virus infection. Biochem Pharmacol, 72, 869-80.

Miller, A. M. \& N. Stella (2008) CB2 receptor-mediated migration of immune cells: it can go either way. $B r J$ Pharmacol, 153, 299-308.

Minagar, A. \& J. S. Alexander (2003) Blood-brain barrier disruption in multiple sclerosis. Mult Scler, 9, 540-9.

Mochizuki, M., Y. Tsuchie, N. Yamada, Y. Miyake \& T. Osawa (2010) Effect of sesame lignans on TNF-alphainduced expression of adhesion molecules in endothelial cells. Biosci Biotechnol Biochem, 74, 1539-44.

Molnár, J., C. Fazakas, J. Haskó, O. Sipos, K. Nagy, Á. Nyúl-Tóth, A. E. Farkas, A. G. Végh, G. Váró, P. Galajda, I. A. Krizbai \& I. Wilhelm (2016) Transmigration characteristics of breast cancer and melanoma cells through the brain endothelium: Role of Rac and PI3K. Cell Adh Migr, 10, $269-81$.

Murikinati, S., E. Jüttler, T. Keinert, D. A. Ridder, S. Muhammad, Z. Waibler, C. Ledent, A. Zimmer, U. Kalinke \& M. Schwaninger (2010) Activation of cannabinoid 2 receptors protects against cerebral ischemia by inhibiting neutrophil recruitment. FASEB J, 24, 788-98. 
Nasser, M. W., Z. Qamri, Y. S. Deol, D. Smith, K. Shilo, X. Zou \& R. K. Ganju (2011) Crosstalk between chemokine receptor CXCR4 and cannabinoid receptor $\mathrm{CB} 2$ in modulating breast cancer growth and invasion. PLoS One, 6, e23901.

Nayak, L., E. Q. Lee \& P. Y. Wen (2012) Epidemiology of brain metastases. Curr Oncol Rep, 14, 48-54.

Ni, X., E. B. Geller, M. J. Eppihimer, T. K. Eisenstein, M. W. Adler \& R. F. Tuma (2004) Win 55212-2, a cannabinoid receptor agonist, attenuates leukocyte/endothelial interactions in an experimental autoimmune encephalomyelitis model. Mult Scler, 10, 158-64.

Nieset, J. E., A. R. Redfield, F. Jin, K. A. Knudsen, K. R. Johnson \& M. J. Wheelock (1997) Characterization of the interactions of alpha-catenin with alpha-actinin and beta-catenin/plakoglobin. J Cell Sci, 110 ( Pt 8), 101322.

Nitta, T., M. Hata, S. Gotoh, Y. Seo, H. Sasaki, N. Hashimoto, M. Furuse \& S. Tsukita (2003) Size-selective loosening of the blood-brain barrier in claudin-5-deficient mice. J Cell Biol, 161, 653-60.

Norden, A. D., P. Y. Wen \& S. Kesari (2005) Brain metastases. Curr Opin Neurol, 18, 654-61.

Obermeier, B., R. Daneman \& R. M. Ransohoff (2013) Development, maintenance and disruption of the blood-brain barrier. Nat Med, 19, 1584-96.

Ohnishi, H., T. Nakahara, K. Furuse, H. Sasaki, S. Tsukita \& M. Furuse (2004) JACOP, a novel plaque protein localizing at the apical junctional complex with sequence similarity to cingulin. J Biol Chem, 279, 4601422.

Ohtsuki, S., H. Yamaguchi, Y. Katsukura, T. Asashima \& T. Terasaki (2008) mRNA expression levels of tight junction protein genes in mouse brain capillary endothelial cells highly purified by magnetic cell sorting. $J$ Neurochem, 104, 147-54.

Paku, S., B. Döme, R. Tóth \& J. Timár (2000) Organ-specificity of the extravasation process: an ultrastructural study. Clin Exp Metastasis, 18, 481-92.

Pan, H. C., D. W. Lai, K. H. Lan, C. C. Shen, S. M. Wu, C. S. Chiu, K. B. Wang \& M. L. Sheu (2013) Honokiol thwarts gastric tumor growth and peritoneal dissemination by inhibiting $\mathrm{Tp} 2 \mathrm{2}$ in an orthotopic model. Carcinogenesis, 34, 2568-79.

Park, E. J., H. Y. Min, H. J. Chung, J. Y. Hong, Y. J. Kang, T. M. Hung, U. J. Youn, Y. S. Kim, K. Bae, S. S. Kang \& S. K. Lee (2009) Down-regulation of c-Src/EGFR-mediated signaling activation is involved in the honokiol-induced cell cycle arrest and apoptosis in MDA-MB-231 human breast cancer cells. Cancer Lett, 277, 133-40.

Peng, H. H., L. Hodgson, A. J. Henderson \& C. Dong (2005) Involvement of phospholipase C signaling in melanoma cell-induced endothelial junction disassembly. Front Biosci, 10, 1597-606.

Penumathsa, S. V., S. Koneru, M. Thirunavukkarasu, L. Zhan, K. Prasad \& N. Maulik (2007) Secoisolariciresinol diglucoside: relevance to angiogenesis and cardioprotection against ischemia-reperfusion injury. $J$ Pharmacol Exp Ther, 320, 951-9.

Persidsky, Y., W. Ho, S. H. Ramirez, R. Potula, M. E. Abood, E. Unterwald \& R. Tuma (2011) HIV-1 infection and alcohol abuse: neurocognitive impairment, mechanisms of neurodegeneration and therapeutic interventions. Brain Behav Immun, 25 Suppl 1, S61-70.

Persidsky, Y., S. H. Ramirez, J. Haorah \& G. D. Kanmogne (2006) Blood-brain barrier: structural components and function under physiologic and pathologic conditions. J Neuroimmune Pharmacol, 1, 223-36.

Pertwee, R. G., A. C. Howlett, M. E. Abood, S. P. Alexander, V. Di Marzo, M. R. Elphick, P. J. Greasley, H. S. Hansen, G. Kunos, K. Mackie, R. Mechoulam \& R. A. Ross (2010) International Union of Basic and Clinical Pharmacology. LXXIX. Cannabinoid receptors and their ligands: beyond $\mathrm{CB}_{1}$ and $\mathrm{CB}_{2}$. Pharmacol Rev, 62, 588-631.

Pisanti, S., P. Picardi, A. D'Alessandro, C. Laezza \& M. Bifulco (2013) The endocannabinoid signaling system in cancer. Trends Pharmacol Sci, 34, 273-82.

Preet, A., Z. Qamri, M. W. Nasser, A. Prasad, K. Shilo, X. Zou, J. E. Groopman \& R. K. Ganju (2011) Cannabinoid receptors, $\mathrm{CB} 1$ and $\mathrm{CB} 2$, as novel targets for inhibition of non-small cell lung cancer growth and metastasis. Cancer Prev Res (Phila), 4, 65-75.

Pérez-Gómez, E., C. Andradas, J. M. Flores, M. Quintanilla, J. M. Paramio, M. Guzmán \& C. Sánchez (2013) The orphan receptor GPR55 drives skin carcinogenesis and is upregulated in human squamous cell carcinomas. Oncogene, 32, 2534-42.

Qamri, Z., A. Preet, M. W. Nasser, C. E. Bass, G. Leone, S. H. Barsky \& R. K. Ganju (2009) Synthetic cannabinoid receptor agonists inhibit tumor growth and metastasis of breast cancer. Mol Cancer Ther, 8, 3117-29. 
Qin, Y., E. M. Verdegaal, M. Siderius, J. P. Bebelman, M. J. Smit, R. Leurs, R. Willemze, C. P. Tensen \& S. Osanto (2011) Quantitative expression profiling of G-protein-coupled receptors (GPCRs) in metastatic melanoma: the constitutively active orphan GPCR GPR18 as novel drug target. Pigment Cell Melanoma Res, 24, 20718.

Rajesh, M., P. Mukhopadhyay, S. Bátkai, G. Haskó, L. Liaudet, J. W. Huffman, A. Csiszar, Z. Ungvari, K. Mackie, S. Chatterjee \& P. Pacher (2007) CB2-receptor stimulation attenuates TNF-alpha-induced human endothelial cell activation, transendothelial migration of monocytes, and monocyte-endothelial adhesion. Am J Physiol Heart Circ Physiol, 293, H2210-8.

Raleigh, D. R., A. M. Marchiando, Y. Zhang, L. Shen, H. Sasaki, Y. Wang, M. Long \& J. R. Turner (2010) Tight junction-associated MARVEL proteins marveld3, tricellulin, and occludin have distinct but overlapping functions. Mol Biol Cell, 21, 1200-13.

Ramirez, S. H., D. Heilman, B. Morsey, R. Potula, J. Haorah \& Y. Persidsky (2008) Activation of peroxisome proliferator-activated receptor gamma (PPARgamma) suppresses Rho GTPases in human brain microvascular endothelial cells and inhibits adhesion and transendothelial migration of HIV-1 infected monocytes. J Immunol, 180, 1854-65.

Reijerkerk, A., G. Kooij, S. M. van der Pol, S. Khazen, C. D. Dijkstra \& H. E. de Vries (2006) Diapedesis of monocytes is associated with MMP-mediated occludin disappearance in brain endothelial cells. FASEB J, 20, 2550-2.

Rom, S., V. Zuluaga-Ramirez, H. Dykstra, N. L. Reichenbach, P. Pacher \& Y. Persidsky (2013) Selective activation of cannabinoid receptor 2 in leukocytes suppresses their engagement of the brain endothelium and protects the blood-brain barrier. Am J Pathol, 183, 1548-58.

Ruiz-Valdepeñas, L., J. A. Martínez-Orgado, C. Benito, A. Millán, R. M. Tolón \& J. Romero (2011) Cannabidiol reduces lipopolysaccharide-induced vascular changes and inflammation in the mouse brain: an intravital microscopy study. J Neuroinflammation, 8, 5 .

Ryberg, E., N. Larsson, S. Sjögren, S. Hjorth, N. O. Hermansson, J. Leonova, T. Elebring, K. Nilsson, T. Drmota \& P. J. Greasley (2007) The orphan receptor GPR55 is a novel cannabinoid receptor. Br J Pharmacol, 152, 1092-101.

Saitou, M., M. Furuse, H. Sasaki, J. D. Schulzke, M. Fromm, H. Takano, T. Noda \& S. Tsukita (2000) Complex phenotype of mice lacking occludin, a component of tight junction strands. Mol Biol Cell, 11, 4131-42.

Sarfaraz, S., F. Afaq, V. M. Adhami \& H. Mukhtar (2005) Cannabinoid receptor as a novel target for the treatment of prostate cancer. Cancer Res, 65, 1635-41.

Schley, M., S. Ständer, J. Kerner, P. Vajkoczy, G. Schüpfer, M. Dusch, M. Schmelz \& C. Konrad (2009) Predominant CB2 receptor expression in endothelial cells of glioblastoma in humans. Brain Res Bull, 79, 333-7.

Singh, T. \& S. K. Katiyar (2013) Honokiol inhibits non-small cell lung cancer cell migration by targeting $\mathrm{PGE}_{2}-$ mediated activation of $\beta$-catenin signaling. PLoS One, 8, e60749.

Soto, M. S., S. Serres, D. C. Anthony \& N. R. Sibson (2014) Functional role of endothelial adhesion molecules in the early stages of brain metastasis. Neuro Oncol, 16, 540-51.

Spilioti, E., B. Holmbom, A. G. Papavassiliou \& P. Moutsatsou (2014) Lignans 7-hydroxymatairesinol and 7hydroxymatairesinol 2 exhibit anti-inflammatory activity in human aortic endothelial cells. Mol Nutr Food Res, 58, 749-59.

Steiner, O., C. Coisne, R. Cecchelli, R. Boscacci, U. Deutsch, B. Engelhardt \& R. Lyck (2010) Differential roles for endothelial ICAM-1, ICAM-2, and VCAM-1 in shear-resistant T cell arrest, polarization, and directed crawling on blood-brain barrier endothelium. J Immunol, 185, 4846-55.

Strell, C. \& F. Entschladen (2008) Extravasation of leukocytes in comparison to tumor cells. Cell Commun Signal, 6,10 .

Sá-Pereira, I., D. Brites \& M. A. Brito (2012) Neurovascular unit: a focus on pericytes. Mol Neurobiol, 45, 327-47.

Takeshita, Y. \& R. M. Ransohoff (2012) Inflammatory cell trafficking across the blood-brain barrier: chemokine regulation and in vitro models. Immunol Rev, 248, 228-39.

Tietz, S. \& B. Engelhardt (2015) Brain barriers: Crosstalk between complex tight junctions and adherens junctions. J Cell Biol, 209, 493-506.

Vidinský, B., P. Gál, M. Pilátová, Z. Vidová, P. Solár, L. Varinská, L. Ivanová \& J. Mojžíš (2012) Anti-proliferative and anti-angiogenic effects of CB2R agonist (JWH-133) in non-small lung cancer cells (A549) and human umbilical vein endothelial cells: an in vitro investigation. Folia Biol (Praha), 58, 75-80. 
Virk-Baker, M. K., T. R. Nagy \& S. Barnes (2010) Role of phytoestrogens in cancer therapy. Planta Med, 76, 113242.

Vishnubhotla, R., S. Bharadwaj, S. Sun, V. Metlushko \& S. C. Glover (2012) Treatment with Y-27632, a ROCK Inhibitor, Increases the Proinvasive Nature of SW620 Cells on 3D Collagen Type 1 Matrix. Int J Cell Biol, 2012, 259142.

Végh, A. G., C. Fazakas, K. Nagy, I. Wilhelm, J. Molnár, I. A. Krizbai, Z. Szegletes \& G. Váró (2012) Adhesion and stress relaxation forces between melanoma and cerebral endothelial cells. Eur Biophys J, 41, 139-45.

Walter, L., A. Franklin, A. Witting, C. Wade, Y. Xie, G. Kunos, K. Mackie \& N. Stella (2003) Nonpsychotropic cannabinoid receptors regulate microglial cell migration. J Neurosci, 23, 1398-405.

Weiss, N., F. Miller, S. Cazaubon \& P. O. Couraud (2009) The blood-brain barrier in brain homeostasis and neurological diseases. Biochim Biophys Acta, 1788, 842-57.

Wiley, J. L., I. D. Beletskaya, E. W. Ng, Z. Dai, P. J. Crocker, A. Mahadevan, R. K. Razdan \& B. R. Martin (2002) Resorcinol derivatives: a novel template for the development of cannabinoid $\mathrm{CB}(1) / \mathrm{CB}(2)$ and $\mathrm{CB}(2)$ selective agonists. J Pharmacol Exp Ther, 301, 679-89.

Wilhelm, I., A. E. Farkas, P. Nagyoszi, G. Váró, Z. Bálint, G. A. Végh, P. O. Couraud, I. A. Romero, B. Weksler \& I. A. Krizbai (2007) Regulation of cerebral endothelial cell morphology by extracellular calcium. Phys Med Biol, 52, 6261-74.

Wilhelm, I., C. Fazakas, J. Molnár, J. Haskó, A. G. Végh, L. Cervenak, P. Nagyőszi, A. Nyúl-Tóth, A. E. Farkas, H. Bauer, G. J. Guillemin, H. C. Bauer, G. Váró \& I. A. Krizbai (2014) Role of Rho/ROCK signaling in the interaction of melanoma cells with the blood-brain barrier. Pigment Cell Melanoma Res, 27, 113-23.

Wilhelm, I., C. Fazakas, K. Molnár, A. G. Végh, J. Haskó \& I. A. Krizbai (2017) Foe or friend? Janus-faces of the neurovascular unit in the formation of brain metastases. J Cereb Blood Flow Metab, $271678 X 17732025$.

Wilhelm, I. \& I. A. Krizbai (2014) In vitro models of the blood-brain barrier for the study of drug delivery to the brain. Mol Pharm, 11, 1949-63.

Wilhelm, I., J. Molnár, C. Fazakas, J. Haskó \& I. A. Krizbai (2013) Role of the blood-brain barrier in the formation of brain metastases. Int J Mol Sci, 14, 1383-411.

Williams, D. W., E. A. Eugenin, T. M. Calderon \& J. W. Berman (2012) Monocyte maturation, HIV susceptibility, and transmigration across the blood brain barrier are critical in HIV neuropathogenesis. J Leukoc Biol, 91, 401-15.

Wu, C., F. Ivars, P. Anderson, R. Hallmann, D. Vestweber, P. Nilsson, H. Robenek, K. Tryggvason, J. Song, E. Korpos, K. Loser, S. Beissert, E. Georges-Labouesse \& L. M. Sorokin (2009) Endothelial basement membrane laminin alpha5 selectively inhibits T lymphocyte extravasation into the brain. Nat Med, 15, 51927.

Wu, W. H., S. H. Wang, I. I. Kuan, Y. S. Kao, P. J. Wu, C. J. Liang, H. F. Chien, C. H. Kao, C. J. Huang \& Y. L. Chen (2010) Sesamin attenuates intercellular cell adhesion molecule-1 expression in vitro in TNF-alphatreated human aortic endothelial cells and in vivo in apolipoprotein-E-deficient mice. Mol Nutr Food Res, $54,1340-50$.

Xie, T. X., F. J. Huang, K. D. Aldape, S. H. Kang, M. Liu, J. E. Gershenwald, K. Xie, R. Sawaya \& S. Huang (2006) Activation of stat 3 in human melanoma promotes brain metastasis. Cancer Res, 66, 3188-96.

Yang, X., J. Di, Y. Zhang, S. Zhang, J. Lu, J. Liu \& W. Shi (2012) The Rho-kinase inhibitor inhibits proliferation and metastasis of small cell lung cancer. Biomed Pharmacother, 66, 221-7.

Yoshimasu, T., T. Sakurai, S. Oura, I. Hirai, H. Tanino, Y. Kokawa, Y. Naito, Y. Okamura, I. Ota, N. Tani \& N. Matsuura (2004) Increased expression of integrin alpha3betal in highly brain metastatic subclone of a human non-small cell lung cancer cell line. Cancer Sci, 95, 142-8.

Yui, Y., K. Itoh, K. Yoshioka, N. Naka, M. Watanabe, Y. Hiraumi, H. Matsubara, K. Watanabe, K. Sano, T. Nakahata \& S. Adachi (2010) Mesenchymal mode of migration participates in pulmonary metastasis of mouse osteosarcoma LM8. Clin Exp Metastasis, 27, 619-30.

Zhang, B., Z. Liu \& X. Hu (2013) Inhibiting cancer metastasis via targeting NAPDH oxidase 4. Biochem Pharmacol, 86, 253-66.

Zhang, H., D. A. Hilton, C. O. Hanemann \& J. Zajicek (2011) Cannabinoid receptor and N-acyl phosphatidylethanolamine phospholipase D--evidence for altered expression in multiple sclerosis. Brain Pathol, 21, 544-57.

Zhang, M., B. R. Martin, M. W. Adler, R. J. Razdan, W. Kong, D. Ganea \& R. F. Tuma (2009) Modulation of cannabinoid receptor activation as a neuroprotective strategy for EAE and stroke. J Neuroimmune Pharmacol, 4, 249-59. 
Zhang, X., Y. Maor, J. F. Wang, G. Kunos \& J. E. Groopman (2010) Endocannabinoid-like N-arachidonoyl serine is a novel pro-angiogenic mediator. Br J Pharmacol, 160, 1583-94.

Zhao, Z., J. Yang, H. Zhao, X. Fang \& H. Li (2012) Cannabinoid receptor 2 is upregulated in melanoma. J Cancer Res Ther, 8, 549-54.

Zlokovic, B. V. (2008) The blood-brain barrier in health and chronic neurodegenerative disorders. Neuron, 57, 178201. 


\section{Acknowledgements}

I would like to express my sincere gratitude to my supervisor Dr. István Krizbai for scientific guidance, support and motivation throughout my $\mathrm{PhD}$. studies. I am especially grateful to my colleague Dr. Imola Wilhelm for the helpful theoretical and practical suggestions, discussions and criticism.

I am grateful to Dr. Yuri Persidsky Professor and Chair and Dr. Servio Ramirez Associate Professor of Department of Pathology and Laboratory Medicine, Temple University, Philadelphia, PA, USA, for providing the opportunity to learn and conduct research in their laboratory for one year.

I am thankful to Dr. Árpád Párducz, the previous and Dr. László Siklós, the present head of the Molecular Neurobiology Unit and to all my colleagues in the group. I would like to thank Dr. László Zimányi, the director of the Institute of Biophysics, and all members of the Institute for the pleasant working atmosphere.

My appreciation also extends to my previous and present laboratory colleagues, Dr. Attila Farkas, Dr. Péter Nagyőszi, Dr. Csilla Fazakas, Dr. Judit Molnár, Ádám Nyúl-Tóth, Kinga Molnár, Mihály Kozma, Andrew Skuba, Dr. Shongshan Fan, Holly Dykstra, Ryan McCormick, Nancy Reichenbach, Jonathan Cenna, Dr. Slava Rom, Dr. Ming Zhang, Yu Zhou, for excellent teamwork and sharing excitement of research and discovery.

I am grateful to all collaborators for enthusiastic participation in the preparation of experiments and manuscripts, especially to Dr. Zsanett Hajdu, Dr. Dezső Csupor, Dr. Judit Hohmann

I am thankful to my family and my friends, for their support.

Finally, I want to thank to Hungarian-American Enterprise Scholarship Fund, GINOP-2.3.215-2016-0020, GINOP-2.3.2-15-2016-0034, GINOP-2.3.2-15-2016-0030 grants and "Apáczai

Csere János Grant for PhD. Students" (TÁMOP 4.2.4.A/2-11-1-2012-0001) for financial support. 


\section{Appendix}

